\title{
Critical Parameters of Complex Geometries of Intersecting Cylinders Containing Uranyl Nitrate Solution
}

Dr. Robert E. Rothe, Consultant June 1999

Idaho National Engineering and Environmental Laboratory Bechtel BWXT Idaho, LLC 


\title{
CRITICAL PARAMETERS OF
}

\author{
COMPLEX GEOMETRIES OF
}

\section{INTERSECTING CYLINDERS CONTAINING}

\section{URANYL NITRATE SOLUTION}

by

Dr. Robert E. Rothe

Consultant

June 14, 1999

This paper is written under contract C96-175866 with the United States Department of Energy administered by the Idaho National Engineering and Environmental Laboratory, although the work was performed at Rocky Flats, Colorado 


\begin{abstract}
About three dozen previously unreported critical configurations are presented for very complex geometries filled with high concentration enriched uranyl nitrate solution. These geometries resemble a tall, thin Central Column (or trunk of a "tree") having long, thin arms (or "branches") extending up to four directions off the column. Arms are equally spaced from one another in vertical planes; and that spacing ranges from arms in contact to quite wide spacings. Both the Central Column and the many different arms are critically safe by themselves when each, alone, is filled with fissile solution; but, in combination, criticality occurs due to the interactions between arms and the column. Such neutronic interactions formed the principal focus of this study. While these results are fresh to the nuclear criticality safety industry and to those seeking novel experiments against which to validate computer codes, the experiments, themselves, are not recent. Over 100 experiments were performed at the Rocky Flats Critical Mass Laboratory between September, 1967, and February of the following year.
\end{abstract}




\section{CONTENTS}

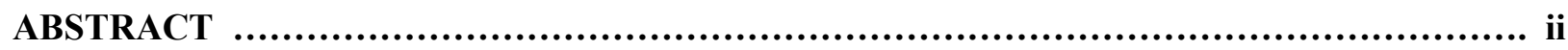

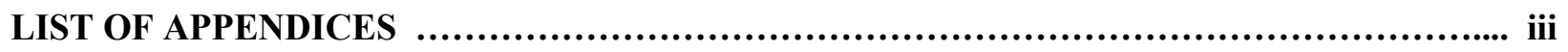

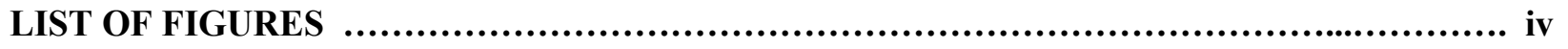

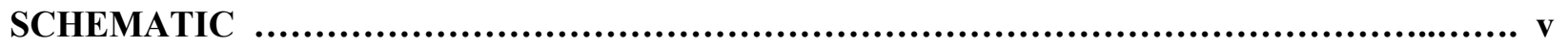

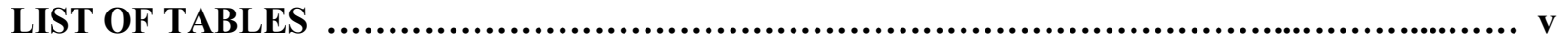

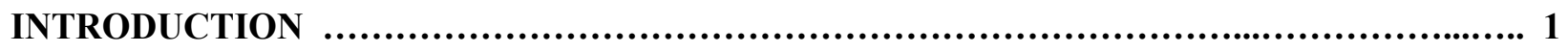

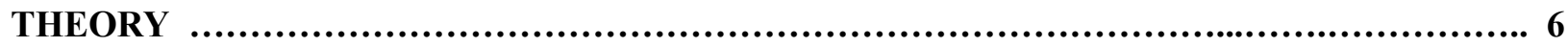

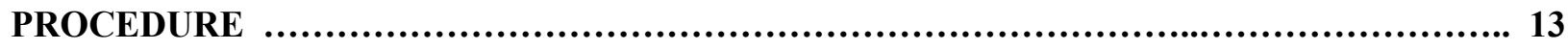

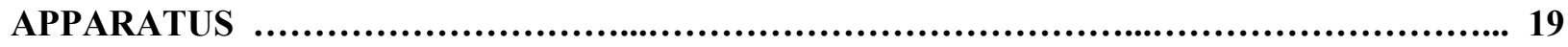

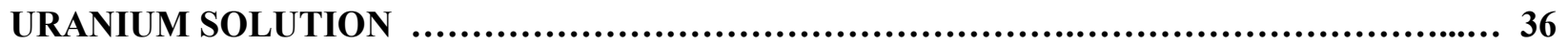

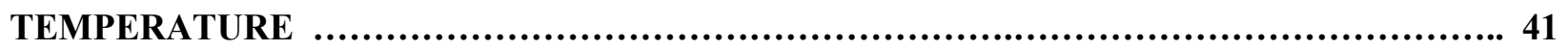

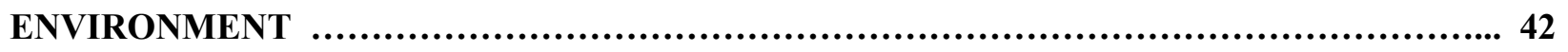

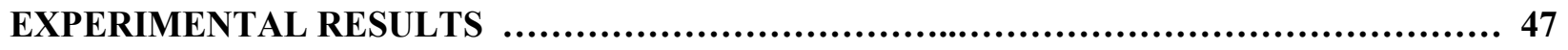

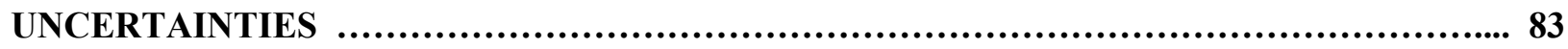

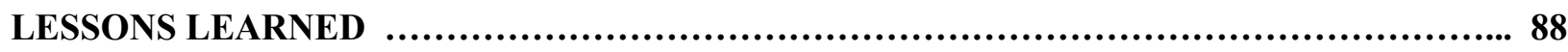

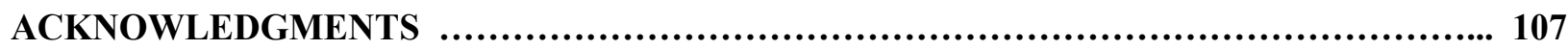

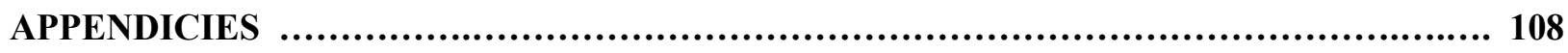

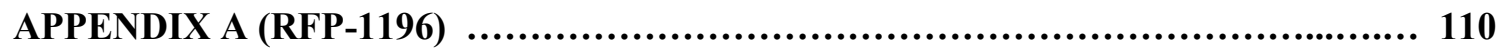

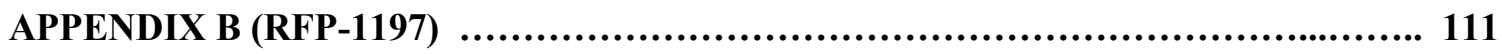

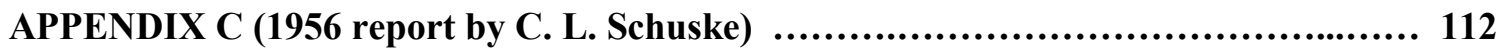




\section{FIGURES}

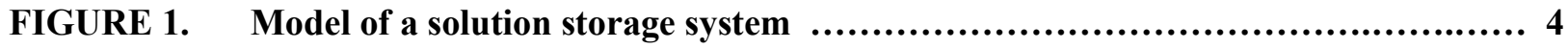

FIGURE 2. Interpolation of criticality from supercritical and subcritical configurations ...... 11

FIGURE 3. Extrapolation of criticality from several subcritical configurations ................ 12

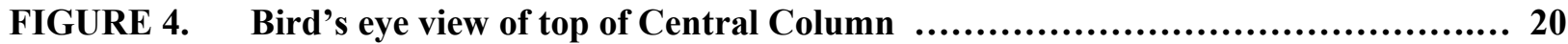

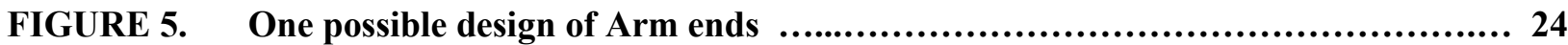

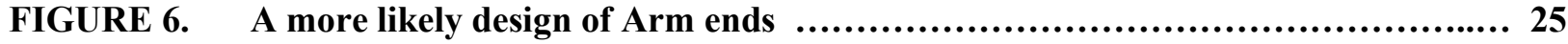

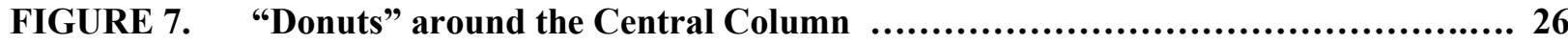

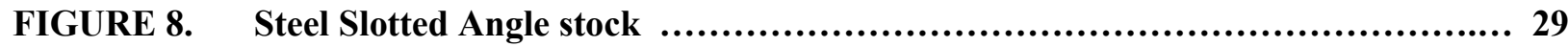

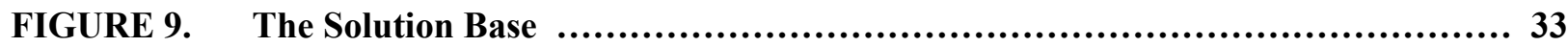

FIGURE 10. Plan view of the Assembly Room showing location of Solution Base ............... 42

FIGURE 11. The Walk-In Assembly Room Hood ............................................ 45

FIGURE 12. Schematic drawing of Central Column with Arms off one face ..................67

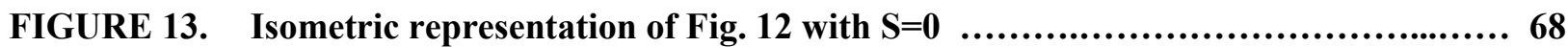

FIGURE 14. Schematic drawing of Central Column with Arms off opposite faces .............. 69

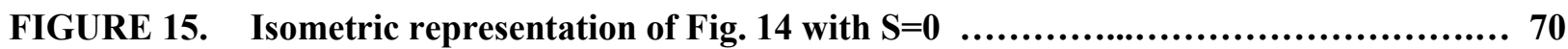

FIGURE 16. Schematic drawing of Central Column with Arms off all four faces ................ 71

FIGURE 17. Schematic drawing of Central Column with Arms off two adjacent faces .......... 72

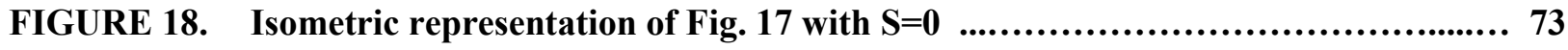

FIGURE 19. Schematic drawing of Central Column with Arms off all four faces,

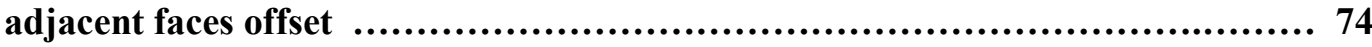

FIGURE 20. Schematic drawing of Central Column with Arms offset off two

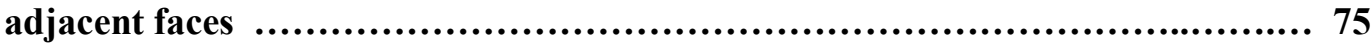

FIGURE 21. Schematic drawing of Central Column with one cone of sloped Arms off all four faces 
FIGURES

(Continued)

FIGURE 22. Schematic drawing of Central Column with two cones of sloped Arms off all four faces

FIGURE 23. Schematic drawing of Central Column with offset sloped Arms

off all four faces

FIGURE 24. Two critical configurations using the "Donuts"

FIGURE 25. Interpolation critical arm diameters for integral numbers of arms

off all four faces 82

FIGURE 26. Elevation schematic drawing of the SCRAM tank vent overflow problem 90

FIGURE 27. Larger view of the SCRAM tank vent overflow problem 93

FIGURE 28. The 250-mm-diameter exhaust duct for contaminated air 94

FIGURE 29. Glass model used to demonstrate the SCRAM tank vent overflow problem 99

FIGURE 30. Schematic drawing of the resolution of the SCRAM tank vent overflow problem 101

FIGURE 31. Photograph of the SCRAM tank vent overflow problem demonstrating the hypothesis

\section{SCHEMATIC}

Drawings of the Central Column and the Solution Base 14

\section{TABLES}

TABLE I. Experimental Configurations for 168.3-mm-Outside-Diameter Arms Oriented at $90^{\circ}$ to the Central Column and in the Simplest Geometries 56

TABLE II. Experimental Configurations for 168.3-mm-Outside Diameter Arms Oriented at $90^{\circ}$ to the Central Column with Various Arms Eligible to Receive Solution 57

TABLE III. Experimental Configurations for Twelve 141.3-mm-Outside-Diameter Arms Oriented at $90^{\circ}$ to the Central Column and Extending off All Four Faces of the Central Column 
TABLES

(Continued)

TABLE IV. Experimental Configurations for 141.3-mm-Outside-Diameter Arms at 90 to the Central Column and Extending Off All Four Faces of the Central Column, But Spaced Vertically From One Another

TABLE V. Experimental Configurations for 168.3-mm-Outside-Diameter Arm at 90 to the Central Column and Extending Off All Or Opposite Faces of It 61

TABLE VI. Experimental Configurations for 114.3-mm-Outside-Diameter Arms at 90 to the Central Column and Extending Off All Four of Its Faces

TABLE VII. Experimental Configurations for 168.3-mm-Outside-Diameter Arms at $45^{\circ}$ Upward Inclination From the Central Column and Extending Off All Four of Its Faces

TABLE VIIA. Arm Elevations (mm) for Configurations of Arms at $45^{\circ}$ Upward Inclination From the Central Column and Described in Table VII

TABLE VIII. Experimental Configurations for 141.3-mm-Outside-Diameter Arms at $45^{\circ}$ Upward Inclination From the Central Column and Extending Off All Four of Its Faces 65

TABLE IX. Experimental Configurations for 177.8-mm-Square Arms at $45^{\circ} \mathrm{Upward}$ Inclination From the Central Column and Extending Off One or Two Faces 65

TABLE X. Experimental Configurations for "Donut" Along the Central Column in Place of Arms

TABLE XI. Various Reactor Periods Very Close to the Critical Uranium Solution Height for One Experiment

TABLE XII. Derived Critical Parameters from RFP-1197 for Arms of All Three Diameters Extending at $90^{\circ}$ Off All Four Faces of the Central Column

TABLE XIII. Derived Critical Number of 168.3-mm-Outside-Diameter Arms Extending in Vertical Contact and $90^{\circ}$ Off One or Two Faces of the Central Column and With That Column Full of solution (from RFP-1197)

TABLE XIV. Derived Critical Parameter from RFP-1197 for Arms of Three Cross Sectional Sizes Inclined at $\mathbf{4 5}^{\circ}$ From the Central Column

TABLE XV. Estimated Weights of Enriched Uranium Eventually Recovered from Various Locations Following the Vent Line Overflow Problem Discovered November 30, 1967 


\section{INTRODUCTION}

This document is the last in a series of seven peer-reviewed papers written under the International Criticality Safety Benchmark Evaluation Project. Originally, only six were planned; but the value of the present effort became apparent in 1997. Together, all seven place into the public domain previously unpublished or inadequately documented experimental data generated at the Rocky Flats, Colorado, Critical Mass Laboratory (CML). The benchmark evaluation project is administered for the Department of Energy by J. Blair Briggs of the Idaho National Engineering and Environmental Laboratory (INEEL). The previous six ${ }^{1,2,3,4,5,6}$ papers were published between 1994 and 1998.

In this last paper, 110 experiments involving highly enriched uranyl nitrate solution in a complex geometry are reported. These laboratory studies include both critical experiments and very reactive - but still subcritical - approaches to criticality. Some critical predictions are the result of extrapolations based on a series of subcritical experiments with one parameter varied such that the critical value of that one parameter could be predicted. A few critical cases were not actually driven all the way to criticality even though they could have been. The addition of a little more solution would have achieved that condition. These represent extrapolations to a critical height from a subcritical one; and that extrapolation is based on the shape of the reciprocal multiplication data collection graphs. Even slightly subcritical experiments might prove marginally valuable to a benchmark criticality study program if future computer capabilities enable the validation of measured degrees of subcriticality. Even now, these subcritical cases could be used to validate that computer codes do not predict criticality.

\footnotetext{
${ }^{1}$ Robert E. Rothe, "Experimental Critical Parameters of Plutonium Metal Cylinders Flooded with Water." INEL96/0250. September, 1994.

2 Robert E. Rothe, "Experimental Critical Parameters of Enriched Uranium Solution in Annular Tank Geometries.” INEL-96-0386. April, 1996.

${ }^{3}$ Robert E. Rothe, "Critical Experiments on an Enriched Uranium Solution System Containing Periodically Distributed Strong Thermal Neutron Absorbers.” INEL/EXT-97-00293. September, 1996.

4 Robert E. Rothe, "Critical Experiments on Single-Unit Spherical Plutonium Geometries Reflected and Moderated by Oil.” INEL/EXT-97-00665. May, 1997.

${ }^{5}$ Robert E. Rothe, "Extrapolated Experimental Critical Parameters of Unreflected and Steel-Reflected Massive Enriched Uranium Metal Spherical and Hemispherical Assemblies." INEL/EXT-97-01401. December, 1997.

${ }^{6}$ Robert E. Rothe, "Massive Subcritical Compact Array of Plutonium Metal." INEL/EXT-98-00293. April, 1998.
} 
That complex geometry consisted of a square Central Column and a number of cylindrical branches called "arms" in this paper. These arms were of four diameters and emanated from one or more faces of that column. The fissile solution was contained in these stainless steel vessels. The cylindrical arms were made from commercial pipe with ends welded shut. The Central Column was a thin-walled vertical cylinder with a square cross section. This column had a bottom welded in place but was open at the top.

These experiments were designed and conducted by Mr. Bruce B. Ernst, an experimenter at the Rocky Flats CML at the time. The author of this paper only assisted Mr. Ernst in the experiments themselves and their preparation. These experiments were performed at Rocky Flats between September, 1967, and January, 1968. Ernst reported his data in the open literature ${ }^{7}$; but that publication (Appendix B of this document) provided inadequate documentation for benchmark purposes into the new millennium. Another paper ${ }^{8}$ containing greater detail had been started about the same time but was never published. Fortunately, one copy of a draft of that document has been found and is printed in its entirety as Appendix A. This is to guard against this information becoming irretrievably lost. Its data has been incorporated into this paper where appropriate.

This study, like all experiments performed at Rocky Flats, was used to provide nuclear criticality safety data to ensure continued safety of plant operations. Data were usually used two ways in those early days of nuclear criticality safety. First, they were applied directly to plant operations if those operations were deemed suitably similar to experiments. The degree of similarity required was often left to the discretion of the Criticality Safety Engineer and, so, was somewhat arbitrary. Secondly, they were used to compare experimental results with calculations from then state-of-the-art computational methods in vogue at the time. These, however, were not very sophisticated in the early days; computers were not even common yet. Again, details of this comparison were often left to the discretion of the Safety Engineer.

${ }^{7}$ Bruce B. Ernst and C. L. Schuske. "Empirical Method for Calculating Pipe Intersections Containing Fissile Solutions". RFP-1197. Rocky Flats Division, The Dow Chemical Company, Golden, CO. September 9, 1968.

${ }^{8}$ Bruce B. Ernst. "Critical Parameters of Bare Intersecting Pipes Containing Fissile Solution.” RFP-1196. Rocky Flats Division, The Dow Chemical Company, Golden, CO. Never published except as Appendix A of this document. 


\section{Practical Applications}

A nuclear materials processing plant - especially one dealing with fissile liquids - contains an unending and often dizzying array of intersecting pipes, lines, vents, and other devices for the transfer of liquids. These come in a wide range of sizes; and some carry fissile liquids while others do not. Even carriers of non-fissile liquids can be a concern to the nuclear criticality safety engineer because of the ability of non-fissile liquids to both reflect and moderate neutrons. These lines can exist parallel to one another in close proximity; or they may intersect one another at any angle.

The nuclear interactions between fissile material contained in this myriad of piping can be difficult to analyze from a criticality safety perspective. Not much experimental data existed at the time of these experiments. Indeed, not a great deal more has been added in the past three decades. This treatise and its foundation document (RFP-1197) present at least some useful data toward filling the void.

In addition to this application, the design of a novel critically safe storage tank for fissile solutions was proposed as a direct result of this experimental program. One thorn challenging the industry for decades had been the perceived problems associated with using fixed nuclear poisons such as Raschig rings to ensure nuclear criticality safety of fissile solutions. The American National Standard in effect since 1971 placed several possibly unnecessary limitations on the use of such rings rendering them unattractive to the industry. Two major concerns, the leachability of the boron content and the glass's mechanical strength, were addressed in the literature ${ }^{9}$ in 1998. That document found Raschig rings really quite adequate; but it was too late to resolve some of the imagined issues over the last third of this century. That treatise should greatly alleviate any future concerns over the use of these rings.

If put into routine use, this proposed tree-like container might prove useful in many applications throughout any nuclear facility dealing with large volumes of fissile solutions ${ }^{10}$. This unique construction is illustrated in the photograph of Fig. 1, modeled one-tenth full size. The proposal featured a number of nearly horizontal arms in several vertical groupings of properly spaced arms. These branched off a

9 Robert E. Rothe, et al, "Parameter Testing of Borosilicate-Glass Raschig Rings for Nuclear Criticality Safety", to be published by the USDOE in 1999.

10 Clarence L. Schuske and Sidney J. Altschuler, "A Storage Vessel for Fissile Solutions". NUCLEAR TECHNOLOGY, 18 June, 1973. 
central manifold column. Advantages of such a design include (1) the total absence of any fixed neutron absorbers such as Raschig rings which would require routine inspection, (2) a large capacity and therefore a reduction in the number of containers needed to store large quantities of fissile solution, and (3) increased security against nefarious diversion because of fewer small containers. Disadvantages include (1) a high fabrication cost due to the large number of weldments, (2) potential leaks from these same welds, (3) potential criticality concerns resulting from accidental flooding with water, (4) concerns over neutron reflection introduced by human beings located between planes of the stacked arms, and, finally, (5) potential radiation received by these same personnel exposed to older stored ${ }^{11}$ fissile solutions.

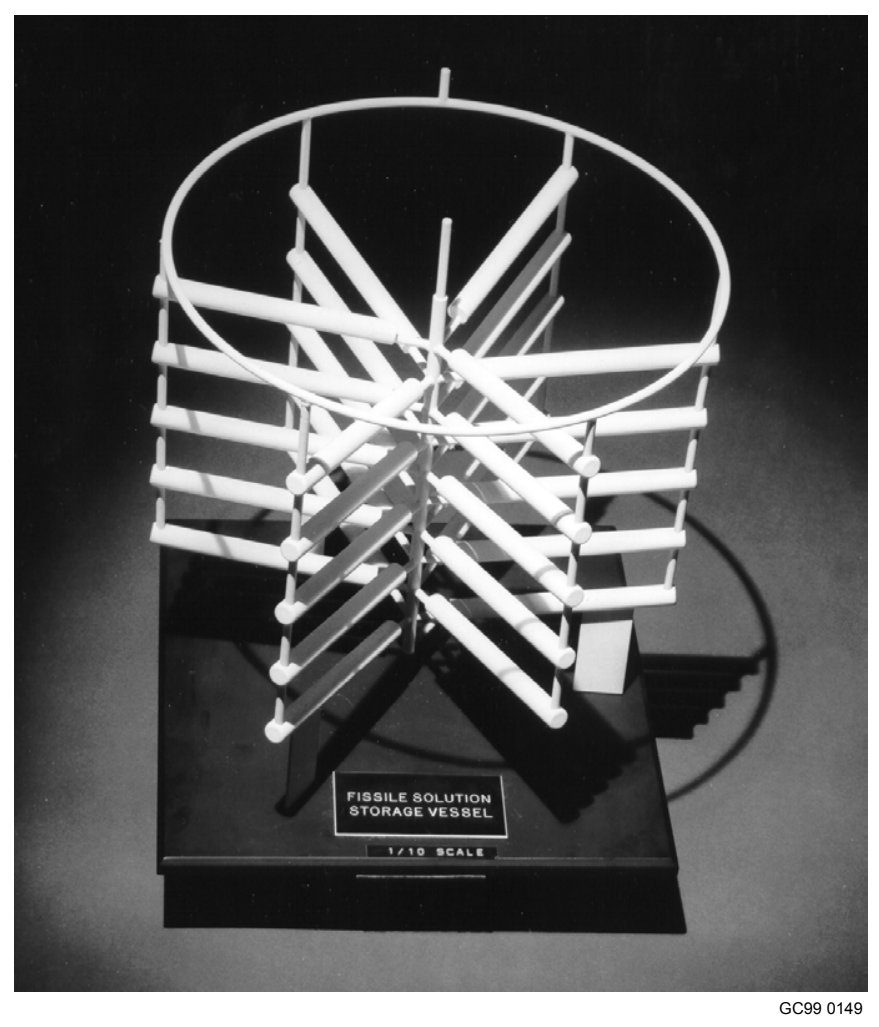

Figure 1. A novel method of routine critically safe storage of large volumes of fissile solution in production facilities was proposed based on these experiments. This one-tenth scale model was built to illustrate the concept. No prototype tank was ever built for testing purposes at Rocky Flats. The notion was rejected because too many welds gave too many potential leak points.

11 Plutonium solutions tend to inbreed an americium isotope with age. This isotope emits potentially harmful radiation from which the worker must be shielded. 
This paper required considerable historical research and personal recollection of important information. This author was not heavily involved in these experiments. On the other hand, the lead experimenter is still available for consultation. He was one of the text reviewers before publication. The entire program, itself, was somewhat arbitrarily chosen simply because it seemed interesting and useful. It never fell under the auspices of a formal, written, Experimental Plan ${ }^{12}$ which were not required until the 1970s. The eventual value of these results was not fully recognized at the time. Documentation of such casual studies was not required in the 1960s. Finally, the wealth of experimental detail required for Monte Carlo codes of the 1990s was not realized. In spite of these reasons, the present paper should provide all the needed data and a good estimate of parameter uncertainties to permit a quality benchmark calculation to be compared against experimental evidence.

The topic of neutronic interactions between intersecting pipes containing fissile liquids has long been of interest to nuclear criticality safety engineers. The individuality of applications tends to diminish the value of a generalized model. A partial listing of the papers dealing with this topic illustrate the popularity of the subject ${ }^{13,14,15,16,17,18,19,20}$. These several references are arbitrarily listed in chronological order. At present, they are in the personal library of this author and may be obtained through his Boulder, Colorado, address. By the year 2000, this collection will be donated to the Archives of Critical Mass Laboratories at the Los Alamos National Laboratory where they will appear under Collection A-96-051.

12 This reason is totally inconsistent with policies and procedures in place throughout the industry after about 1970 .

${ }^{13}$ C. L. Schuske. "An Empirical Method for Calculating Sub-Critical Pipe Intersections". The Dow Chemical Company. July 17, 1956. This document the USDOE Office of Scientific and Technical Information designation TID-5451. Its technical content is copied in Appendix B.

${ }^{14}$ C. L. Schuske, B. B. Ernst, and H. W. King. "Empirical Analysis of Bare Arrays of Cylinders Containing Enriched $\mathrm{UO}_{2}\left(\mathrm{NO}_{3}\right)_{2}$ ". The Dow Chemical Company. RFP-315, May 29, 1963.

15 Grover Tuck and Harold E. Clark. "Critical Parameters of a Uranium Solution Slab-Cylinder System". NUCLEAR SCIENCE and ENGINEERING 40 (1970).

16 Harold E. Clark and Grover Tuck. "An Empirical Formula Which Predicts the Critical Parameters of a Planar Array of Uranium-Solution-Filled Cylinders". NUCLEAR APPLICATIONS and TECHNOLOGY. 9 “(1970).

17 Deanne Dickinson. "Calculational Study of Arrays of Cylinders of Fissile Solution". The Dow Chemical Company. RFP-1821, March 24, 1972.

${ }_{18}$ Deanne Dickinson. "Nominally Reflected Pipe Intersections Containing Fissile Solutions". NUCLEAR TECHNOLOGY. 26 (1975).

19 Robert E. Rothe. "Benchmark Critical Experiments on High-Enriched Uranyl Nitrate Solution Systems”. NUCLEAR TECHNOLOGY. 41 (1978).

${ }^{20}$ Gary R. Smolen, Raymond C. Lloyd, and Hideyuki Funabashi. "Criticality Data and Validation Studies of Plutonium-Uranium Nitrate Solutions in Cylindrical and Slab Geometry”. NUCLEAR TECHNOLOGY. 107 (1994). 


\section{THEORY}

Approaches to criticality were monitored by a method called the Reciprocal Multiplication technique. Use of this method ensured safety. This became the standard method of performing criticality experiments at the Rocky Flats CML through the very last experiment ever performed there in 1989. In this method, the fact is used that the neutron count rate at any and every point within a system increases as criticality is approached. At the critical height, $\mathrm{H}_{\mathrm{c}}$, this count rate, $\mathrm{C}\left(\mathrm{H}_{\mathrm{c}}\right)$, may be hundreds of thousands times greater than at the start of an experiment, $\mathrm{C}_{0}$. The ratio of count rate to initial count rate, called the multiplication of the system ${ }^{21}$, is essentially infinite at criticality. The inverse of this multiplication is the reciprocal multiplication already mentioned, mathematically, $\mathrm{C}_{\mathrm{o}} / \mathrm{C}(\mathrm{H})$. This ratio approaches zero when criticality is reached, an attractive feature for graphing safe critical approaches. For safety, reciprocal multiplication curves should have all parameters fixed save one. In this program, that one parameter is the height of uranyl nitrate solution in the Central Column and however many arms were at or below that level. An important point with this methodology is that all other features remain constant.

Another important definition is that of the neutron reproduction factor, $k$. It and the true multiplication, $\mathrm{M}$, are related by the following equation:

$$
\mathrm{k}=\mathrm{M} /[\mathrm{M}+1]=[1+(1 / \mathrm{M})]^{-1} .
$$

Here, the last term on the right hand side, $1 / \mathrm{M}$, is very close to the reciprocal multiplication already defined.

The increasing neutron flux is related to the increase in reactivity of the system. Reactivity, $\rho$, and the reproduction factor are related by:

$$
\rho=[\mathrm{k}-1] / \mathrm{k}
$$

\footnotetext{
${ }^{21}$ Actually, this empirical ratio is only an approximation to the true multiplication because of other complications to the theory which are explained later.
} 
The term really pertains to the state of the system relative to criticality but is often loosely applied to the physical addition of that one parameter being varied, fissile solution in this case. Adding solution to these arrays added "reactivity" to the system through increased fissile fuel.

The reciprocal multiplication technique begins with the completely assembled tree-like configuration consisting of the Central Column and some number of arms. These components are securely positioned but empty of fissile solution. A set of radiation detectors is also properly situated, as is an external source of neutrons. That neutron source was a small, sealed, thimble-sized container filled with a mixture of polonium and beryllium such that about $10^{7}$ neutrons per second are produced. The philosophy behind locating this source is that its neutrons must pass through fissile solution before encountering a radiation detector. Often, the source was placed on top of one arm very close to the Central Column. The source should not be placed such that its neutrons pass through the detectors without passing through a considerable amount of fissile solution.

The neutron count rate at this initial condition is noted for each of these several very sensitive neutron detectors called proportional counters positioned nearby. These counters detect a constant percentage (usually about 25\%) of the neutrons incident upon them, even at quite low counting rates. In theory, detector response to the neutron source in the absence of any fissile solution $(\mathrm{H}=0)$ is called $\mathrm{C}_{\mathrm{o}}$. As the first solution is introduced, reactivity is increased by fissions taking place within the solution. Other factors also contribute to the observed changes in count rate: thermalization by the hydrogen in the solution and neutron reflection. Thermalization brings more fission-energy neutrons into the energy range of the counters. A small amount of absorption of neutrons by the hydrogen also occurs. These effects alter the energy spectra seen by the detectors and, therefore, the instrument's detection efficiency. This is the reason that the count rate ratio observed later in the experiment is not a precise measure of the true multiplication. In these experiments, a small amount of fissile solution was introduced into the lower parts of the apparatus to minimize the thermalization and absorption effects of this initial amount. In no case did this quantity of solution contribute any significant reactivity.

The reciprocal multiplication technique continues by adding more fissile solution into the Central Column and arms. As reactivity increases, the count rate increases accordingly; and the neutron count rate ratio, $\mathrm{C}_{\mathrm{o}} / \mathrm{C}(\mathrm{H})$, is graphed against the critical approach parameter - the fissile solution height $\mathrm{H}$. Eventually, as enough solution is added to stabilize detector response effects, further additions really do represent essentially a true measure of increased reactivity due to increased fissions; and the system 
approaches criticality. The source neutron moderating and absorbing effects continue to exist; but they are greatly overshadowed by orders of magnitude by the increased reactivity caused by fissions.

The reciprocal multiplication technique ensures safety by allowing experimenters a continually improving estimate of the point at which criticality is projected to occur as the fissile solution height increases. At frequent intervals during the critical approach, additions are interrupted to measure the current value of $\mathrm{C}_{\mathrm{o}} / \mathrm{C}(\mathrm{H})$; and this result is plotted on the reciprocal multiplication graph. The shape and linearity of this decreasing function is used to estimate the greater height, $\mathrm{H}_{\mathrm{c}}$, at which criticality would be predicted to occur. Based on such an analysis, both experimenters agree upon the next increment of solution to be added and the rate at which it could be added safely.

During this procedure toward criticality, the possibility always exists that some particular reciprocal multiplication curve might exhibit a sudden downward tendency such that criticality would, indeed, occur at a much lower height than predicted by the last evaluation by the experimenters. This would-be unsafe feature was guarded against by a simple administrative expedient. During the addition of each solution increment, both experimenters had continual audible information giving the instantaneous neutron flux for each detector. The administrative control was that the next data point in the reciprocal multiplication curve would be taken before the neutron flux had increased a factor of e $(\approx$ 2.718), even if that occurred at a height lower than agreed upon. This administrative control was, itself, protected by adopting a smaller factor - usually doubling. This procedure became the laboratory's operational procedure throughout the lifetime of the facility.

This procedure continued until one of two possibilities happened. Either the apparatus became full of solution such that further additions were not possible without overflowing the Central Column or solution was added until criticality occurred. The former meant that the system under study would never attain criticality regardless of how much solution might have been added. Theoretically, some systems might have attained criticality if a little more solution could have been added above the physical top of the Central Column; but this theoretical case never happened in this program. Stated differently, these cases would have remained subcritical even if an infinite height could have been achieved.

Sometimes in this program, criticality was not actually attained even though it could have been. In these cases, the reciprocal multiplication curve generated up to the last solution height measured appeared to pinpoint the critical height $\mathrm{H}_{\mathrm{c}}$ well enough that actually attaining criticality was not deemed 
necessary. Usually, the critical height by this extrapolation procedure and the actual critical height would have been indistinguishable from one another; but this may not always have been the case. This fact has been borne out by several subsequent experiments in several subsequent programs conducted by this author since the late 1960s. Experience, then, has shown that this decision to terminate an experiment short of criticality may not have been wise. Even small curvature in a reciprocal multiplication curve over a short extrapolation beyond the subcritical data could introduce some uncertainty into the published critical height.

Whenever criticality was actually achieved in one of these experiments, the last few increments of fissile solution were added very slowly and very carefully. During these last additions, the neutron flux becomes so large that the proportional counters used to graph this critical approach begin to suffer dead-time losses in their observed counting rates. Here, detectors could not physically detect the same percentage of neutrons incident upon them that they did at the start of the experiment. This physical defect is non-conservative from a safety perspective. The actual multiplication extant would be larger than indicated.

This recognized and understood flaw was compensated for by abandoning the reciprocal multiplication technique in favor of another method for the final attainment of criticality. Other radiation detection equipment, known as ionization chambers, produce a quasi-DC current proportional to the instantaneous neutron flux incident upon them. These detectors are known not to experience dead time losses until neutron fluxes many orders of magnitude greater than those encountered in these experiments are reached. These same detectors, however, were not at all sensitive to neutron fluxes early in an experiment. Thus, ionization chambers, alone, could not have been used for a safe critical approach. In anticipation of this need, ionization chambers had been placed in the vicinity of the experimental apparatus, in many cases right alongside proportional counters.

Both ionization chambers and proportional counters were equally viable beginning somewhere about the middle of the experiment. Both yielded nearly identical extrapolated predictions of the critical solution height. Both were followed by both experimenters for safety reasons; so the transition from the reciprocal multiplication technique to ionization chamber data for the final attainment of criticality was no compromise to safety. 
In critical cases, incremental additions of solution continued until the neutron count rate continued to rise slowly even after additions had ceased. At this point, the entire experimental system was very slightly supercritical. Actually, this condition was called delayed criticality because the neutron population within the system continued to grow based on the number of prompt neutrons emitted plus only some portion of the delayed neutrons produced at the same time. The fewer delayed neutrons needed, the closer the entire system was to prompt criticality; and prompt criticality was an undesirable condition. Therefore, for safety, these experiments were not carried very far past the situation where all delayed neutrons were needed. This slow exponential growth in the neutron count rate with no more solution additions defined the positive reactor period, mathematically, the time required to increase the neutron flux by a factor of e (about 2.7). In the case of the present experiments, positive periods of a few to several minutes were the goal. This supercritical solution height would be maintained only long enough to measure it accurately. Then, a very small amount of solution was sometimes returned to storage. This rendered the system very slightly subcritical and produced a negative reactor period. Again, negative periods of a few to several minutes were the goal; and this slightly subcritical solution height would also be maintained just long enough to measure it accurately.

Some critical heights quoted in this paper were obtained by the linear interpolation between reciprocal periods at these slightly supercritical and slightly subcritical fissile solution heights. At least, that interpolation technique became the general method of pin-pointing very accurate critical heights at this laboratory from one very slightly subcritical and one equally slightly supercritical measurement. Whether or not this detailed a determination had been developed by this early date is not recalled these three decades later. If it had not been, then an actual claim of "criticality" for one of these experimental configurations in this paper probably corresponded to an experimental system for which a very long reactor period - either slightly positive or slightly negative - existed. That is, the uranium solution height specified would not have been quite as close to the true critical condition as could have been derived from the interpolation technique. This may not be a very serious problem at all. Often, in other programs, systems could be established for which clearly distinct positive and negative reactor periods existed with no observable difference in uranium solution height to within 1 part in 100,000! For example, one program showed such extreme sensitivity as a few milliliters of solution were added to a meter-diameter slab. Still, if this interpolation procedure had been used in these early experiments, an example is shown in Fig. 2. This example is actually drawn from another program and, so, may be regarded as "hypothetical" in this study. 


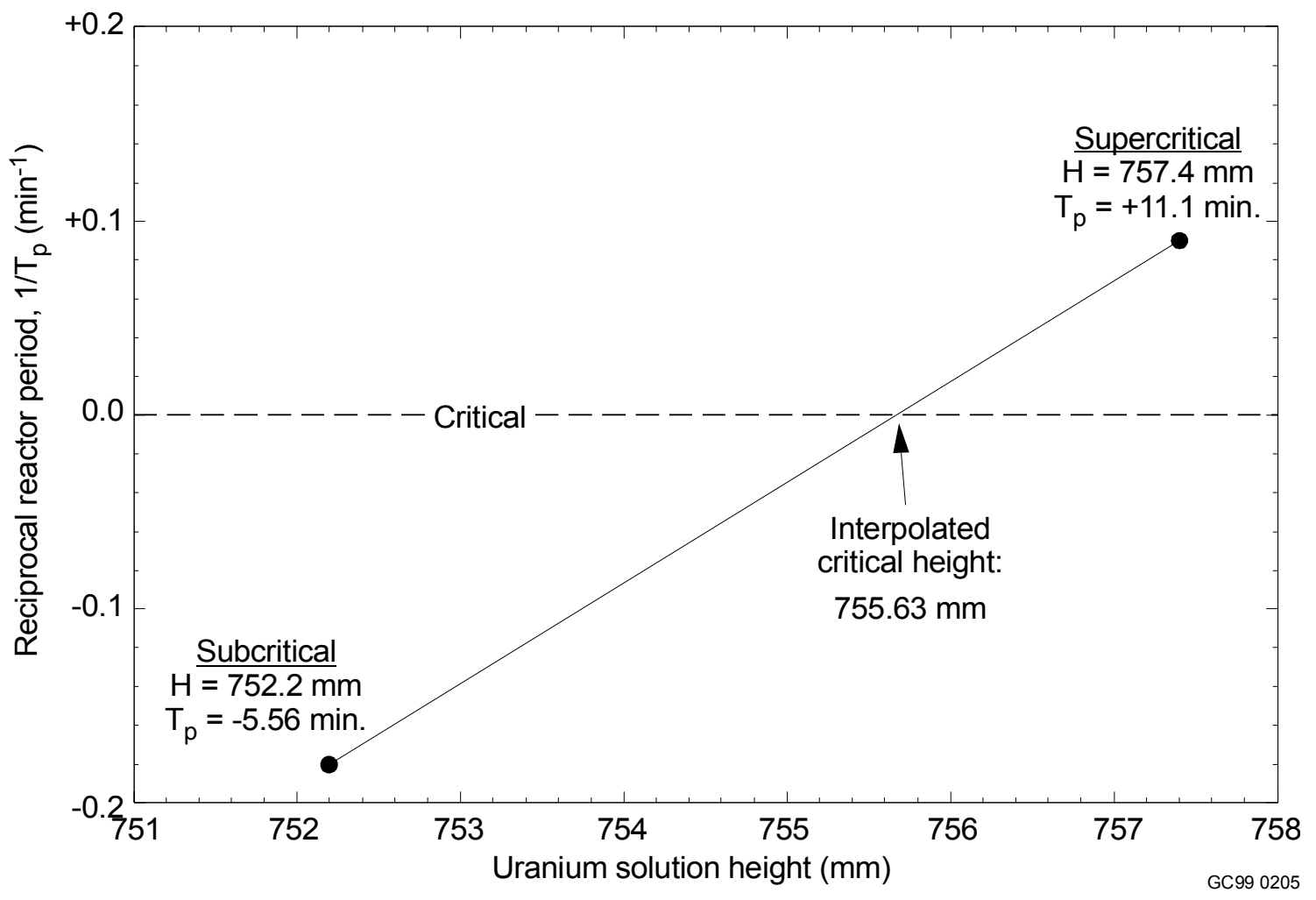

Figure 2. Precise critical heights of uranium solution may have been obtained from this interpolation technique between two heights very close to but on opposite sides of criticality. This became the standard method at this CML; but may have been used only occasionally in this program. This is a hypothetical example.

The validity of this method of determining critical heights using the reciprocal of measured reactor periods was documented in the literature ${ }^{22}$.

Some critical heights quoted in this paper were determined from a series of subcritical runs which were otherwise identical except for one varied parameter. Here, the reciprocal multiplication corresponding to a configuration full of fissile solution was graphed as a function of that one parameter; and configurations closer to criticality when full exhibited greater multiplications. This data was graphed as shown in Fig. 3; and an extrapolation of the subcritical cases predicted the critical one.

\footnotetext{
${ }^{22}$ Robert E. Rothe, NUCLEAR SCIENCE AND ENGINEERING: 35 (1969).
} 


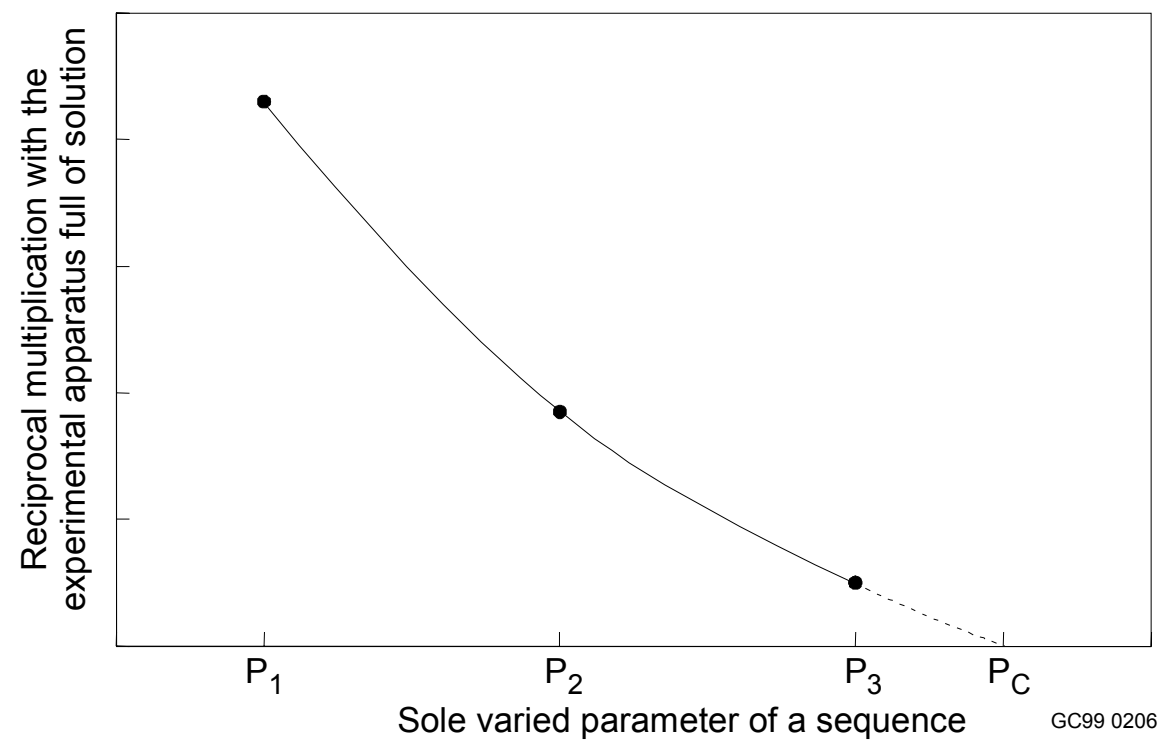

Figure 3. Less precise critical heights of uranium solution may be obtained from this extrapolation technique. The last reciprocal multiplication value recorded each time the Central Column was full of solution for a sequence of identical experiments except for one changing parameter, $\mathrm{P}_{\mathrm{i}}$, may be graphed as shown here. One example of this changing parameter might be the spacing, $\mathrm{S}$, between arms. A smooth curve through the last few points extrapolates to a critical value of the parameter, $\mathrm{P}_{\mathrm{c}}$.

Still other critical heights quoted in this paper were simply extrapolated from a lesser height to the critical height which could have been reached within the limitations of the apparatus. In these rare cases, an extrapolation was deemed as good as actually attaining criticality; and the shortcut was both safer and faster. This was a questionable decision in light of present-day knowledge about curvature in extrapolation regions; but, nonetheless, it was sometimes done as a simple expedient.

Once criticality had been measured by any means, all necessary data had been obtained and the experiment could be terminated. Keeping the system at or very near criticality any longer only increased the risk of an accident and added to the (really very small) fission product inventory. The uranium solution was simply allowed to flow back to storage. As expected, the neutron count rate on the proportional counters would return to the $\mathrm{C}_{\mathrm{o}}$ value; and the ionization chamber currents would return to their initial near-zero level. 


\section{PROCEDURE}

Each critical approach experiment was preceded by a construction of the specific apparatus to be studied. Once the tall, vertical, Central Column had been put in place at the beginning of the entire program, that column was never moved; but the chosen assembly of arms, also to be filled with uranium solution during the critical approach, would vary from experiment to experiment. The Central Column was installed such that its four faces were rotated $45^{\circ}$ with respect to the Solution Base. (The Solution Base, described in more detail later, was the large, heavy table on top of which the experiment was built.) That happenstance was the result of the small size of the bottom plate to the Central Column and the need to install three couplings in that small area. The schematic drawing on the following page is of the Solution Base and the Central Column. Normals to the Solution Base edges faced north, south, east, and west and these are abbreviated N, S, E, and W, respectively. Therefore, normals to the four faces of the Central Column faced NW, NE, SW, and SE; and these designations are used in later tables.

The desired number and diameter of arms for the tree-like assembly were selected and carried into the Assembly Room Hood for assembly into the intended configuration. Arms branching off any given face of the Central Column were held in a vertical plane by a light-weight structure of a commercial steel product called Slotted Angle. Some experiments had arms branching off all four faces, some used two faces, and a few, one. When two faces had arms, these branched off either opposite or adjacent faces of the Central Column. Up to four arms were sometimes built in a given stack off one face. These could be spaced some distance apart; or the arms could be resting on one another in contact. In addition to these parameters, arms could be horizontal or inclined upward at $45^{\circ}$ from the vertical. Many combinations of experimental configurations were possible. Once installed, arms were connected to the solution distribution manifold.

Many experiments had more arms in place than were allowed to receive fissile solution. This was done to reduce the amount of handling between similar experiments which differed only in the number of arms containing solution. A given configuration may have had, say, sixteen arms in four vertical planes of four arms each. Experiments with twelve, eight, and four arms were easily set up simply by disconnecting the upper four, eight, and twelve arms, respectively. In these cases, the disconnected arms remained present but were not eligible to receive solution. This detail is important because unfilled arms still constituted a minimal neutron reflector. 

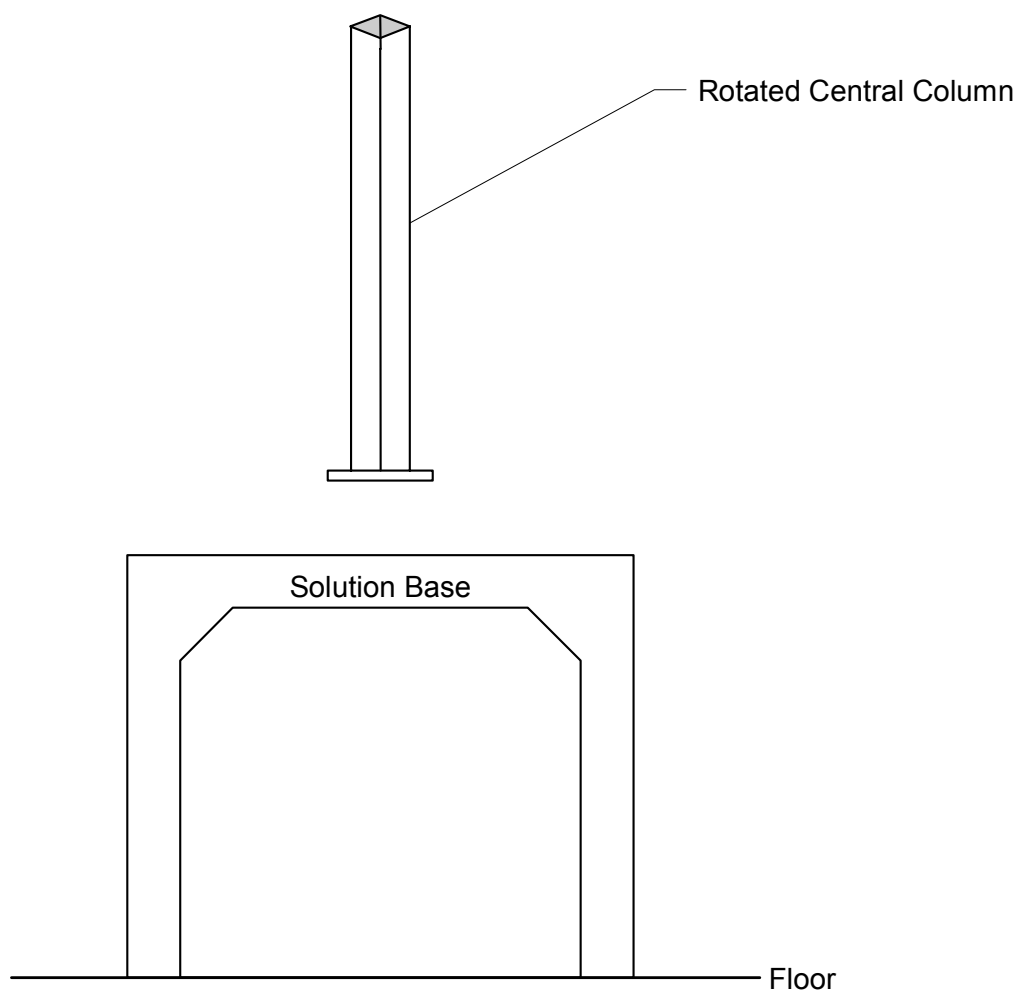

Elevation View

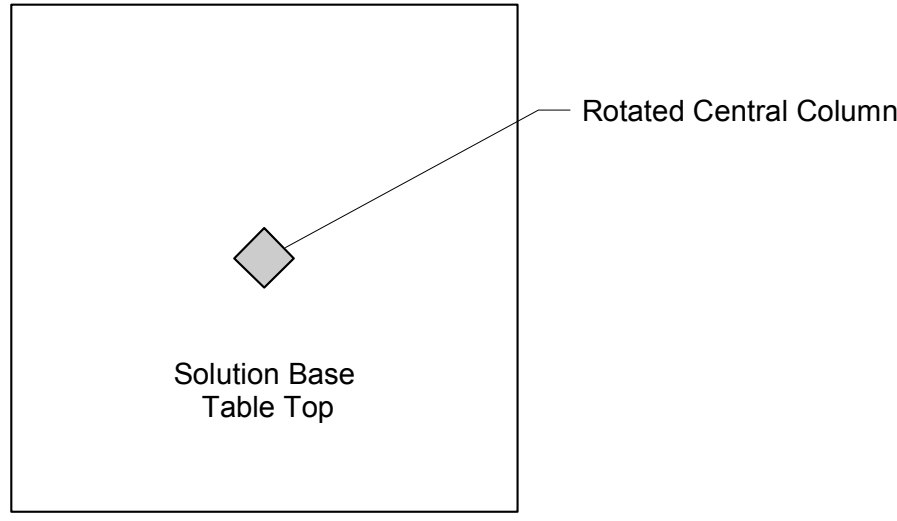

Plan View

GC99 06181

The elevation view of this schematic drawing of the apparatus includes the heavy-weight table of the Solution Base and a truncated Central Column. Both views shows the Central Column rotated $45^{\circ}$ on the Solution Base table. Arms and fill and SCRAM connections have been omitted for clarity. The drawing is not to scale. The very top of the Central Column, rotated $45^{\circ}$ with respect to the Solution Base Table Top, is shown in a bird's eye view instead of true elevation view - to reveal the interior of the hollow column. 
Once all the apparatus was in position and desired arms connected, the Assembly Room was vacated and locked securely. All doors were sealed via rubber gaskets to prevent any possible movement of air between that room and the rest of the world. In addition, all ventilation lines into and out of the room were remotely closed and sealed. These air movement precautions mitigated fission product release to the environment in the unlikely event of a criticality accident. The intent was to contain any radioactive byproducts from the hypothetical excursion within the room and prevent their escape into the atmosphere. These precautions were adopted with every one of the 1700 critical approaches conducted at the CML during its productive quarter of a century. Happily, no criticality accident ever occurred at Rocky Flats.

The fissile solution was stored in a number of critically safe tanks located in another room. Prior to leaving the area, manual valves in both rooms were properly positioned to allow solution to flow back and forth between the two rooms. Remotely controlled automatic valves prevented any movement of solution until the experimenters intentionally performed that function.

Uranium solution was pumped from the storage tanks into the experimental apparatus pausing now and then as discussed earlier to record neutron multiplication data for a safe approach to criticality. This procedure is described in the Theory section of this paper. Three different pumps were available to the experimenters for better control over the approach to criticality. Even these pumps were, themselves, variable in their output delivery. The greatest output was about one liter of solution per second; and this was restricted in use to heights well below criticality. The lowest continuous delivery output was about one liter per hour! Even that was considered variable in that short incremental additions of but a few seconds at that output setting were easy to perform. In summary, the flow rate of uranium solution into the experimental apparatus was easily controlled over a very large range; and the slowest possible delivery rate never proved to be too great for a safe approach toward criticality.

The Central Column and its arms were filled with fissile solution simultaneously. Of course, the dynamic act of pumping solution into this complex system of pipes, columns, and a myriad of flexible tubes would result in a momentary overfilling of one component at the expense of another. This effect was seen only with the pump having the greatest delivery rate. The other two pumps had such slow rates that no such momentary situations occurred." This was the result of slightly unequal impedances to solution flow among the various components. These unequal fillings would, of course, come to 
equilibrium within a few seconds after the pumped solution addition ended even at the fastest addition rate.

The uranium solution height in the Central Column and the several arms would also come into equilibrium with the solution height in a long vertical length of clear plastic tubing. This tubing was located about $2 \mathrm{~m}$ away from the experimental apparatus; but its lower end was connected to yet another short nipple welded to the Central Column very close to the bottom of a side. This clear vertical tube served as a "sight gauge" allowing experimenters to view solution height via closed-circuit television from a safe distance away in a well-shielded room. A linear scale was mounted adjacent to this clear plastic tube to translate observed solution heights into readable metric units of length. Years later, expensive engraved metal scales were used for this purpose; but wooden meter sticks with printed scales served this function in these early years at the CML. Three meter sticks were mounted end-to-end to cover the full height of the Central Column in this program.

One problem with viewing such a sight gauge through television was recognized early on. That problem was parallax which would exist as a television camera at a fixed elevation was required to look at solution heights spanning more than two meters in height. Even though the camera and its mount were capable of both zoom and vertical rotation to follow the rising solution, some parallax would exist whenever the camera was looking other than perfectly horizontal at the solution meniscus. This problem was resolved for this study by constructing a vertical mast mechanism with a motor drive. This contraption could move an always-horizontal television camera up and down the mast; and the solution height was always read at about the same location on the television monitor. This further reduced parallax. The camera could then follow the solution without changing the parallax. With this device, the television camera always viewed the different heights of the uranium solution with no - or at least a constant - parallax.

As the solution height increased in the Central Column and its adjacent arms, neutron multiplication data was collected as discussed in the Theory section. In time, the data collected would prove one of two results. Either the configuration built for that experiment would never attain criticality no matter how much uranium solution were added (subcritical case) or the situation yielded a critical height which would fall at some height attainable within the apparatus (critical case). 
Details of the actual procedure used whenever criticality was attained are not recalled for every experiment these three decades after the completion of the study. Criticality was truly achieved; that fact is clearly recorded. Furthermore, the detailed procedure is known to have changed a little during the course of this program. Prior to the $18^{\text {th }}$ experiment, no capability existed to move the external source ${ }^{23}$ remotely; so, criticality had to be achieved with that neutron source present. After that time, that capability was added; and the final approach to critical was performed in the absence of any external source of neutrons.

When achieving criticality in the absence of an external source, final increments of solution were added along with slow and incremental removals of the external source. These reactivity changes came in slow alternating increments in order to keep the neutronic response of the entire system within limits allowed by the instruments. By this stage in an experiment, a source was no longer needed anyway because the entire system contained so many fission neutrons that it could easily and safely perpetuate neutrons without it. After 1970, that external source was made of californium with a long half life. For this program, the source was PoBe with a nominal emission of about $10^{7}$ neutrons per second. PoBe sources were short lived and new ones had to be obtained every few months.

Once the neutron source was removed a great distance away, the solution height was adjusted one final time to produce a very slow exponential increase in neutron population. This condition was slightly supercritical; but still safely in the delayed critical $^{24}$ range. This slow growth in neutron population produced a measurable positive reactor period. Then, a small amount of solution was allowed to drain away from the apparatus to define a new and slightly lower (sometimes unmeasurably lower!) height. At this height the neutron population decreased exponentially; and a negative reactor period was measured. These two solution heights bracketed the critical uranium solution height; and this critical height was interpolated by the method described in the Theory section. Log Books for this study do not often record details of both periods; but this method is believed to have been employed on occasion.

${ }^{23}$ In fact, the presence of the source slightly complicated the precise definition of criticality. At criticality, the neutron population should remain essentially constant over long intervals. Without the source, that is possible. With the source, the neutron population would continue to increase slowly but continuously even at precise criticality.

${ }^{24}$ No system at Rocky Flats was ever allowed to come anywhere near prompt criticality. 
At this point, the experiment was finished. Solution was allowed to return to storage. Often this was accomplished by reversing the solution flow through the fill line which then served as a "return" line. In these cases, the SCRAM valves remained closed; and the solution would not enter the SCRAM tanks. On other occasions, the solution was intentionally allowed to leave the apparatus by passing into the SCRAM tank. This was accomplished simply by activating the Manual Scram capability at the Control Console. The decision as to which method of return was used was completely arbitrary. No advantages or disadvantages were recognized to either procedure. Much later in the program, the disadvantage of using the SCRAM tanks was recognized; and this topic is well covered in the section Lessons Learned.

Many experiments were interrupted by accidental activation of the SCRAM safety system. Sometimes, two or three unplanned shutdowns occurred before an experiment could be successfully completed. The reason for this was not immediately recognized. Later, it was determined that these SCRAMs were caused by the unusually high hydrostatic pressure head resulting from such a tall column of solution pressing against the two electrically closed SCRAM valves. If the electrical solenoids holding these valves closed during the experiment allowed even a small amount of solution to leak past their seals because of this pressure, that leaked solution would collect in the SCRAM tank and indicate that the SCRAM tank was not empty. By design, that safety tank had to be completely empty throughout an experiment for the experiment to proceed. 


\section{APPARATUS}

\section{Central Column}

The Central Column was a length of stainless steel tubing with a square cross section. The nominal vertical length of this column was $2438 \mathrm{~mm}$; but the actual length was $2435.4 \mathrm{~mm}^{25}$. At least that was the height corresponding to the top of the column on the height measuring sight gauge used throughout the experiment. In practice, the Central Column was declared "full" when solution reached a few millimeters below the top. This practice prevented overflowing the column during an experiment. The second height, only $2.6 \mathrm{~mm}$ lower than the nominal one, probably represents the true height of the finished column, although it could also be attributed to a small bias in the placement of the scales used to read solution heights. Since this latter task was done quite carefully, the former seems more likely. The column was open at the top; and the only photograph of this column available anywhere is in Fig. 4. This photograph was reproduced off of a single frame of a short movie made during the investigation of the incident discussed in the Lessons Learned section. That movie has been converted to video for preservation in the LANL Archives. While open at the top, the square tubing was welded to a square stainless steel base at the bottom. The inside dimension of this square Central Column was $177.8 \pm 1.6$ $\mathrm{mm}$; and the walls were reported to be $3.18 \mathrm{~mm}$ thick. The column is believed to have been commercial stainless steel tubing extruded to these dimensions and then cut to length.

The stainless steel is almost certain to have been either Type 304 or Type 316; but no information is available to specify which of the two was used. They both were common types used at Rocky Flats in all stainless steel applications over many decades. Most common extruded shapes are of those two types.

The bottom of the Central Column was welded to a stainless steel square plate slightly larger than the column itself. That fact is certain. Details of this plate, however, are not recorded; so faint recollection must be combined with sensible design arguments to arrive at its possible dimensions. The size of the square was not a great deal larger than the column; that is recalled and supported by available (but undimensioned) sketches. It would most likely have been either an integer, half-integer, or, possibly, a quarter-integer dimension specified in English units (inches). Likely candidates are 7.5-inches (190.5 $\mathrm{mm}), 7.75$-inches $(196.9 \mathrm{~mm})$, and 8-inches (203.2 mm) square. The latter would seem unnecessarily

${ }^{25}$ The last three experiments of this study used equipment other than arms projecting from the Central Column. The height of the Central Column was remeasured at $2428.3 \mathrm{~mm}$ after this change. Apparently, the scale alongside the sight gauge had shifted $7 \mathrm{~mm}$ during this modification. 


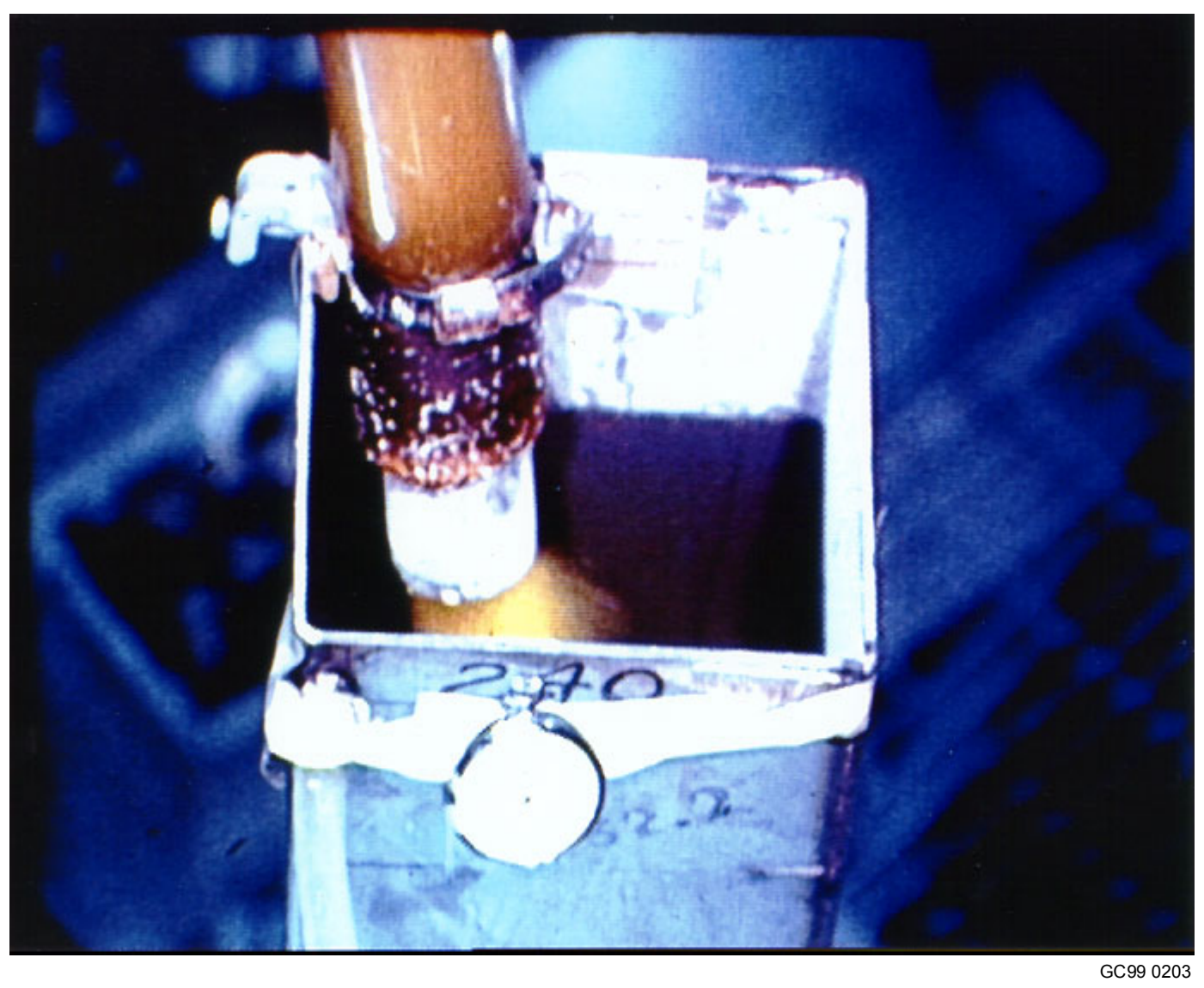

Figure 4. The open top of the tall Central Column had small-radius corners. The dark area below the top is uranyl nitrate solution. The large diameter plastic tubing to the upper left is the SCRAM tank vent line as it had been reinstalled following the incident described in the Lessons Learned section. The photograph is but a single frame from a short movie made of the problem incident. The stopwatch was placed for this movie.

large; and first would have been just adequate to accept the weld bead. So, the middle size is assumed to have been the size selected. This is arguable conjecture; and some uncertainty must rise from that absent knowledge. The thickness of this plate must also be estimated by similar arguments. It would not have been 1/4-inch-thick because that would not have been ample to retain rigidity when welding the couplings needed for the fill line connection and two SCRAM valves. The most likely candidate is $1 / 2$-inch stock which would be $12.7 \mathrm{~mm}$ thick, although 3/8-inch plate $(9.5 \mathrm{~mm})$ would have been marginally reasonable. Based on these speculations, the bottom plate to the Central Column is argued to have been $197 \pm 4 \mathrm{~mm}$ square by $12.7 \pm 2 \mathrm{~mm}$ thick.

All three couplings to the bottom plate of the Central Column were of a type known as "Marmon Couplings". These were used on all experimental programs involving fissile solution at the Rocky Flats 
CML over its lifetime to connect the experimental tank to the fixed plumbing of the Solution Base. Three Marmon Couplings were required. Two were larger and connected the SCRAM valves to the apparatus's bottom plate. The third was the fill/normal return coupling. These couplings had a complicated design probably not worthy of detailed description. They could reasonably be approximated by thin $(12.7 \mathrm{~mm}$ thick) circular rings extending below the bottom of the apparatus (the square bottom plate in this case). The two SCRAM couplings would be $109 \mathrm{~mm}$ OD by $70 \mathrm{~mm}$ ID; the single other coupling, $58 \mathrm{~mm}$ OD by $27 \mathrm{~mm}$ ID. These three couplings left very small pockets of fissile solution protruding below the top surface of the bottom plate. All three pockets would be about $20 \pm 5 \mathrm{~mm}$ thick by $70 \mathrm{~mm}$ diameter (SCRAM couplings) and $27 \mathrm{~mm}$ diameter (fill/return coupling). These three couplings were welded in an isosceles triangular pattern with the smaller coupling centered at the apex of this triangle and the other two centered at opposite ends of the base of the triangle. This base was $132 \mathrm{~mm}$; and the altitude was $76.2 \mathrm{~mm}$. These three couplings pretty well occupied the entire area of the square bottom plate of the Central Column since the diagonal of the inside dimension of the Central Column was only $251 \mathrm{~mm}$ - just a little greater than the spacing between the outer edges of the SCRAM valves $(191 \mathrm{~mm})$. With this orientation of couplings, faces of the Central Column had NW, NE, SW, and SE normals as mentioned earlier. Often, information is not available as to which particular face(s) had arms extending from them. Some experiments did specify, others did not. If all four faces had arms, no ambiguity exists. If fewer did, which face(s) were without arms is sometimes not known. This is probably not a serious omission because not many neutron reflectors existed nearby to influence the tree-like assembly.

The four faces of the Central Column were perfectly smooth and free of any features except for two small nipples near the bottom. This was important to allow arms to extend off the column at any height and off any face without the possibility of being restricted by a protrusion. Those two nipples were both 12.7-mm-diameter stainless steel tubing, and were used for hose connections. Their length is uncertain; but they were certainly between 13 and $25 \mathrm{~mm}$ long. Both extended off the same face near the bottom of the column. One was but a few millimeters above the bottom plate; and this allowed solution to pass into the vertical, clear plastic tube used for a sight gauge. The other was 100 to $200 \mathrm{~mm}$ above that plate; and it was used to pass solution to all of the arms as described elsewhere.

\section{Arms}

All arms were lengths of commercial stainless steel tubing. This tubing was almost certainly either Type 304 or Type 316, although that fact is nowhere stated in records. The reason behind this claim is the same as for the Central Column. Most arms had a circular cross section, although one set 
was made from the similar (but possibly not identical) stock as the Central Column. Therefore, this set had a square cross section. These were used on only four experiments. The outside length of all arms, regardless of cross section, was $1.372 \mathrm{~m}$; and this length was considered to be "effectively infinite". That is, longer arms were believed not to contribute significant reactivity to any experimental configuration. Whether or not this theoretical assertion is true is uncertain but also irrelevant. The geometry of the system tested can be described quite accurately; so no assumptions need be made about the reactivity contributions from regions of solution near, at, or beyond the end of the actual arms.

All arms were welded shut at both ends forming, when full, "pencils" of solution. The thickness of the stainless steel end plates was not specified; but a reasonable estimate would assume this thickness to be the same as the wall thickness of the tube itself. Three sizes of circular cross section pipe were used and are described below. The precision implied by five significant figures is probably unrealistic; but this is a concession to the conversion between English units and metric units for nominal commercial pipe diameters.

(1) The smallest arms were $110.08 \mathrm{~mm}$ in ID by $114.30 \mathrm{~mm}$ OD; therefore, the wall thickness was 2.108 $\mathrm{mm}$. This corresponds to a nominal "Four-inch stainless steel Schedule 5 pipe" in a commercial catalog of such materials. Both documents reproduced in Appendices A and B identify the inside diameter of these arms as either 4.344 inches $(110.34) \mathrm{mm}$ ) or, less precisely, 4.34 inches $(110.24 \mathrm{~mm})$. No argument exists that the outside diameter is other than 4.5 inches $(114.30 \mathrm{~mm})$. Under these assumptions the wall thickness would have been either $1.98 \mathrm{~m}$ or $2.03 \mathrm{~mm}$. The overwhelming argument must remain that commercial sized pipe would have been used. Therefore, the first-stated dimensions are assumed correct. Furthermore, the $110.08 \mathrm{~mm}$ diameter corresponds to English units of 4.334 inches. A simple transcription error to 4.344 inches (as in the Appendix) is a quite believable error. Therefore, considerable confidence exists that these arms were lengths of a standard catalog item.

(2) Middle-sized arms were $135.76 \mathrm{~mm}$ in ID by $141.30 \mathrm{~mm}$ OD; therefore, the wall thickness was 2.770 $\mathrm{mm}$. The same catalog lists this wall thickness as belonging to "Schedule 10 pipe" but only up to a nominal two-inch-diameter pipe. Larger diameter pipe tended to have a slightly thicker wall (3.05 $\mathrm{mm})$. The catalog did not list Schedule 10 pipe in this large a diameter. However, the company did acknowledge that special sizes could always be obtained. The catalog did list Schedule 40 five-inch pipe which had the correct outside diameter; but its wall thickness was much too large $(6.553 \mathrm{~mm})$. Therefore, Schedule 40 pipe was not used. This author recommends using the dimensions given above $(135.76 \mathrm{~mm}$ ID by $141.30 \mathrm{~mm}$ OD) even though the catalog does not list that size. 
(3) The largest arms were $162.64 \mathrm{~mm}$ in ID by $168.28 \mathrm{~mm}$ OD; therefore, the wall thickness was 2.82 $\mathrm{mm}$, again, probably consistent with Schedule 10 stainless steel pipe, this time in the nominal six-inch size. This large size is not listed in the catalog. All six-inch pipes catalogued had the correct outside diameter $(168.28 \mathrm{~mm})$; but Schedule 40 pipe was too thick $(7.11 \mathrm{~mm})$ and Schedule 80 pipe was even thicker $(10.97 \mathrm{~mm})$. The author's suggestion is to assume that this was a special purchase of six-inch Schedule 10 stainless steel pipe having the dimensions: $162.64 \mathrm{~mm}$ ID by $168.28 \mathrm{~mm}$ OD.

The arms with a square cross section had the same inside dimensions as the Central Column $(177.80 \mathrm{~mm})$. The wall thickness seems to be a little confused. One document (RFP-1196), the one never published, reported this thickness as $1.98 \mathrm{~mm}$. This thickness is the same as the smaller-diameter round arms and may have been simply a copying error. The published document (RFP-1197) specifies the same wall thickness as for the Central Column. Use of the same stock makes sense. Why a second square stock would have been purchased rather than making these square arms from additional square tubing as had been used for the Central Column would be hard to understand. The possibility exists that this wall thickness is recorded wrong in Appendix A. Having pointed out that potential error, the suggested dimensions for the set of square arms are: $184.15 \mathrm{~mm}$ outside by $177.80 \mathrm{~mm}$ inside.

Two kinds of arm orientations were studied throughout this program. For one, the arms were horizontal placing them orthogonal to the vertical Central Column. For the other orientation, arms extended upward and outward at a $45^{\circ}$ angle. These angled arms and the axis of the Central Column formed a vertical plane out of which arms never skewed. When this orientation was used, ends of arms were also flush with the face of the Central Column. Therefore, at least one end of these arms ended at that $45^{\circ}$ angle rather than $90^{\circ}$. Clearly, these tube end plates would be elliptical in shape with the minor axis equal to the tube diameter and the major axis $\sqrt{2}$ times larger.

Conflicting evidence exists regarding possible differences in the end geometry of the two ends of an arm; and memory does not resolve this question. Two possibilities exist although the second is argued more plausible. (1) One free-hand drawing entered in the Log Book of the $4^{\text {th }}$ experiment in this program is sketched in Fig. 5. It suggests that different end designs for each arm would allow a single one to serve either orientation. Horizontal orientations would use the arms as shown in the figure leaving the sloped end pointing away from the Central Column; but experiments featuring $45^{\circ}$ arms would reverse the arms end-for-end leaving the squared-off end pointing away and upward. If this were to have been the case, 


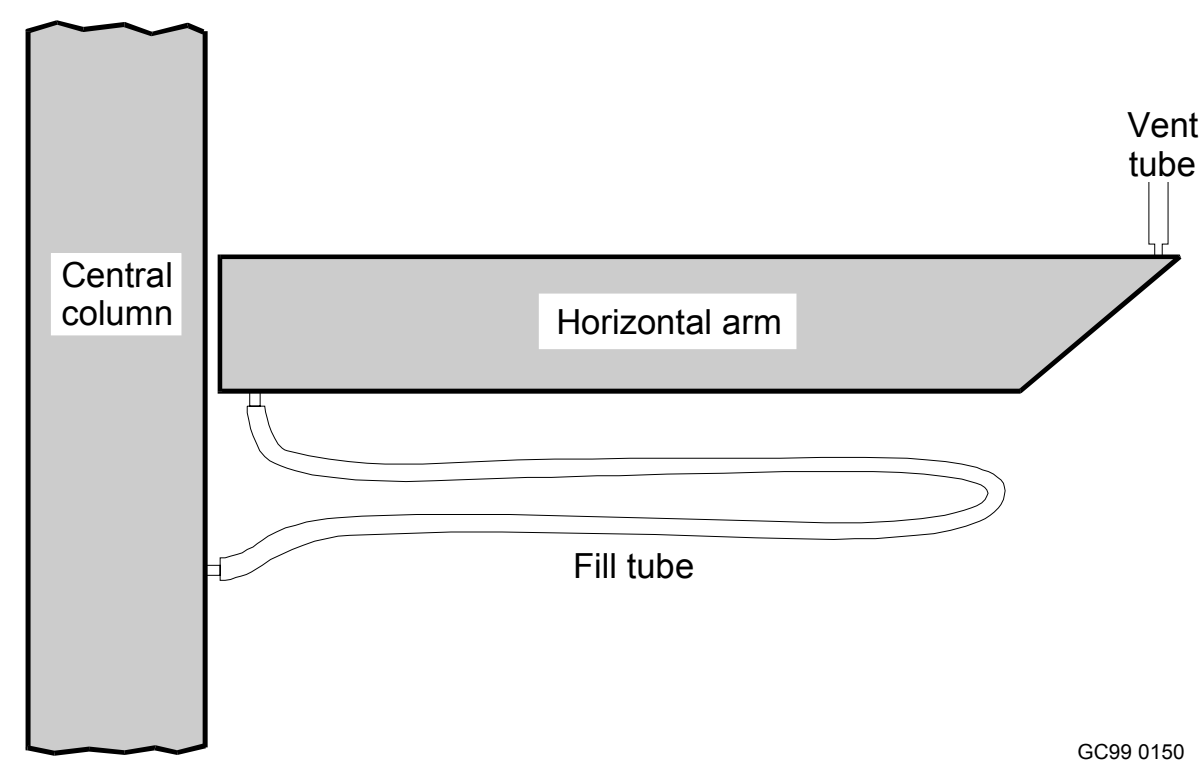

Figure 5. One possible design of arms contained different geometries at either end. Even though this drawing was copied out of the Log Book for this program, the cross section for arms actually used in the $45^{\circ}$ arm orientations was believed to be a true trapezoid with identical end plates at the same slope. The question of design of opposite ends of arms is discussed in the text.

reversed arms would also have to be rotated $180^{\circ}$ about their cylindrical axis. This rotation would make the vent nipple in one orientation the fill nipple in the other and visa versa. Arguments in favor of this design are that it would reduce the number of arms fabricated; and the exact design of the outer end would be truly unimportant if they were, in fact, long enough to be considered "effectively infinite". (2) All figures, such as Fig. 6, in the unpublished paper (copied in Appendix A) show arms used in the $45^{\circ}$ sloped experiments having outer ends parallel to the inner ends. The cross section of a side view, then, would be a parallelogram with that acute angle between two pairs of adjacent sides. Arguments in favor of this design are that a much simpler geometry appeals to the computer modeler even though a few more arms had to be fabricated; and, furthermore, the preponderance of figures presented in the unpublished paper show this design although they are only drawings and not photographs. This second design is believed to have been the one used, although the possibility exists that this conclusion is wrong. 


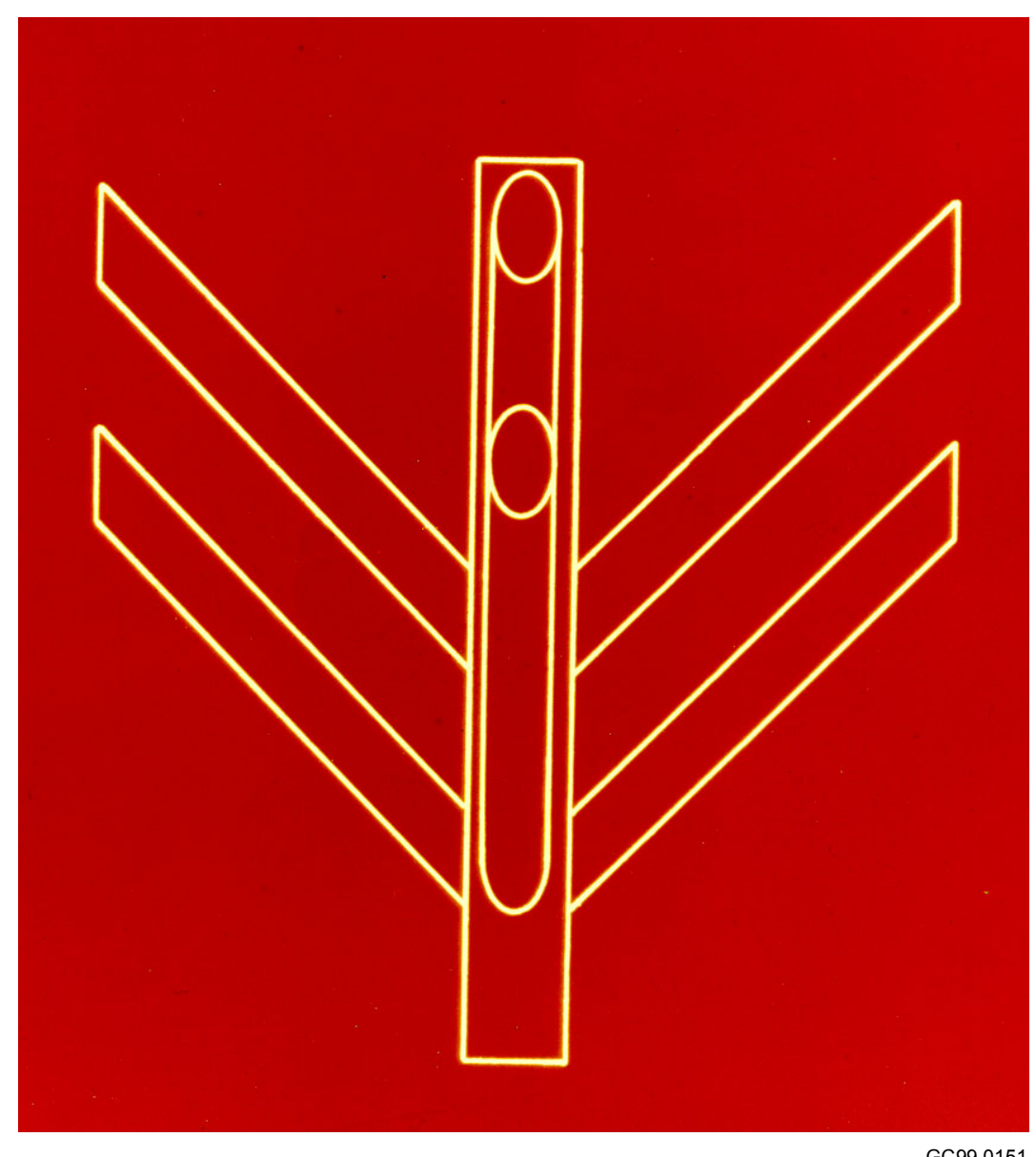

Figure 6. The more likely design for arms used in the $45^{\circ}$ orientations were trapezoids as shown in this photograph of a drawing.

Even the "horizontal" arms were not always installed absolutely level according to one terse comment. A very small slope downward toward the Central Column was built into at least one of these configurations. The purpose of this slope was to enhance solution drainage. Whether or not such a slope was a general practice is not known. On this one experiment, the outer end was $2.5 \mathrm{~mm}$ higher than a point $607 \mathrm{~mm}$ closer to the Central Column. That length $(607 \mathrm{~mm})$ does not represent any particular aspect of an arm. Instead, that length is noted to be just about the length of a commercial two-foot-long level which, evidently, had been used to measure this slope. These measurements suggest that this one "horizontal" arm actually had a drainage slope of about $0.24^{\circ}$. 
Even perfect fabrication of components would mean that uranium solution regions in the Central Column and arms would be separated by the thickness of two stainless steel walls (the column and one of the arm's end plates). One measurement of the air gap found between one arm and the Central Column was reported as about $1 \mathrm{~mm}$. Maximum air gap governing all experiments would be $3 \mathrm{~mm}$. A reasonable value, then, for this air gap between arms and column would be $2 \pm 1 \mathrm{~mm}$.

\section{"Donuts"}

The last three experiments in this study did not employ any arms at all. Instead, a different container was fitted around to the Central Column to add reactivity in the attempt to attain criticality. The column alone, although quite reactive, was still subcritical even when filled to the top with high concentration uranyl nitrate solution. That new container was somewhat the shape of a donut as shown in Fig. 7.

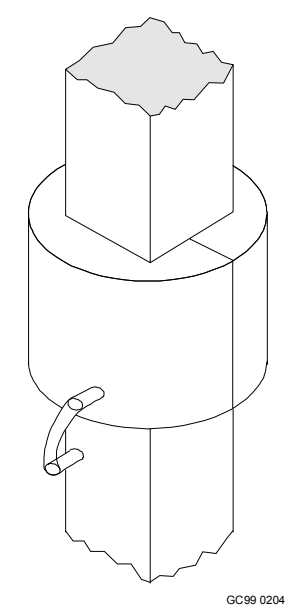

Figure 7. Three experiments did not employ arms at all to increase reactivity of the Central Column. Instead, "donuts" were fit around the column. Donuts were fabricated in two halves which came together as shown; and they were filled by nipple connection just as the arms were.

Geometrically, the donut was a right circular cylinder considerably larger in diameter than the column but with a square hole axially through it. The hole was just slightly larger than the Central Column; so it could easily fit close to the column. The donut's cross section was rectangular; and it was divided into two semicircular components to permit the two to be placed around the column without sliding it over the full length. The donut was almost certainly made of stainless steel, although that fact is not written down nor remembered. The assertion is based on a logical expectation of what material would have been used. No other components holding fissile solution in this program were made of any other 
material. The thickness of the stock is likewise neither known, recalled, nor recorded. Common sense suggests that a thickness typical of the arms might have been used. A thickness of $2.4 \pm 0.3 \mathrm{~mm}$ is suggested; but this thickness is simply reasonable conjecture.

Dimensions of the donut, excluding the square hole, were $305 \mathrm{~mm}$ in diameter by $177 \mathrm{~mm}$ high; that data is recorded (at least for one donut). Documentation does not state, however, whether these are inside or outside measurements; so this point, too, is not certain. Humans would be more likely to specify outside measurements for such a container because those are the only ones amenable to measurement after fabrication. Therefore, these are assumed to be outside measurements. If both assumptions are correct, then the interior dimensions available to solution would be $300 \mathrm{~mm}$ in diameter by $172 \mathrm{~mm}$ high. The measurement down from the top of the Central Column ${ }^{26}$ was $1420 \mathrm{~mm}$ for the first of these three experiments

A second donut was placed on top of the first for the last two of these three experiments. After the second one was added, that distance down from the top of the Central Column reduced to $1265 \mathrm{~mm}$. If the first donut had not been moved prior to adding the second, the difference, $155 \mathrm{~mm}$, suggests that the two donuts may have been of different thicknesses. Another possibility is that the first had been lowered in order to keep the two more centered along the column. Which possibility is correct cannot confidently be recalled these many years later.

One further confusion concerning the overall height of the two donuts involves a logged comment entered during the third of these experiments. This states that "the sum of the two donut heights was about $280 \mathrm{~mm}$ ". In summary, one donut was $177 \mathrm{~mm}$ tall; that appears clear. The second may have been the same height, $155 \mathrm{~mm}$, or (as seen later) $103 \mathrm{~mm}$. Clearly, some discrepancies regarding the height(s) of these two donuts exist. This last experiment also identifies the distance down from the top of the column as $1320 \mathrm{~mm}$. This is greater than the $1265 \mathrm{~mm}$ given above even though the last two experiments appear to have been nominally identical.

One possible set of circumstances explains all observed donut heights as well as their locations along the Central Column. In that scenario, the first experiment had a donut $177 \mathrm{~mm}$ high located 1420

${ }^{26}$ The top of the Central Column for these three last experiments was reported lower than it had been for all previous experiments. That height was $2428.4 \mathrm{~mm}$ instead of the previous value: $2435.4 \mathrm{~mm}$. 
$\mathrm{mm}$ down from the top of the column. The second experiment had a thinner donut $(103 \mathrm{~mm})$ added on top of the first; but the two were lowered to place the top of the upper one $1265 \mathrm{~mm}$ down from the top. The third experiment, identified as $280 \mathrm{~mm}$ tall, was simply the same two donuts (177 $\mathrm{mm}$ and $103 \mathrm{~mm}$ ) repositioned along the column to be $1320 \mathrm{~mm}$ down from the top. This argument is pure conjecture; but it is consistent with the measurements observed.

The existence of discrepancies is truly unfortunate because both experiments with two donuts in place proved to be critical. They would make excellent benchmark validation calculations. One occurred with the second donut not quite full; the other occurred with $9 \mathrm{~mm}$ of solution in the Central Column above the filled second donut. Both are illustrated in a figure from the Results section (Fig. 24). The expected strong sensitivity of $\mathrm{k}_{\mathrm{eff}}$ to this solution height in such compact geometries could help resolve this discrepancy. One assumption should yield both calculated $\mathrm{k}_{\text {eff }}$ values very close to unity; the other, very far from criticality.

These donut halves were probably filled and vented through nipple connections similar to those on arms. If so, each half would have one fill nipple close to the half-square hole near the center of the donut and a second nipple on the opposite surface at its outer radius. Nipple use nor location were not specifically mentioned in available records.

Evidently, these right circular cylinders were not perfectly made. The average gap between the two halves of the lower donut was about $8 \pm 2 \mathrm{~mm}$; and the same gap for the upper donut was about 5 $\mathrm{mm}$ on an average. Both these gaps were probably simply visual estimates.

\section{Arm Support Structure}

The arms projecting off any one face of the Central Column were held in a vertical stack by a light-weight, L-shaped, steel structural material called Slotted Angle. This material was a gray-painted, mild steel product extruded in the shape of a thin angle iron with unequal legs. The material can be seen in a totally different application in Fig. 8. The angle stock was sheared to length as needed and bolted together. Dimensions of this stock were not recorded; but they are recalled to have been commercial 2" by $11 / 2$ " stock which would be $51 \mathrm{~mm}$ by $38 \mathrm{~mm}$. The thickness was probably $1.6 \mathrm{~mm}$ because this would have been a common commercial thickness (one-sixteenth of an inch); and the material is recalled to have been easily sheared to length by a tool purchased for that purpose. Both faces of the L-shaped material were perforated with a regular pattern of round and oval holes. These holes covered about $30 \%$ 


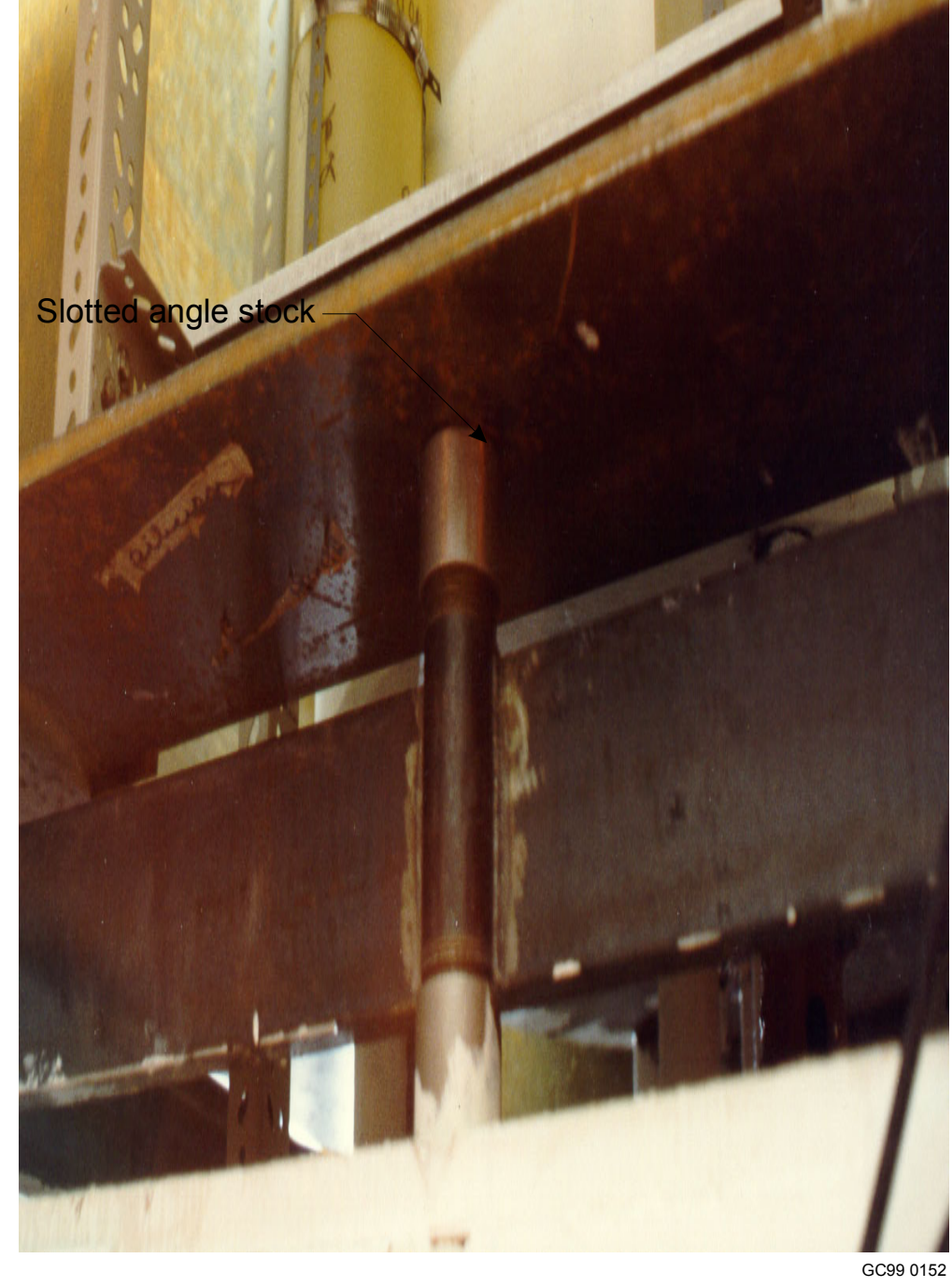

Figure 8. The Slotted Angle stock supporting the arms in vertical planes was used in many subsequent programs. This 1984 photograph portrays a totally unrelated experiment almost two decades later.

to $40 \%$ of the surface area of the commercial product. Holes were sized to receive common commercial English-sized bolts. Probably, 3/8" bolts were the size used, although commercial 5/16" or 1/4" bolts may have been the size used. The bolt size used is not certain.

Details of the support assembly constructed from this Slotted Angle were not, unfortunately, recorded; and neither are they clearly recalled by anyone. No photographs were taken during the entire program, another unfortunate oversight; so photographs can not aid memory. Therefore, the following description of the support structure for arms branching off a given face of the Central Column results from a combination of the author's dim recollection aided by his knowledge of how persons involved in the experiment's design thought. Another factor contributing to this description is an understanding of the ease with which any reasonable proposal would meet with administrative approval (a minimal level of 
requirements and a dearth of procedural documentation was usually practiced in those days). A final contributor is common sense - a description of a reasonable assembly procedure that might come to mind today. Nonetheless, details of this support structure remain an uncertainty within this program. Fortunately, this support structure probably does not have a great deal of neutronic influence on the reactivity of any experiment; so the missing data are truly less essential.

Two vertical planes of Slotted Angle probably supported each group of arms off a given face. One plane would have been on each side of the arms. This fact is fairly certain. Each plane probably consisted of two vertical members separated radially from the Central Column by two or more horizontal stringers. The vertical pieces were the ones which defined the plane of support because they were in contact with the arms. One vertical member would have been, perhaps, a short distance away from the Central Column while the other vertical member would have been, perhaps, $1 / 3$ the length of the arm in from the outer end. This supposition is at least consistent with the size of the Solution Base table top. Its diagonal was $2.1 \mathrm{~m}$; and the assumption just presented for the location of the outermost vertical member would place these members $2.0 \mathrm{~m}$ apart. One face of each L-shaped vertical member probably touched the arms while its orthogonal face extended away from them.

The horizontal stringers of each plane may have simply held vertical members radially apart; or they may have provided support for some of the arms. That detail is not recalled. In any case, the horizontal face of these horizontal stringers would have extended inward, not away from the arms as the vertical members. This relative orientation permitted bolting mating faces of the vertical members and the horizontal stringers together.

The two vertical planes were probably separated by short lengths of Slotted Angle, called cross ties, bolted to the vertical members at both ends. Geometrically, then, the completed support structure for one set of arms extending off one face of the Central Column could be described as a rectangular parallelepiped. The thickness of this three-dimensional "box" would have exactly equaled the diameter of the arms being used. Thus, each vertical stack of spaced arms would have been well supported both close to the Central Column and at their opposite end, preventing any azimuthal rotational movement. The height of these cross ties was probably set to support at least some individual arms at the proper height along the Central Column. That not every arm was supported by steel cross ties is clearly recalled; and consequences of this design is discussed in a later section (Lessons Learned). In some cases, one arm was held above the one below it by plastic or wooden spacer blocks. Wooden spacer 
blocks were carefully cut from 38.1-mm-thick wood; and they were about the width of an arm's diameter by the precise height needed. These blocks were held in place simply by the weight of the arm(s) above it. Plastic spacers were much smaller but also held in place by weight, they were used for smaller vertical spacings.

Under this design, pairs of support planes would flank each vertical stack of spaced arms and be tied together with cross ties. If arms extended off two faces, then two rectangular parallelepipeds would be used. If four faces had arms, four structures were needed. An experiment having, say, three arms extending off each of the Central Column's four faces must have been a complicated assembly. A considerable amount of time must have been required to bolt together this "erector set" hardware. Sadly, no photographs of this complicated superstructure are available.

Once the arms were properly positioned off the requisite number of faces and at the desired heights, they were connected by lengths of clear flexible tubing via a home-made distribution manifold. The tubing was thin-walled $12.7 \mathrm{~mm}$ nominal inside diameter inner-braided plastic. Standard commercial stainless steel hose clamps were used to fix the tubing onto a series of commercial stainless steel plumbing "Ts". The center leg of each "T" fed solution to one arm; and the other end extended the string to the next "T". The connection to each arm occurred at the bottom of the arm at the end closest to the Central Column. The first "T" of the series was connected to a $12.7 \mathrm{~mm}$ short nipple near the bottom of the Central Column. With this design, that lowest nipple fed all arms involved in the experiment regardless of number. A very large number of potential leak points were created by this arrangement; but, happily, no great incidence of leaks is recalled.

These arms had to be vented also; so additional tubing of the same size tied these arms together for that purpose. These tubes were attached to short nipples welded to the arms. These vent nipples were on the top side of an arm at the outer end of that arm - diametrically opposed to the fill nipples. Details of how these arm vent tubes tied together into some ventilation manifold can not be recalled with confidence. The computer modeler will note that all these fill and vent hoses would contain the same fissile solution as in the rest of the apparatus.

\section{Solution Base}

The Central Column rose above the top surface of the Solution Base. The column, any number of arms, and the Slotted Angle framework holding the arms in place were all supported by a 
sturdy heavy-weight steel table. This table was called the Solution Base and was used in a dozen or more experimental programs involving uranium solution over the quarter-of-a-century productive life of the CML. This table remained essentially unmodified from program to program while the apparatus erected upon it varied markedly for each program studied. This heavy table, in turn, stood on the stainless steel floor of the walk-in Assembly Room Hood. In particular, it was about centered in the south half of this hood. The north half contained a very light-weight machine called a Vertical Split Table. This vertical table was another reactivity assembly device and was not a part of the present program at all. It was composed mostly of thin-walled steel tubing; and, so, it contributed very little reflection to neutrons leaving the present tree-like experiments.

The Solution Base consisted of a thick steel square table surface supported by a heavy-duty framework welded together of structural steel shapes. The framework stood about as high as the table top was square. The space within the framework and under the surface contained the two large-diameter SCRAM valves and the associated SCRAM tank ${ }^{27}$. Most of these features can be seen in Fig. 9. The photograph was taken in 1985; but little has changed on the Solution Base itself. The hardware just above the light colored table is unique to another program and was not present during the tree-like experiments. One component of the Vertical Split Table blocks the right hand portion of the Solution Base in this photograph .

${ }^{27}$ These SCRAM components provided the needed shutdown capability in the event of a nuclear accident during one of the experiments. Such an event never occurred during 1700 experiments at the CML; but if it were to have happened during this program, the following sequence of events would have occurred. The SCRAM valves, which are normally open such that they must be electrically held closed throughout an experiment, would open automatically in response to an electrical signal that some preset limit had been exceeded. The fissile solution would rapidly flow out of the possibly supercritical experimental apparatus into the critically safe long, thin SCRAM tank. This redistribution of the solution would render the experimental apparatus, again, subcritical because the subcritical volume of the SCRAM tank had also been filled with part of the offending (supercritical) volume of solution. Once this redistribution had settled and the solution come to a new equilibrium height, a more-informed decision could be made as to whether or not a criticality accident had, indeed, occurred. If not, the non-irradiated solution could easily be recovered from its SCRAM condition in the Assembly Room, returned to storage, and made ready for a resumption of experiments. If a criticality accident had, indeed, occurred, then the highly radioactive solution would be fully contained in a critically safe configuration in a sealed and isolated room until the next course of action could be thoughtfully determined.

Many situations other than a criticality accident could allow the uranium solution to enter the SCRAM system. That route could be intentionally arbitrarily selected as a means of terminating any experiment. An inadvertent approach too close to an automatic trip release on one of the detector channels could initiate the SCRAM response even though the system was nowhere close to criticality. Several other aspects of an experiment could send this same false signal to the safety shutdown mechanism leading, in turn, to this SCRAM sequence. 


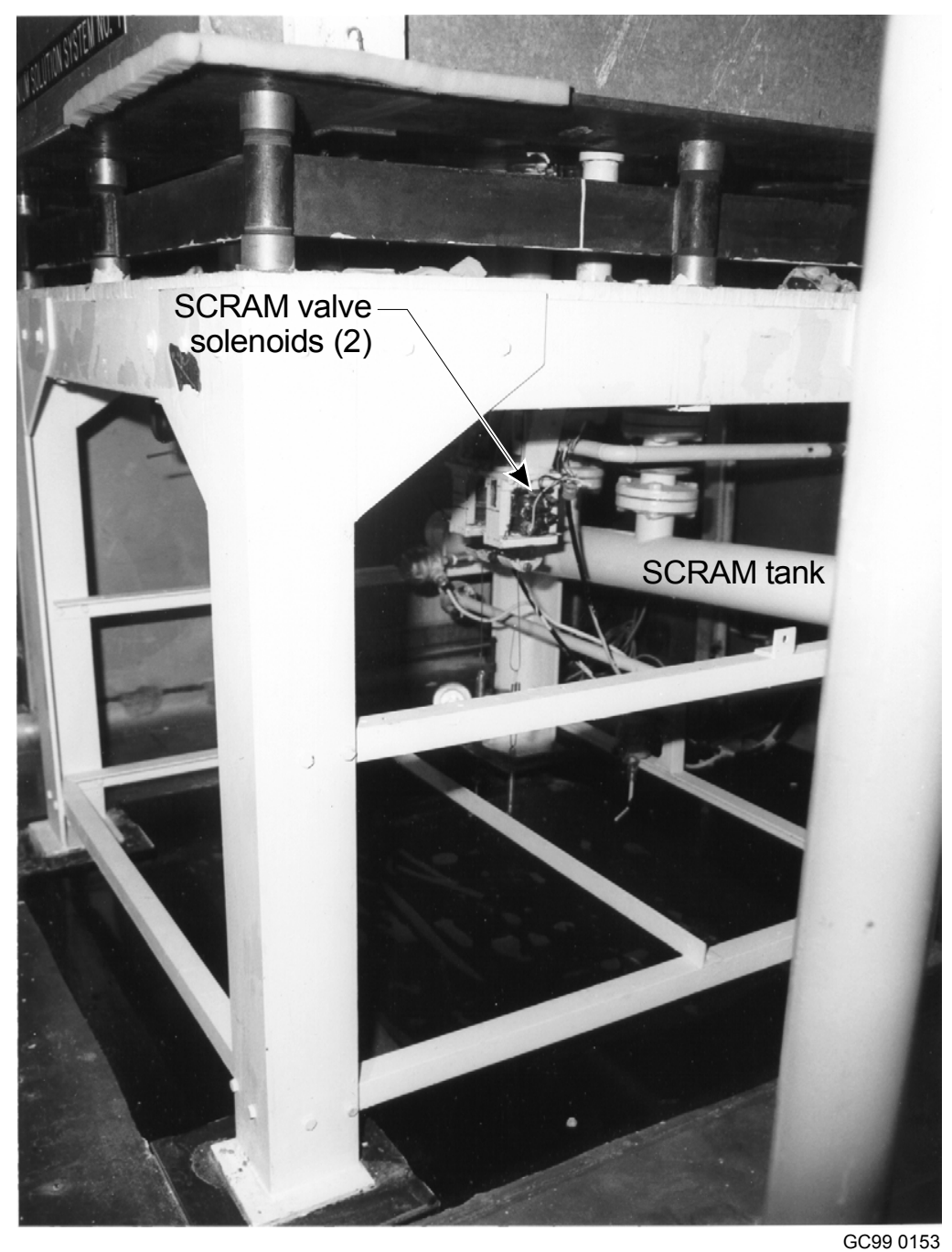

Figure 9. The Solution Base appears white in this 1985 photograph. The equipment on the table's surface near the top of the photograph belongs to another program; and the dark-colored pads below the white ones were not present during the present study.

The mild steel table top of the Solution Base was $1.50 \mathrm{~m}$ square and $25 \mathrm{~mm}$ thick. It was split into two rectangular pieces which fit together to form a solid top. Each piece had a triangular hole at the proper location such that, when both were in place, a larger triangular hole existed in the very center of the square top. The size and shape of this hole was just large enough to allow the two SCRAM lines and the normal fill/return line to pass to the experimental apparatus from below the table's top. The hole was roughly an isosceles triangle with rounded corners. The base of this hole was about $220 \mathrm{~mm}$; and its altitude was about $140 \mathrm{~mm}$. The Central Column was elevated nominally $250 \mathrm{~mm}$ above this surface. 
This is the distance by which the SCRAM valve seats extended above the table's surface. Unfortunately, the hardware to support this column at that height is not recalled. Once installed there, the Central Column was never moved during the course of the entire program. The arm support hardware, described in another section, was also probably supported by this surface. That fact is neither documented nor recalled for certain; rather, it is claimed as a highly probable truth because no other method of supporting this hardware is at all feasible.

The seismic stability of this apparatus is open to criticism in light of modern-day thinking on this point. The Central Column may not have been protected against transverse oscillations; and any structural reenforcements tying together the arm-support hardware is not recalled. This apparatus may be described as "flimsy" by current standards.

The table's framework was constructed of $152 \mathrm{~mm}$ x $152 \mathrm{~mm}$ x $11 \mathrm{~mm}$ thick steel angle iron welded into another square $1.50 \mathrm{~m}$ on a side. The thick steel table top merely rested on this table frame. The four corners supporting that square frame had legs of the same angle iron stock. Thick steel pads (203 $\mathrm{mm}$ square by $9 \mathrm{~mm}$ thick) were welded to the bottom of these legs to reduce the point loading on the concrete floor. Figure 8 shows these pads as light colored; but much later, other larger pads were placed under these to decrease the floor point loading even further. The larger pads were not in place at the time of the present experiments. The height of the top surface of the table top rose about $1.38 \mathrm{~m}$ above the floor. Triangular gussets welded the legs to the frame's horizontal angle iron; and these gussets strengthened the structure. The combined material of these eight gussets (two per corner) was about 0.25 $\mathrm{m}^{2}$ of 9-mm-thick mild steel plate. The only other steel associated with this table's construction was about $6 \mathrm{~m}$ of angle iron stock ( $50 \mathrm{~mm} \times 50 \mathrm{~mm}$ x $6 \mathrm{~mm}$ thick) welded horizontally to the legs near the bottom. This kept the legs of the Solution Base from spreading under load.

The spacious underside of this sturdy table supported a few components in addition to the SCRAM valves and tank already discussed. These other components were associated with the fissile solution delivery and recovery system. Regions which contained fissile solution during an experiment are described even though they may be small. 
1. A single stainless steel solution "fill pipe" made of commercial 1-inch schedule 40 pipe. This passed solution into the tank during an experiment and formed one optional route for solution return after the experiment. This line would have fissile solution in it throughout the experiment. It extended about 0.5 $\mathrm{m}$ below the tank before a $90^{\circ}$ bend near the center of the table; and it had a long horizontal run away from the table.

2. The SCRAM valve design left a $50 \mathrm{~mm}$ diameter by approximately $20 \mathrm{~mm}$ deep pocket of solution above each valve. This solution remained as long as these valves were closed electrically. The valves, themselves, were a complex geometry but each could be approximated by about $0.5 \mathrm{~m}$ length of commercial 3-inch schedule 40 pipe extending below the tank with a heavy electric solenoid hung about $0.6 \mathrm{~m}$ below the tank's bottom. These SCRAM valves and their connection to the SCRAM tank contained no solution during the experiment except for the small pockets described just above.

3. An electronic device mounted with its liquid-sensitive probe a few millimeters above the stainless steel floor of the Assembly Room Hood. This device would detect solution leaks if one were to occur and advise experimenters of that condition.

4. The SCRAM tank was constructed of nominal 5-inch diameter schedule 10 stainless steel pipe. It was $1.8 \mathrm{~m}$ long and an average of about $0.9 \mathrm{~m}$ below the tank's bottom. A ventilation line rose vertically from the higher end of the dump tank to a great height above the Solution Base. This vent was nominally 2-inch schedule 10 stainless steel pipe. 


\section{URANIUM SOLUTION}

The fissile liquid was uranyl nitrate solution. The uranium was highly enriched in ${ }^{235} \mathrm{U}$; and the uranium concentration was very close to that for which the critical spherical volume would be a minimum. This condition is called "optimum moderation". The solution was formed from a high-purity uranyl nitrate hexahydrate salt,

$$
\mathrm{UO}_{2}\left(\mathrm{NO}_{3}\right)_{2} \bullet 6 \mathrm{H}_{2} \mathrm{O}
$$

This salt was dissolved in dilute nitric acid to form the solution.

This solution has a unique history that instills confidence in its long-term chemical stability. The same solution has been housed in the same set of tanks in the same building and used for the same purpose (criticality experiments) over the full quarter of a century of its entire life. It served this purpose from 1965 to 1989 . This long-term stability lends confidence and credence to whatever measurements may have been made on the solution around the time of the present experiments (late 1960s) even from data accrued decades later. The solution was that stable. For example, impurity analyzes collected much later may be considered upper bounds on the impurity content at the time of these measurements; and even when finally removed from the facility in the mid-1990s, these impurities were quite low. The solution would understandably not have lost impurities over many year's exposure to many different kinds of containers and materials.

The uranium solution has only passed back and forth between storage and various experimental components over two-and-a-half decades. It has been involved in about 1000 critical or critical approach experiments. All critical experiments involved very low power; so fission product inventory has remained low because of this and the short time criticality was maintained. The only other significant operation performed with this solution during those decades was the occasional measurement of its uranium weight, done for material accountability purposes.

This solution, shipped to the CML as "Uranium Feed Solution", was prepared at Rocky Flats in 1965 in Building 81 (now, 881). The first ten 55-gallon stainless steel drums were shipped during the summer of that year at the rate of 2 to 4 drums per day. Drums were, of course, Raschig ring filled for criticality safety. Interestingly, shipments came on canvas-enclosed trucks; and each drum was lowered to the ground on the hydraulic tailgate and wheeled into the building and through the office area via a 2- 
wheeled hand cart. This method of delivery would hardly be considered feasible in the 1990s. The technique for transferring solution from the drums into the already volume-calibrated tanks is not recalled.

Ten drums were shipped in June and July at an estimated 106 liters each. The average concentration claimed was $483.4 \mathrm{gU} /$ liter. Thus, this initial delivery should have transferred 512,404 $\mathrm{g}$ of uranium; but the quantity measured immediately upon receipt was 1030 liters at an average concentration of $465 \mathrm{gU} /$ liter (478,950 g). This shipper/receiver difference (almost $33.5 \mathrm{~kg}$ ) was later traced to liquid held up in the drums, a badly calibrated slab tank in the manufacturer's building, and concentration measurement errors by the analytical laboratory. (They had never measured such high concentrations before.) The technique employed was a $\gamma$-counting method; and this contained unrecognized selfshielding errors for such rich solutions.

A final shipment (11th drum) came to the laboratory August 25, 1965. The sum of all shipments and small administrative adjustments led to a government-approved reconciliation of 569,711 $\mathrm{g}$ of uranium in the fall of 1965 . The uranium weight has been measured periodically since then for material accountability purposes. Even when the solution was finally removed from the CML in the mid-1990s, the shipped amount was in good agreement with that initial inventory measurement adjusted for many known (measured or estimated) small removals and a few very small returns over this period of about three decades. The CML has always maintained a large quantity of this high concentration uranyl nitrate solution. The initial $465 \mathrm{gU} /$ concentration evolved to $450.8 \mathrm{gU} /$ solution used in the program just preceding this one. Over the next two years, the concentration drifted back up a little; and then it was intentionally decreased in 1972 to its long-term concentration a little below $400 \mathrm{gU} /$. Between 1972 and the mid-1990s, this uranium concentration varied only a little around $370 \mathrm{gU} /$. In addition to this holding of high concentration solution, two lessor concentrations were maintained for many years. Neither of these low concentration solutions were ever involved with the present experiments in any way. Historically, these two were combined into a single concentration in 1989. The entire inventory of all three concentrations was finally removed from the CML facility in the mid-1990s.

No recorded measurement of uranium solution properties associated specifically with this program could be found. Measurements may have been made; but results uniquely tied to this program for certain were not uncovered. Fortunately, this missing data is less important than it might appear for 
several reasons. The long-term stability of the solution has already been pointed out; and this program was sandwiched between two others for which solution measurements were reported. Both of these concentrations differed by only about $2 \%$. Finally, all these high concentration solutions are so close to the so-called "minimum critical volume concentration" (optimum moderation) that an error of a few grams per liter would be hardly important to a criticality safety analysis.

The physical properties for the uranium solution reported in the literature ${ }^{28}$ for the first experimental program ever to use this uranium solution included a concentration of $450.8 \mathrm{gU} /$, a density of $1.611 \mathrm{mg} / \mathrm{mm}^{3}$, an excess nitric acid normality of $0.72 \mathrm{~N}$, and a fissile isotopic enrichment of $93.19 \%$ ${ }^{235} \mathrm{U}$. These properties were the ones first assumed still to apply to the present study when the first (unpublished) report of this work was written. This unpublished report is copied as Appendix A to this document to avoid its loss to posterity. This assumption about the solution concentration was made at that time because this program took place only a few months after that first one. Assuming the same concentration seemed reasonable. The uranium concentration of the next study, however, about a year after the present program, was about $462 \mathrm{gU} /$. Apparently, uranium concentrations did shift a few grams per liter over a period of time. Taking into account the imprecise knowledge of when and how the solution changed from one concentration to the other, some uncertainty exists as to the true concentration for this program. Therefore, the uranium concentration to be assumed for the present program is suggested to be $453 \pm 2 \mathrm{gU} /$. The uncertainty is not a measured standard deviation but only a reflection of missing data.

Decades of experience measuring chemical properties of this solution at Rocky Flats reveals a very tight linear relationship between density and concentration. The mathematical relationship between the two is:

$$
\text { density }\left(\mathrm{mg} / \mathrm{mm}^{3}\right)=0.001365 \mathrm{x} \text { concentration }(\mathrm{gU} /)+1.001409
$$

This equation was developed over a wide range of parameters over a span of two decades. Using this equation, the density of $453 \mathrm{gU} /$ fissile solution would be $1.62 \mathrm{mg} / \mathrm{mm}^{3}$. The above uncertainty in concentration translates into an uncertainty in density of about $\pm 0.003 \mathrm{mg} / \mathrm{mm}^{3}$. The nitric acid normality is not likely to have changed much between programs; so a value of $0.72 \mathrm{~N} \pm 0.02$ would seem

\footnotetext{
${ }^{28}$ Robert E. Rothe. "Critical Measurements on an Enriched Uranium System". Nuclear Science and Engineering, 35 (1969).
} 
reasonable. This remark about the stability of the nitric acid normality is based on 35 years of monitoring this parameter for this particular solution in this laboratory. All changes in normality ever seen can be traced to large-scale events in the life of this solution. No such events occurred at this time. The isotopic enrichment of $93.3 \%{ }^{235} \mathrm{U}$ is proposed as a compromise between that for the preceding program and the value quoted in the unpublished paper. Measurement techniques are probably not good enough to warrant reporting enrichments to four significant figures anyhow.

The analytical laboratory's method used to measure such high concentrations in those early days is not recalled. The then-common $\gamma$-ray spectroscopy method was not suitable for such high concentrations and was not sufficiently precise for this application. In later years, concentrations were determined by a method called Gravimetric Titration, generally recognized as a high-precision method. The density of solutions was measured by weighing a $3 \mathrm{~mL}$ pycnometer. Later, this was replaced by a 25 $\mathrm{mL}$ temperature-calibrated pycnometer for added precision. The isotopic composition of the solution was obtained from mass spectrometry measurements.

Impurities were seldom measured on solution samples in those early days; it was not deemed important. That importance was recognized in the early 1970s; and this information has been measured and reported ever since. Methods called Spark Source Mass Spectroscopy and Optical Emission Spectrometry were used in later years; but these may be in error by factors of 2 or 3. The long-term stability of this quite pure solution allows the use of later measurements as upper bounds on impurity estimates. The average elemental impurities measured on this one set of samples several years later are expressed below in parts per million by weight relative to the uranium weight:

$\mathrm{Al}=350 \pm 190 ; \mathrm{B}=4.4 \pm 1.7 ; \mathrm{Bi}=6.8 \pm 5.1 ; \mathrm{Cd}=7.8 \pm 2.6 ; \mathrm{Cu}=81 \pm 26 ; \mathrm{Fe}=515 \pm 200 ;$

$\mathrm{Mg}=250 \pm 150 ; \mathrm{Mn}=27 \pm 10 ; \mathrm{Mo}=75 \pm 27 ; \mathrm{Ni}=69 \pm 37 ; \mathrm{Pb}=44 \pm 11 ; \mathrm{Si}=43 \pm 20$

$\mathrm{Sn}=280 \pm 190 ;$ and $\mathrm{Zn}=230 \pm 100$.

Even a coarse estimate of impurity levels is important. It is needed to adjust uranium concentrations a little during the laboratory analysis procedure. In the Gravimetric Titration method, solution is evaporated to the dry salt, uranyl nitrate hexahydrate. This is calcined at a high temperature to drive off water of hydration and the oxides of nitrogen. The result is uranium oxide, specifically, $\mathrm{U}_{3} \mathrm{O}_{8}$ combined with the oxides of all impurity metals. This weight, then, equals the sought for weight of 
uranium oxide plus the weight of oxide states of all impurity elements. This latter correction was so small that errors of a factor of 2 or 3 in impurity content make little difference.

Another important reason for measuring some impurities concerns their neutronic importance. Boron and cadmium would be strong thermal neutron absorbers; and beryllium could contribute additional neutrons through the $(\mathrm{n}, 2 \mathrm{n})$ reaction.

One laboratory analysis dated February 28, 1968, was discovered while searching past records for information pertaining to this program. That this sample may have represented the uranium solution used in the experimental program is very doubtful. Results are unusual, especially with respect to the excess nitric acid content. These analytical results are believed to represent a much smaller quantity of solution possibly recovered from the ventilation line overflow problem of three months earlier (the subject of the Lessons Learned Section of this document); but that fact is not clearly documented one way or the other. Still, the result is presented here in an effort to publish all available information. The Analytical Laboratory Requisition (\#3816) bore the identifying label "Tree Experiment" alongside the date, although this probably referred to a small container of solution recovered from the incident occurring during the “Tree Experiment." The results were a solution concentration of $466.9 \mathrm{gU} / \ell$ or $0.2847 \mathrm{gU} / \mathrm{g}$ sample, a density of $1.64 \mathrm{mg} / \mathrm{mm}^{3}$, and a surprising excess acid normality of $4.10 \mathrm{~N}$. This acid level result tends to support the analysis as being associated with recovered solution. This report also gave impurities: $\mathrm{Al}=$ 100; $\mathrm{B}=2 ; \mathrm{Ca}=55 ; \mathrm{Cd}=10 ; \mathrm{Co}=2 ; \mathrm{Cr}=20 ; \mathrm{Cu}=10 ; \mathrm{K}<25 ; \mathrm{Mg}=200 ; \mathrm{Mn}=3 ; \mathrm{Mo}=100 ; \mathrm{Na}=10$, $\mathrm{Ni}=30 ; \mathrm{Pb}=3 ; \mathrm{Si}=2 ; \mathrm{Sn}=1 ;$ and $\mathrm{Ti}=1$. 


\section{TEMPERATURE}

These experiments were performed at room temperature. This probably varied between about 18 and $21^{\circ} \mathrm{C}$ throughout a year, depending upon the season. This guess is based on later temperature recordings of other experimental programs in the same facility. The thick walls of the Assembly Room prevented seasonal changes in temperature from affecting temperatures within that room very much. The solution was stored in a room with much thinner walls and only a thin sheet metal ceiling. This room might have been affected by seasonal weather changes much more except that it was temperature-heated and controlled for personnel comfort. Still, this storage room changed a little more than the Assembly Room response to seasonal changes. On the other hand, these experiments were performed in the fall of 1967 through the winter of the following year; so no truly warm days happened during the program. The temperature range quoted is expected to be a good upper limit on variations during this program. No logged entries identify temperatures in this room during these early years.

Uranium is not a strong alpha particle emitter. Unlike plutonium, which is quite warm to the touch due to energy dissipated through radioactive decay, uranium solution has essentially no thermal input. Likewise, the inventory of radioactive fission fragments within the solution was small; so these nuclei would not contribute much heat to the solution. The number of fragments were small because the power level of critical assemblies was intentionally kept quite low and because the length of time an experimental configuration was maintained at or near criticality was also kept as low as reasonable. 


\section{ENVIRONMENT}

Experiments were performed within the Assembly Room Hood within the Assembly Room at the Rocky Flats Plant's Critical Mass Laboratory (CML). Most of the 1700 critical and critical approach experiments performed at Rocky Flats since 1964 were carried out in that room, although not all within that hood. The Assembly Room is a large concrete room containing only a few items large enough and/or close enough to these tree-like assemblies which could, sensibly, provide any significant neutron reflection to the systems described here. A drawing of this room and its major components is shown in Fig. 10.

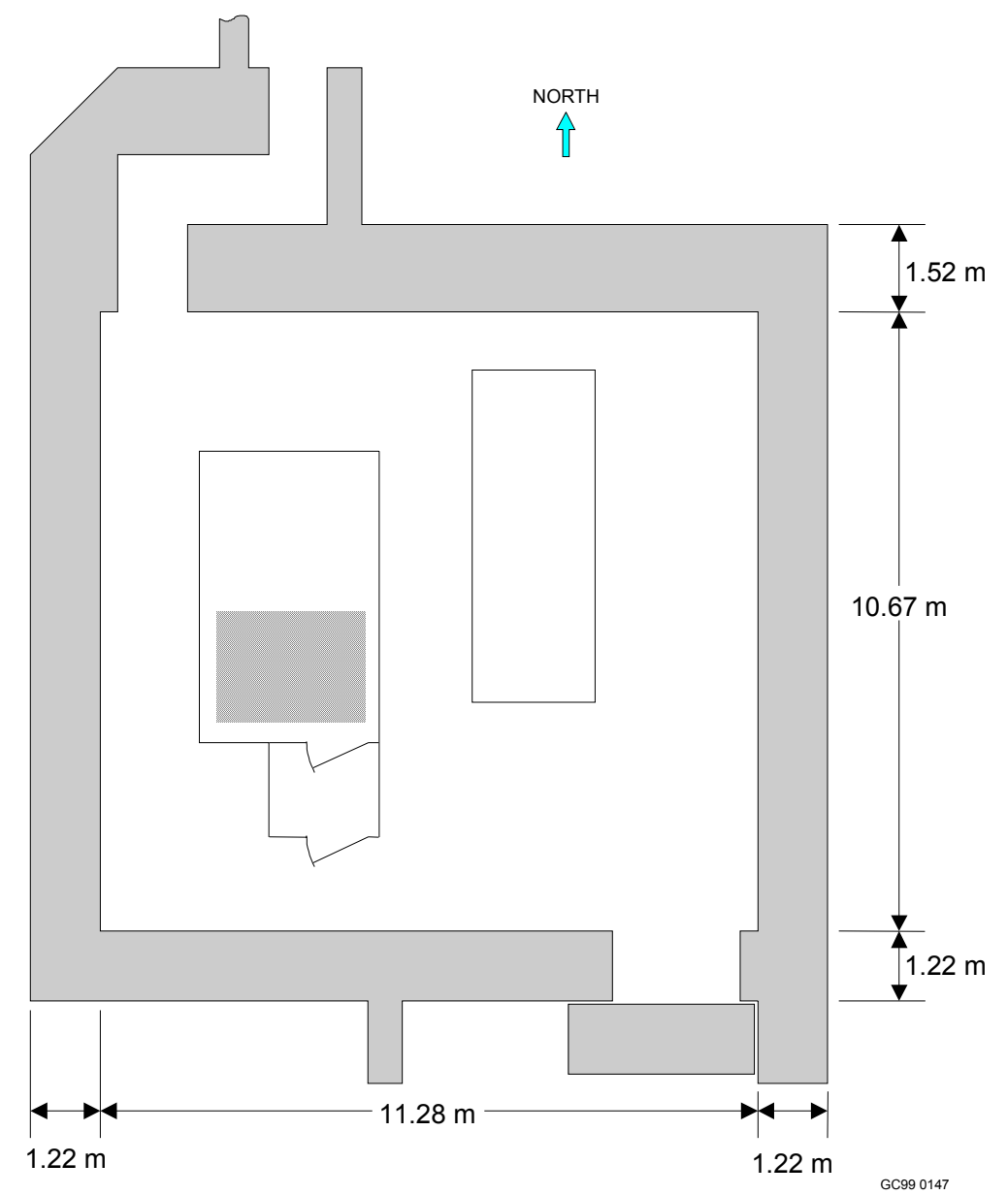

Figure 10. This plan view of the Assembly Room locates that portion of the walk-in Hood in which these experiments were performed (shaded area). The long rectangle to the east is the Horizontal Split Table. Thick walls provided needed radiation shielding; and the Z-shaped labyrinth prevented this radiation from streaming down the access hallway. 
The interior of this room, also referred to as Room 101, measured $11.28 \mathrm{~m}$ in the east/west direction by $10.67 \mathrm{~m}$ in the other. The room was $9.75 \mathrm{~m}$ high. The north wall was $1.52-\mathrm{m}$ thick; but the other three were only $1.22 \mathrm{~m}$. The north wall was made thicker because people occupied rooms to the north; and the small additional shielding would further protect them from radiation during experiments. The thick ceiling was $0.61-\mathrm{m}$ thick. The floor was 0.20 - $\mathrm{m}$ thick but rested directly upon compacted earth. Interestingly, the floor was isolated from the walls by thin rubber pads; so the floor was, indeed, free to creep small amounts over long times without cracking the rest of the structure.

Concrete walls and ceiling were formed in one, continuous, monolithic (seamless) pour in 1964. The concrete was quite common, one for industrial applications. Type I Portland cement was used at 307 $\mathrm{kg} / \mathrm{m}^{3}$. The maximum content of chemically pure water in the fresh mix was $30 \mathrm{~kg} / \mathrm{m}^{3}$; and the allowed aggregate sizes ranged from 6 to $18 \mathrm{~mm}$. This rock was required to be low in amorphous siliceous materials. Walls were strengthened with two layers of crossed steel rebar. One layer was about $80 \mathrm{~mm}$ in from the outer surface; the other, the same distance out from the inner surface. Horizontal rebars were \# 8 on $0.3 \mathrm{~m}$ centers; vertical ones were \#6 on the same centers. Approximately $7000 \mathrm{~kg}$ of steel strengthens the concrete.

The walls were probably not yet painted although this minor detail is not recalled for certain. The floor probably was painted with a grey epoxy paint. Again, this minor detail is not certain.

Two doorways penetrated this room. One at the west end of the north wall was a 1.0-m-wide by 2.1-m-tall passage way used for personnel access. Small experimental components were introduced here too. The passage way extended the full thickness of the north wall plus $1.2 \mathrm{~m}$ before making a $90^{\circ}$ turn east. A similar turn back north about $2.5 \mathrm{~m}$ east completed a Z-shaped labyrinth. The purpose of this labyrinth was to prevent radiation streaming out of the room in the event of a nuclear criticality accident. The wall at the end of the passage way was also very thick. The result of this design was that radiation from the hypothetical accident might pass through the closed steel door to the room; but it would not make the two right angle turns to propagate down the hallway. The second doorway was diagonally across the room. It was in the south wall but at the east side. This was an equipment doorway connecting to the out-of-doors. The opening was larger to accommodate movement of larger and heavier components. The opening measured $2.4-\mathrm{m}$ wide by $2.1 \mathrm{~m}$ tall. This equipment opening was backed by a concrete, sliding shield door. This massive shield was $1.07-\mathrm{m}$ thick. Its $3.1-\mathrm{m}$-wide by 2.8 -m-high size effectively would stop any radiation streaming out of the room due to that same hypothetical accident. 
Both door openings were protected against radiation streaming out of the Assembly Room by the labyrinth to the north and the shield door to the south; but two other consequences of the hypothetical accident would be 1) the formation of a large inventory of radioactive daughter products from the fission process, and, 2) possibly, a very small explosive blast. Some of these daughter products would be gaseous and all needed to be contained. The worst possible explosive yield has been estimated to be much less that a single stick of dynamite. The containment of these two side effects was accomplished at the two openings by the use of strong blast doors with a rubber seal between them and the room. One such door existed at the personnel passage way; and two were used at the heavy equipment opening. Each door was $1.2-\mathrm{m}$ wide by $2.4-\mathrm{m}$ high and $0.15-\mathrm{m}$ thick, although the fairly thick door was constructed as a honeycomb to reduce its weight. All three blast doors were made of steel and can be modeled as two 13-mm-thick plates on either face separated by $10 \mathrm{~m}$ of honeycomb material $13-\mathrm{mm}$ thick by $130-\mathrm{mm}$ wide. Each blast door weighed about $750 \mathrm{~kg}$.

The entire experimental apparatus was about centered in the south half of a stainless steel hood built for contamination control. This hood was called the Assembly Room Hood and was situated within the west half of that room. It is shown in the photograph of Fig. 11. The hood, itself, was $3.0 \mathrm{~m}$ wide by $4.9 \mathrm{~m}$ long and stood $5.7 \mathrm{~m}$ tall. It was constructed of 11 gauge stainless steel ( $3 \mathrm{~mm}$ thick); but about $19 \%$ of the four walls contained 13-mm-thick plastic windows for viewing. In addition, four small windows $(0.5 \%$ of the wall area) were composed of safety glass. The hood had a stainless steel floor coved into the walls to provide complete containment of a fissile solution spill should one occur. The ceiling was also stainless steel. Both walls and ceiling were stiffened on the outside by stainless steel structural members as can be seen in the figure; but these are not described. The other half of the hood was occupied by another reactivity addition device called a Vertical Split Table. This table is not visible in the figure because it had not yet been installed at the time of this early (1964) photograph. The Vertical Split Table's light-weight and open, "airy," construction contained very little stainless steel tubular stock; and the entire table is considered to contribute no significant neutron reflection to the experiments discussed here. Therefore, the mechanism is described no further because of its low mass and its distance from the tree-like apparatus. The long dimension of the hood stood parallel to the west wall of the Assembly Room, described above. The southwest corner of this hood was $1.6 \mathrm{~m}$ east of this west wall and $3.3 \mathrm{~m}$ north of the south wall. 


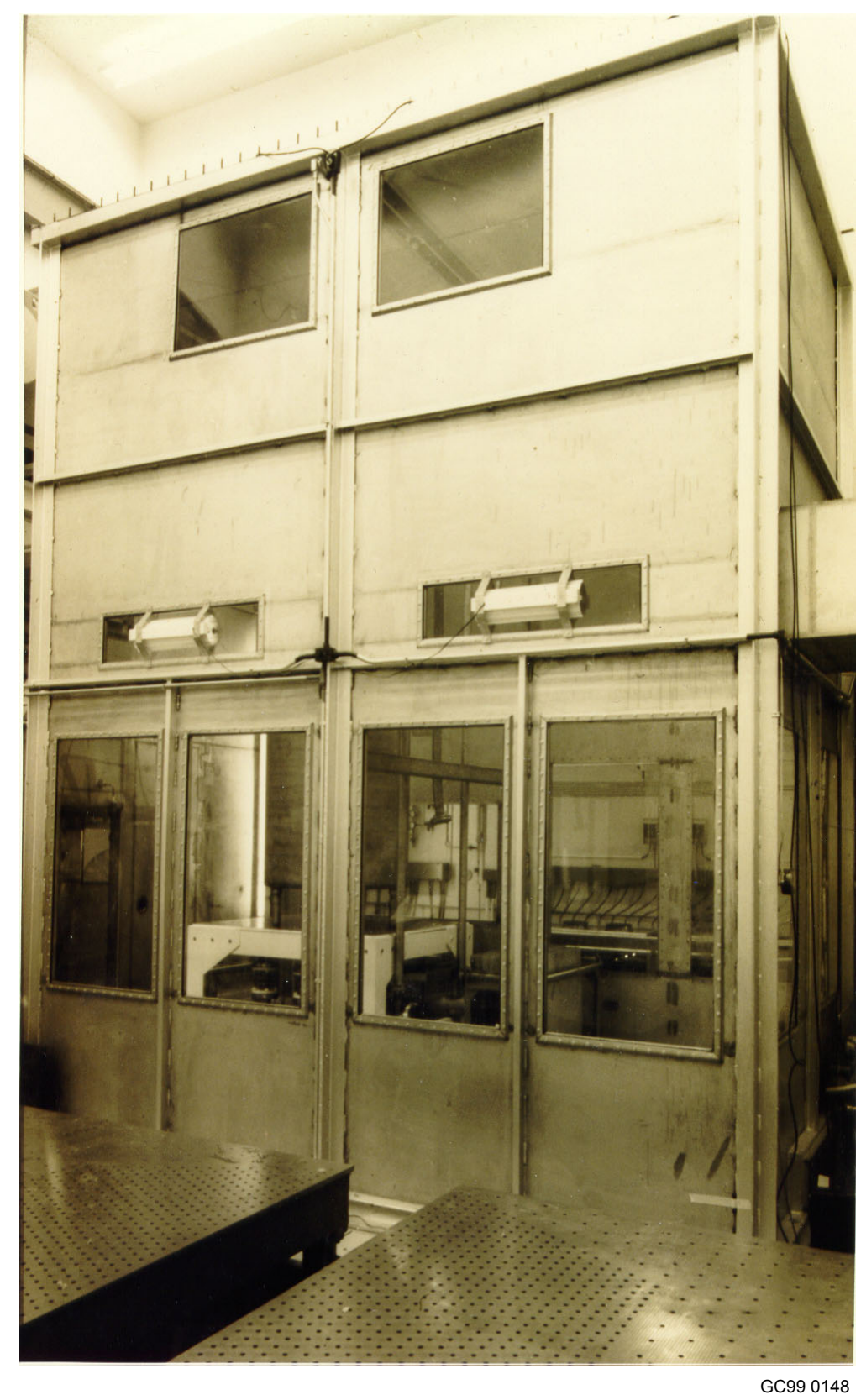

Figure 11. This photograph of the walk-in Assembly Room Hood and the Horizontal Split Table (lower foreground) was taken in early 1965 before any fissile material had even been admitted into the CML. The Solution Base can be seen as white through the middle two of the lower four windows.

Outside the Assembly Room Hood, the closest large item was a Horizontal Split Table. This is another one of the reactivity addition devices belonging to the laboratory. This table measured about 5.4 $\mathrm{m}$ long by about $2.2 \mathrm{~m}$ wide; and it rose about $0.7 \mathrm{~m}$ above the concrete floor. The mild steel table weighed about $5000 \mathrm{~kg}$. Although the table had a fairly complicated geometry of honeycombed steel webbing and structural steel (channel), a close upper limit approximation to its steel content would be a 
25-mm-thick vertical rectangular cylinder of the outside dimensions just given (5.4 m x $2.2 \mathrm{~m}$ ) supporting two co-planar, horizontal, $1.9-\mathrm{m}$-long by 2.2-m-wide table tops. One of these table tops was at each end of the rectangle leaving an open space between. These table tops were $50 \mathrm{~mm}$ thick. The length of this table was parallel to the long dimension of the Assembly Room Hood and about $1.9 \mathrm{~m}$ east of it. The northeast corner of the Horizontal Split Table was $2.4 \mathrm{~m}$ west of the east wall and $1.1 \mathrm{~m}$ south of the north wall.

An elevated air-handling deck existed several meters away to the southwest. This structure supported the room's heating and cooling apparatus; but this equipment consisted of thin sheet metal (steel) and can probably be ignored. Another component of the room is the heavy equipment traveling crane built into the room for general use. Although constructed of heavy structural steel shapes, this crane was sufficiently far away and so close to the ceiling as to be ignored as a potential neutron reflector to the tree-like apparatus. Furthermore, the location of this traveling crane during experiment was never recorded. Finally, the Assembly Room contained other smaller pieces of equipment; but these are considered far too small and too far away to be worth description. Large portable tool boxes and normal clutter found around any productive laboratory are included in this list.

No materials in this program were chemically analyzed for their elemental composition for these studies. Therefore, material descriptions are given rather generally with the code validator required to assume typical compositions for each material. 


\section{EXPERIMENTAL RESULTS}

Log Books of early-day experimental programs varied markedly from book to book and even from page to page as to the amount of detail provided about a given experiment. No systematic protocol had yet been developed, the result of inexperience on the part of those conducting the experiments. Other factors included different proclivities of recorders as to what information would eventually be needed and the lack of any procedural requirements as to what information ought to be recorded in these books. Some persons wrote more information directly on the sheets of graph paper used to plot reciprocal multiplication curves and less in the Log Books; others tended in the opposite trend. Although these graphs have been lost, they were available to the authors composing the two in-plant documents already referenced (RFP-1196 and RFP-1197). This document is a last-chance effort to collect all the needed data to allow present-day computer techniques to calculate many of these experimental systems. This author is one of the last two persons still alive who even recall the studies. The other person (Bruce B. Ernst) was one of the peer-reviewers for this manuscript.

A number of experiments contained the level of detail in the Log Books to make interpretation of criticality quite easy. Here, the apparatus is discussed in considerable detail including measurements locating one or more arms with respect to either the top or bottom of the Central Column or, sometimes, both. The location of other arms is sometimes specified although that information is still clearly defined through the documentation of the number of arms, their diameter, and the spacing between them. Said differently, arm elevations were identified vertically along the Central Column by either direct measurement written into the Log Book or they can be derived (calculated) from other information. In almost every experiment, the elevation of the bottom of the lowest arm (or horizontal plane of arms) was clearly recorded in the Log Book. This data is recorded simply as the letter "a" (where adjacent arms were offset from one another, the letter "a"' was used) in the several tables of experimental results. This same lowest arm information may confidently be inferred for following experiments to be the same as the earlier one when the entire configuration of arms has not been altered except for documented changes which do not affect the lowest arms. Then, the bottom elevation and/or the top elevation of each arm (or horizontal plane containing more than one arm) may be calculated from the known dimensions of arms and spacings. Formulas for this calculation are presented at the end of this section."

Unfortunately, measured elevations do not always agree perfectly with derived information. For example, the elevation of the underside of the bottom of, say, three arms and the elevation of the top of 
the uppermost arm were often recorded; but the difference between the two did not always agree closely with the sum of three arm diameters and two spacings. These differences, sometimes several millimeters, constitute one measure of uncertainties in arm locations.

Many experiments document arm elevations by referencing the previous run with changes noted. For example, an experiment identical to the previous one except for a change in arm spacing might say: "The apparatus is the same as the previous experiment except the spacing has been changed to [some value]". This statement is taken to imply that the lowest arms were not changed and only the hardware between layers was changed to yield the desired spacing. This assumption is often (but not always) confirmed by comments written into the books.

A few experiments, sadly, are totally devoid of any recorded documentation as to the elevation of arms. Fortunately, a survey of all experiments reveals a consistent effort to locate arms such that there always exists a considerable portion of the Central Column both below the lowest arm and above the highest one. For that reason, the precise measurement of the top or bottom of any arm relative to either the bottom of the column of solution or the very top edge of the Central Column is not really very important. The length of solution below the bottom of the lowest arm, as well as the full height of solution above the top of the highest arm to the top of the Central Column is considered essentially infinite in length. Even an error of several millimeters would hardly be consequential. The dimensions which are important are those which locate the arms relative to one another somewhere along an effectively infinite column of solution. Although some uncertainty would be introduced, a computer simulation would not be in great error if the location of the underside of the lowest set of arms were assumed to be between 800 and $900 \mathrm{~mm}$ above the bottom of the Central Column in these few poorlydefined cases.

A chronological record of the experiment follows apparatus details; but, as started above, the amount of detail varied greatly. This record often presents a complete chronology including the time solution was first introduced, times at which solution addition rates were modified to keep reactivity addition rates under safe control, and the time and solution height at which criticality was attained. These are the most useful records. At the other extreme, sometimes one entry states the start time and the next entry declares that the experiment has ended. The experiment may or may not have attained criticality. An important observation is that the lack of a clear reference in the Log Books as to the possible attainment of criticality does not imply that criticality was not reached. Some experimenters preferred to 
record this data on the reciprocal multiplication graph sheets and omit it altogether from the Log Book. Fortunately, both Log Books and graph pages were available to those writing the early reports on this study. Some experiments were clearly recorded as being subcritical even when the Central Column was full of solution; but these were not always so recorded. Again, the absence of a written statement one way or the other does not preclude either condition. Finally, when criticality was attained, a few cases even list one or more nuclear reactor periods corresponding to different solution heights. These are also very useful records.

For these reasons, a careful reading of the Log Books provides a wealth of detail in some cases and a dearth in others. Personal acquaintance with the experimenters and their personalities was helpful to this author in reconstructing actual configuration geometries. Some conclusions could be drawn with substantial confidence because of these relationships while absence of this insight might not permit these inferences. Nonetheless, in some cases, uncertainties in configuration geometries are probably greater than later experimental programs at this laboratory.

\section{Sequential Results}

The best possible geometrical description for each of the 110 experiments in the entire program is presented in Tables I to X. These tables and the associated figures are all gathered together at the end of this section of the paper because they are so cross-corollated. These tables describe the configuration of arms extending from the Central Column regardless of whether or not criticality was thought to have been attained. Criticality information is listed in the first columns and appears in bold face font. The Log Book sometimes makes a specific reference to an experiment being critical and at what height. This was the Experimenter's observation at the moment it happened; he may have been witnessing a slowly growing neutron population from the existing configuration of solution-filled apparatus. That observation is dutifully recorded in the first column of Tables I to VIII in bold face type. An exponential growth in neutron population corresponds to a slightly supercritical configuration; and the recorded solution height may slightly exceed the true critical height. In almost every case, this distinction is hardly consequential. Some experiments were recorded in the Log Book as being subcritical with equal confidence by the Experimenter. In these cases, the word "No" is entered in that first column. The absence of any entry in this column does not imply that the configuration specified was or was not critical. Those experiments appear blank. Generally, only information entered into Log Books in the late 1960s is copied in these ten tables. Sometimes, easily derived dimensions such as elevations of other arms are presented; but this information was determined in 1999 and is always recorded in italics font. The fact that recorded 
elevations are not always perfectly consistent with arm diameters and stated spacings has already been noted.

The experimental configurations studied were quite complex and involved a wide variety of different parameters. Simple written textual descriptions of the many possible combinations of variables could be sometimes ambiguous and would be difficult to follow. In an effort to eliminate ambiguity, these ten tables have been closely associated with the drawings of Figs. 12 through 24. Tables and figures are cross correlated with one another; and, because of this, these figures, like the tables, are gathered together at the end of this section of the paper. Tables refer to one or more figures which illustrate the elevation view of the configuration(s) being described. In return, the right-hand-most columns present arm elevation dimensions - relative to the top and/or bottom of the Central Column - which can be found along the right side of most figures. Lower case letters refer to arm elevations measured from the bottom of the Central Column. Sometimes, measurements were recorded down from the top of the Central Column; and these are entered as capital letters ( $\mathrm{T}$ and $\left.\mathrm{T}^{\prime}\right)$.

The tables are sufficiently complicated that a detailed explanation is provided for each column and each block of data. The table's title always gives the diameter of the arms (one of three choices) and their orientation $\left(90^{\circ}\right.$ or $\left.45^{\circ}\right)$ relative to the Central Column. In a very few cases, arm diameters were comingled; and this anomaly is described in footnotes. Angle orientations were never mixed. The title sometimes goes on to describe other features constant throughout that table. Table II, for example, refers to many-armed configurations where not all arms were connected to the solution distribution manifold. That is, the arms were present but solution would not flow into them. Table III provides another example. Arms extended from all four faces of the Central Column for all experiments represented by that table.

Two or more allied sets of experiments having the common characteristics described in the table's title but otherwise differing consistently in some other parameter are broken up into multiple blocks or regions. For example, Table VII shows four sets of 4, 2, 3, and 3 experiments, respectively, such that each block differed in one way or another from the others; but all fell under the main features described in the title.

The first column of each table contains any information as to the criticality or subcriticality of that configuration that had been recorded in the Log Books. The absence of an entry in this first column does not mean that the experiment was subcritical, although it may have been. This has also been 
discussed earlier. When a critical solution height was noted in the Log Book, that height is simply recorded in that column in bold face font. Many cases also had the reactor period(s) recorded; and that information is specified in a footnote. A few had both positive and a negative periods recorded for different solution heights; and, in these cases, the interpolation technique discussed earlier was used to obtain the bold face entry. One experiment, the second of two that were accidentally numbered \#61, had several comments describing the closeness to criticality for seven different solution heights. These situations are listed in Table XI. The purpose in including these non-quantitative "descriptions" is to illustrate the worst-case uncertainty in critical height determinations possible under this program. This case is expected to be one of the worst for precision in the critical solution height because the Central Column was almost full. Therefore, the solution was well above the highest arm. The configuration was almost an "infinite" situation; and this would be expected to be fairly insensitive to height. Some experiments were clearly recorded as being subcritical; and these cases show the word "No" in that first column. Most experiments have no entry in that first column. This absence should not be taken to mean that criticality had not occurred. It merely means that criticality was not recorded.

The second column gives the experimental sequence number. The only usefulness of this information is to distinguish which experiment preceded others. Many parametric studies were gathered around a few sequential experiments; and the use of run numbers helps determine the order in which small changes were made. Generally, configurations were described in the Log Book as being "the same as the preceding experiment except .....". Another value to including this information is the aid to future investigators who may attempt to glean additional knowledge from their own review of Log Books. These Log Books will be donated by the year 2000 to the archives maintained at LANL. Known-to-becritical experiment numbers are also highlighted by bold faced font. The first six experiments were intentionally omitted. They were familiarization runs and not expected to produce useful data; their configurations were extremely simple and are not discussed. A few experiments were repeats of identical configurations; and both numbers are shown in the same line.

The third column is the vertical (edge to edge) spacing between adjacent arms in a vertical plane. This is the parameter labeled $S$ on the figures. Different values of $S$ were never used on any one experiment. No ambiguity is possible concerning this parameter for those experiments for which arms extended at $90^{\circ}$ to the Central Column. That is not true when arms met the column at a $45^{\circ}$ angle. In those cases, S was measured vertically, not normal to the arms. Several factors probably contribute to the lack of agreement, already discussed, between measured arm elevations and derived dimensions obtained 
from arm diameters and spacings. First, arms were made from commercial pipe sections with welded ends. Even though standard commercial pipe is really quite true to its stated dimensions, welding could cause some warping in the cylinder's measurements. Weld beads and/or longitudinal warping may have prevented arms from resting upon one another completely whenever $\mathrm{S}=0$. Finally, spacings $\mathrm{S}$ were sometimes made from materials having only nominal dimensions; and these are sometimes known to be slightly different than true thicknesses. For example, if an experiment had a recorded spacing, S, of "one inch", then a small block of 1-inch-thick plastic was most likely used. This material is recognized to be often undersized as manufactured.

The next two or three columns addressed the number of arms and from which faces of the Central Column they extended. When arms extended from all four faces throughout the entire table, that fact is reflected in the title and no column is needed. Table III is an example. Several experiments had arms extending from only two faces. These could be opposite faces or adjacent faces. In the former, both sets of arms lay in the same vertical plane. In the latter, the planes of arms formed an "L". Exactly which faces, as specified by compass directions, were free of arms and which ones had arms extending from them is sometimes not stated, although sometimes it is. This is not a serious defect because of the overall symmetry of the apparatus and the considerable distance away to the nearest asymmetric reflector materials. Three experiments had arms extending from only one face; and this was the NE face.

The number of arms present in a configuration is important to computer modeling whether or not all arms were allowed to receive solution. Unfilled arms served as neutron reflectors to some extent. This number is contained in one column unless it is reflected in the title to the table. Not all arms were always connected to the solution filling manifold. Whenever fewer arms were connected than present, the disconnected arms always were at the top of the configuration. Table IV yields an example. Experiment \#73 had sixteen arms extending off all four faces; and each set of four were separated in their vertical plane by $127 \mathrm{~mm}$. The preceding experiment had the upper set of four arms disconnected (but still present); and the experiment even preceding that one had only the bottom eight arms eligible to receive solution. Finally, in that sequence, experiment \#70 had just the lowest four arms connected to the manifold and the upper twelve disconnected but still present. In most cases where all four faces were involved, the total number of arms is an integral multiple of four. That always means a symmetric distribution of the same number of arms off each face. When only two faces (opposite or adjacent) were involved, the total number of arms is an integral multiple of two; and the same number of arms appeared in both vertical planes. 
The only experiments having an odd number of arms - and, therefore, a non-symmetric distribution of arms - were runs \#88 through \#92. This configuration consisted of six arms stacked on top of one another (in contact) off one face and five arms similarly stacked off the opposite face. This sequence began with ten arms in two co-planar stacks of five arms in contact. The next run added one arm to one stack forming the six/five asymmetry. Run \#89 found the top arm of the taller stack disconnected but still present. Except for the extra stainless steel, this would have been a repeat of the ten-arm run. The next two experiments found two more arms omitted from solution eligibility each time.

A complicating feature of some configurations involves the "offset", O. This offset means that the bottom of arms extending off either one face or a pair of opposite faces are at a different elevation than the arms extending off the adjacent face or two faces. Tables concerned with an offset geometry have a column devoted to that information. If no offset information is presented, adjacent arms were not offset relative to one another. This offset geometry can be seen more clearly in Figs. 19, 20 and 23. Sometimes (but not always) this offset was nominally equal to the arm diameter being used. The number of arms extending off offset faces was sometimes one less than the number off adjacent faces. That is how six arms can extend from four faces as in Table II. Experiments involving offset arm arrangements are shown in the upper portion of Table II, the lower portion of Table IV, and the second block in Table VII.

The rest of the columns in these several tables pertain to information needed to specify arm elevations. The first of these columns identifies the relevant figure or figures (drawings) which describe the geometry. Two drawings are given for cases where arms are stacked on top of one another such that the spacing, $\mathrm{S}$, is zero. The right hand sides of non-isometric drawings contain lower case letters which locate arms relative to the bottom of the Central Column. The bottoms of arms are designated by alternate letters: a, c, e, ... ; their tops, by b, d, f, ... . Offset arms are designated by primed letters: a', b', c', $\mathrm{d}^{\prime}, \ldots$. Elevations in ordinary font were specifically recorded in the Log Books or implied from immediately preceding experiments through comments such as "similar to previous setup except ...". That is, ordinary font refers to original data with an origin in the late 1960s. Elevations in italic font were derived, calculated, or inferred in 1999 from other data. They should be considered less accurate. Table II cites two examples. In the lower block of data, the measured $f$ is greater than the derived $g$ (and they ought to be equal) and the same measured $\mathrm{f}(1305.4 \mathrm{~mm})$ is different from the derived $\mathrm{f}(1300.4 \mathrm{~mm})$ calculated starting at the bottom $(\mathrm{a}=795.4 \mathrm{~mm})$. Typically, these derived elevations were obtained from obvious formulas. If a configuration featured $\mathrm{N}$ arms of diameter $\mathrm{D}$ and with a spacing $\mathrm{S}$ between, then: 


$$
\text { [top elevation of } \left.\mathrm{N}^{\text {th }} \text { arm }\right]=\mathrm{a}+\mathrm{ND}+(\mathrm{N}-1) \mathrm{S} \text {, }
$$

where "a" is the measured elevation of the underside of the lowest arm. Values derived in 1999 should be considered less reliable than measured values.

Later in the course of study, experimenters began to record the distance down from the top of the Central Column to the top of the highest arm; and these measurements are given by capital letters, such as $\mathrm{T}$ and $\mathrm{T}^{\prime}$. Again, primed parameters refer to offset arms. For the same example, this parameter would simply equal:

$$
\mathrm{T}=2435.4 \mathrm{~mm}-\left[\text { top elevation of } \mathrm{N}^{\text {th }} \text { arm }\right]
$$

where the very top of the column corresponded to a solution height of $2435.4 \mathrm{~mm}$.

Figures 22 and 23 yield similar equations for geometries with arms inclined at $45^{\circ}$ from the Central Column:

$$
\text { [top elevation of } \mathrm{N}^{\text {th }} \text { arm] }=\mathrm{a}+N D \sqrt{2}+(\mathrm{N}-1) \mathrm{S} \text {, }
$$

and

$$
\mathrm{T}=2435.4 \mathrm{~mm}-\left[\text { top elevation of } \mathrm{N}^{\text {th }} \text { arm }\right]
$$

This geometry introduces still one more parameter: U \& U'. These represent the vertical elevation gain between the outer end of the upper arm and the top of the Central Column. This parameter was never measured but can be calculated from simple geometry if the length of an arm is L:

$$
\mathrm{U}=2435.4 \mathrm{~mm}-\left[\text { top elevation of } \mathrm{N}^{\text {th }} \text { arm }\right]-\mathrm{L} /(\sqrt{2})
$$

The parameter, $\mathrm{U}$, is sometimes negative which means that the arms extended upward and outward to an elevation above the top of the Central Column. Obviously, this portion of an arm could never fill with fissile solution. As before, lower case letters still refer to arm elevations at the point of contact with the Central Column. 
As stated above, recorded arm elevations as well as measurements relative to the top of the Central Column are not always consistent with one another and with measured arm diameters and specified spacings. The size of these inconsistencies appear to be only a few millimeters for a number of examples calculated. This defect must be recognized as an uncertainty in the measured physical parameters of this program. The failure to document all physical aspects of a potentially critical configuration may be attributed to inexperience of the several researchers involved and to the inability to anticipate at the time the eventual need for such a high level of detail to meet the requirements of modernday computing capabilities. 


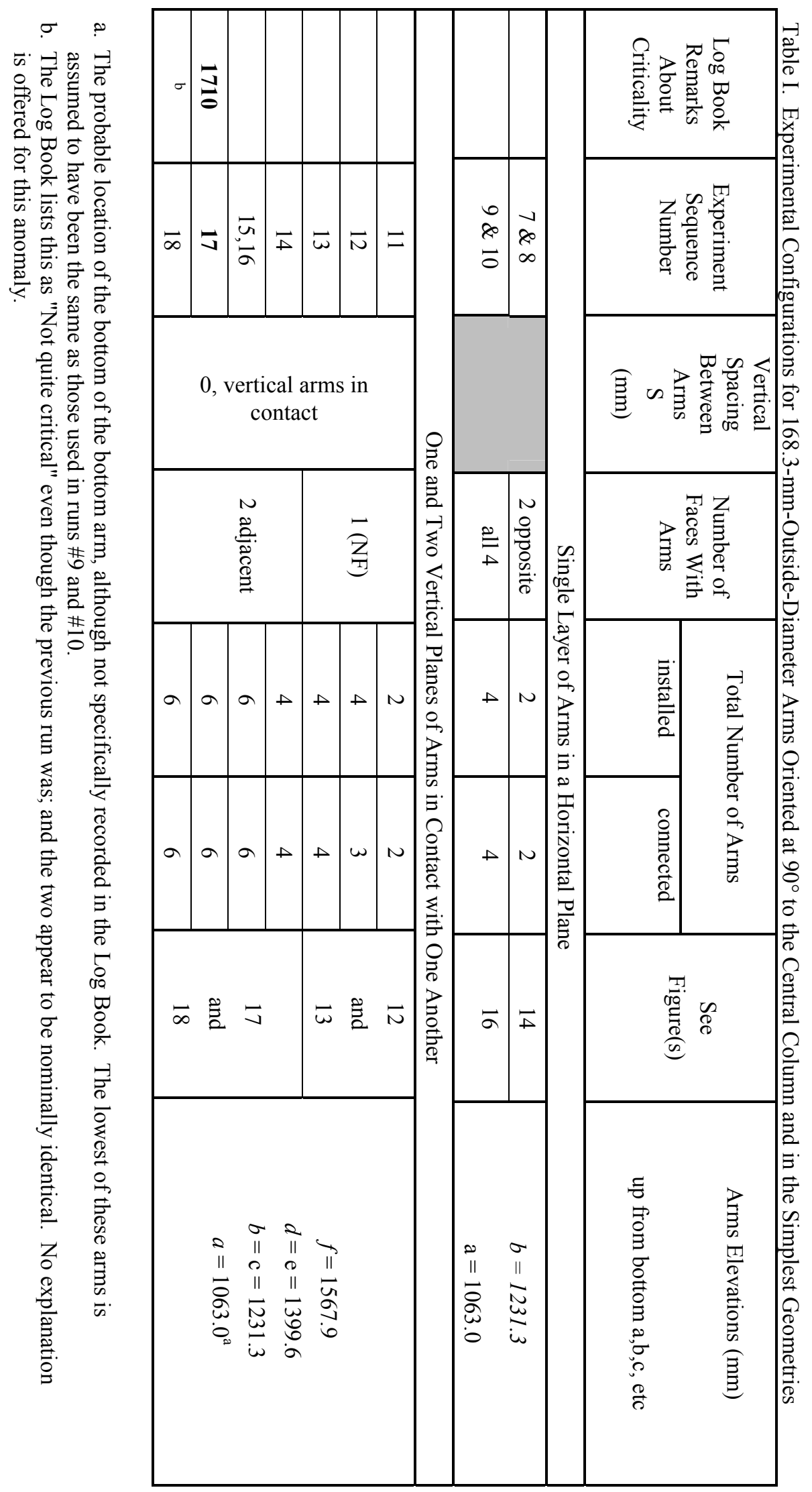




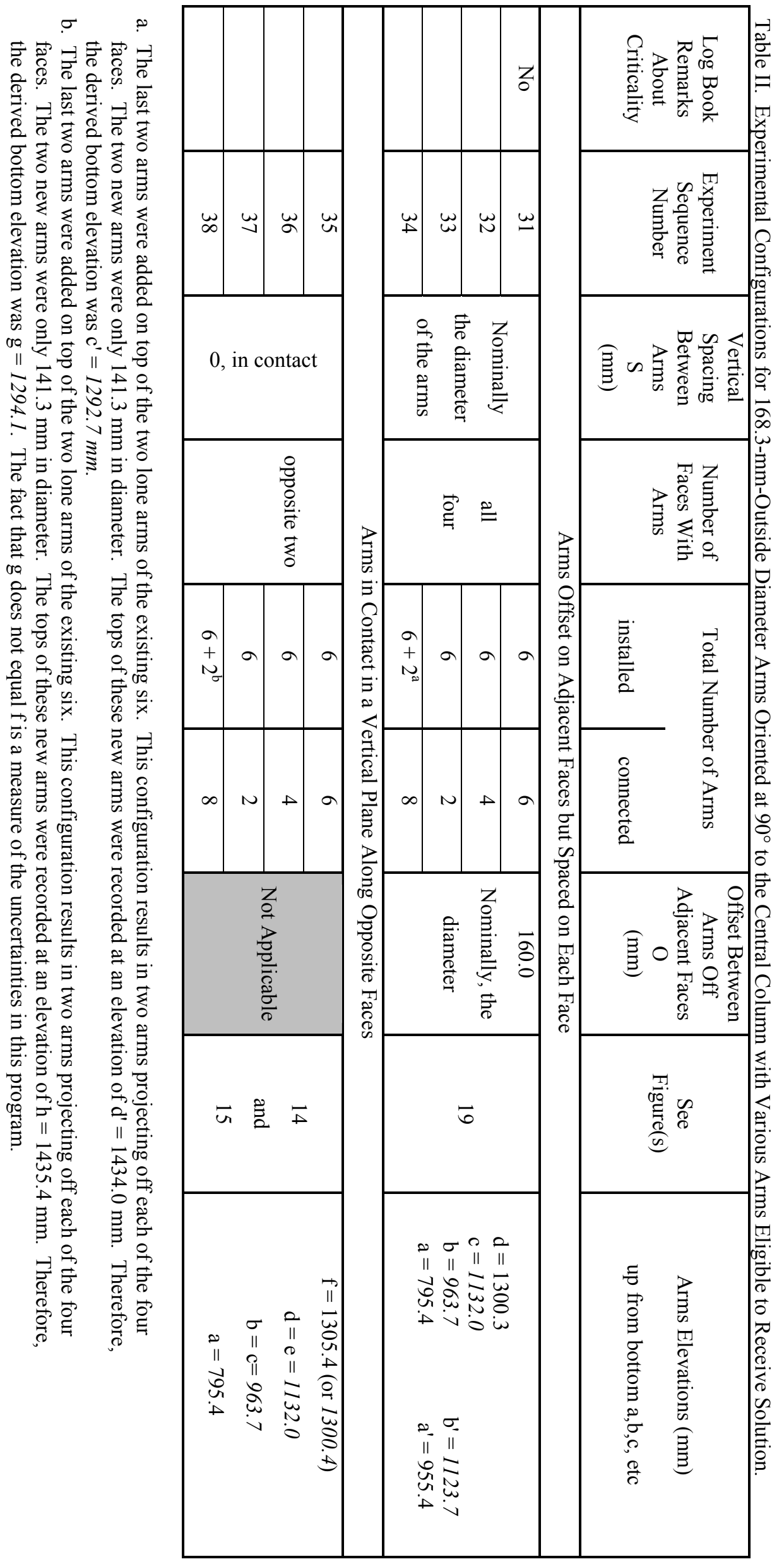




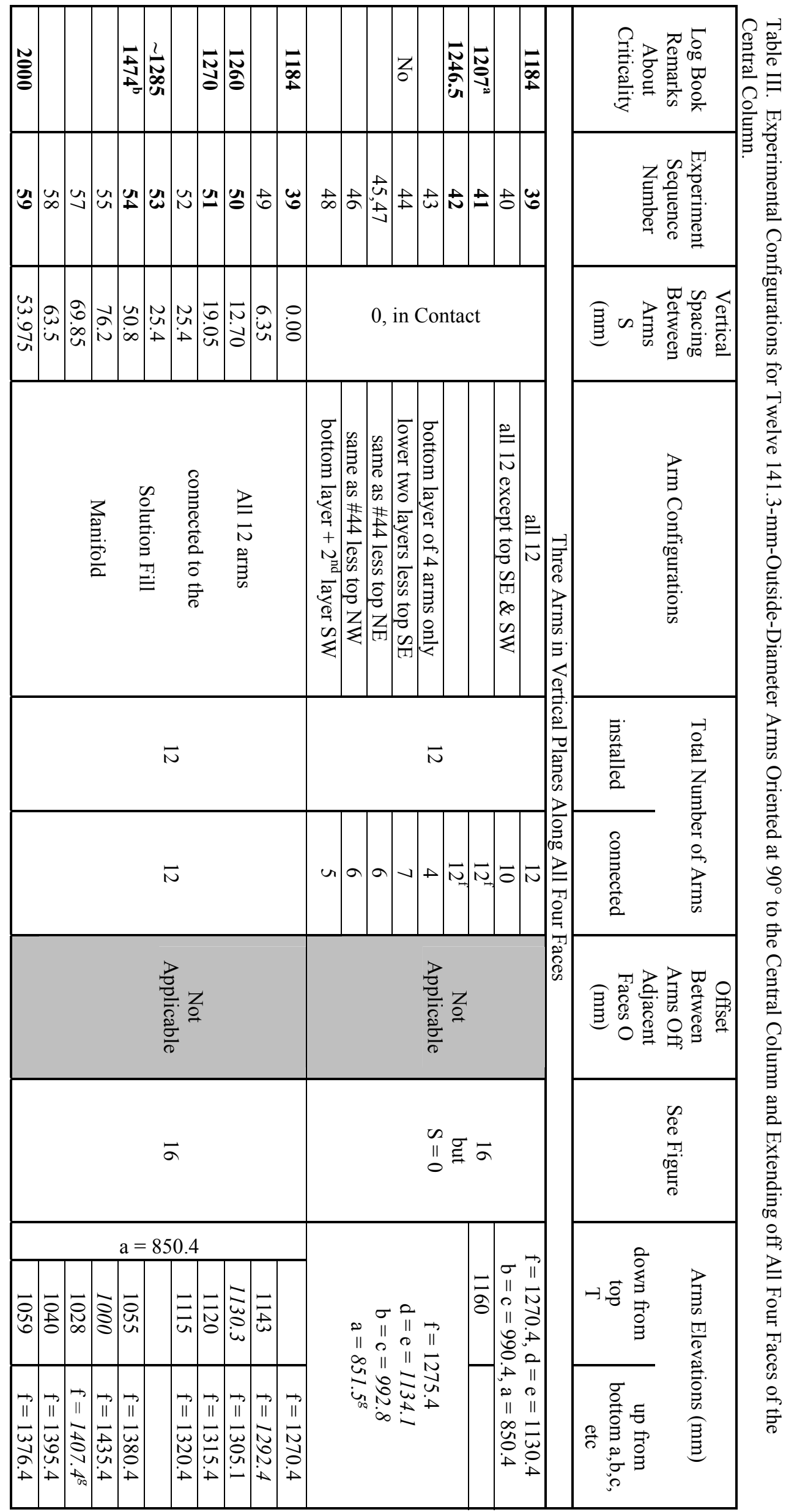




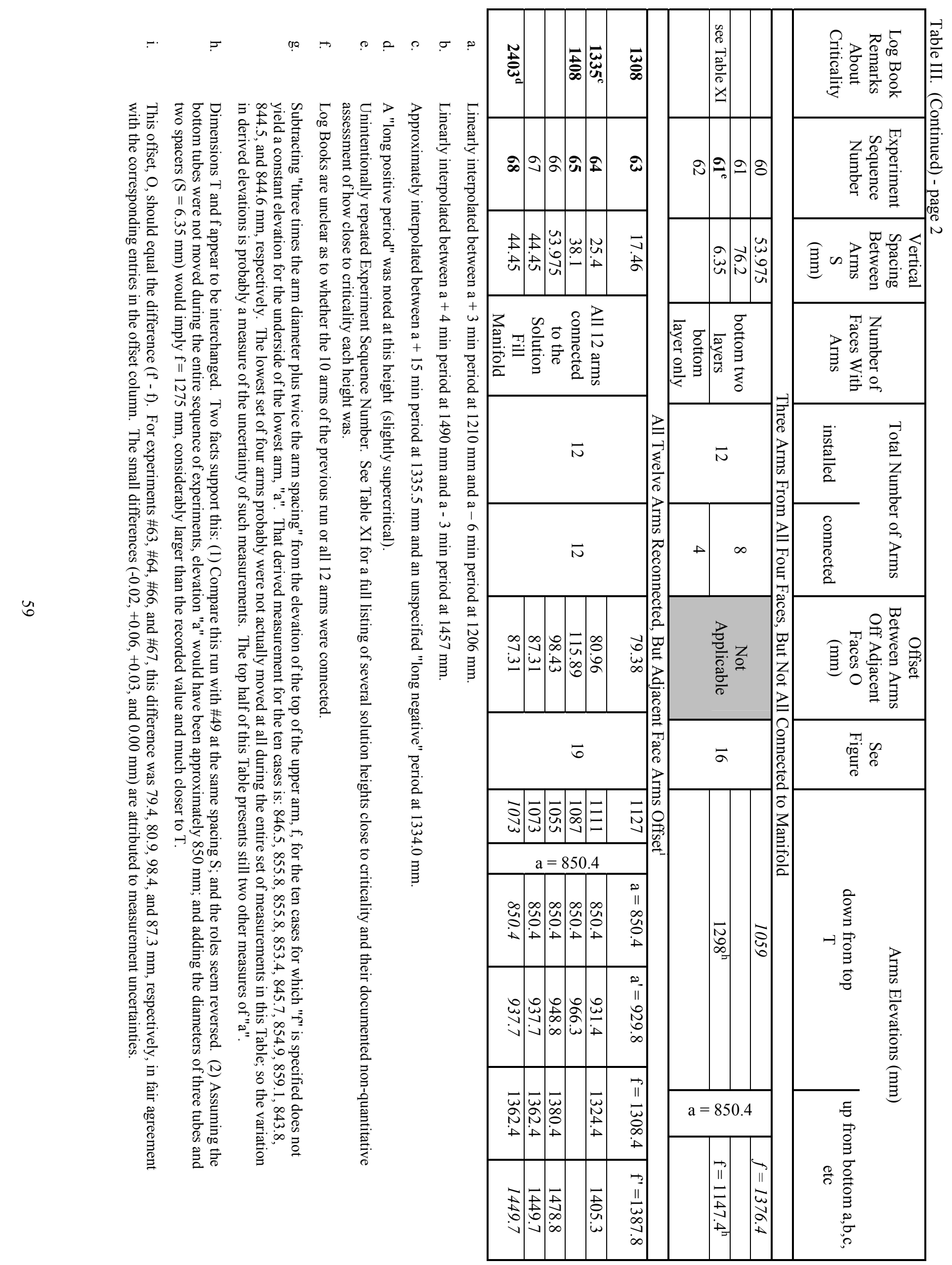




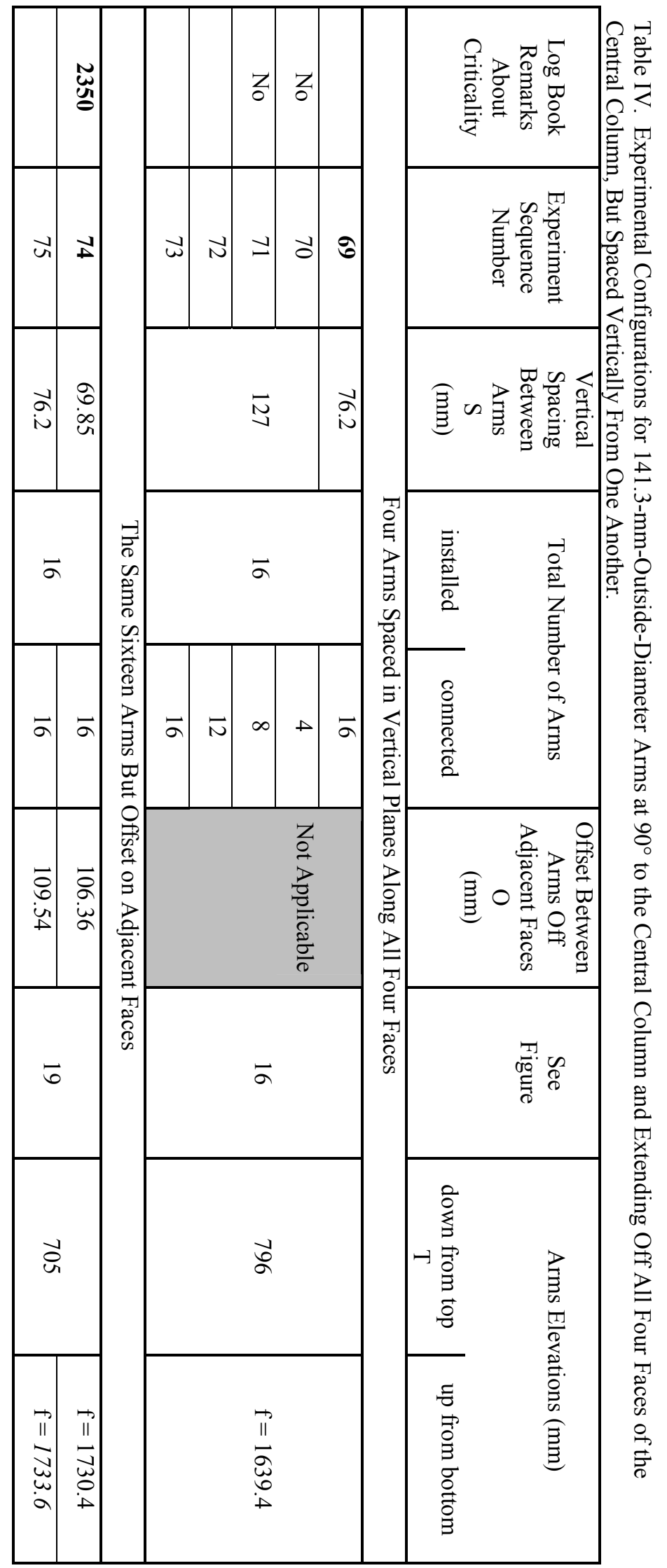


Table V. Experimental Configurations for 168.3-mm-Outside-Diameter Arm at $90^{\circ}$ to the Central Column and Extending Off All Or Opposite Faces of It.

\begin{tabular}{|c|c|c|c|c|c|c|c|}
\hline \multirow{2}{*}{$\begin{array}{l}\text { Log Book } \\
\text { Remarks } \\
\text { About } \\
\text { Criticality }\end{array}$} & \multirow{2}{*}{$\begin{array}{l}\text { Experiment } \\
\text { Sequence } \\
\text { Number }\end{array}$} & \multirow{2}{*}{$\begin{array}{c}\text { Vertical } \\
\text { Spacing } \\
\text { Between } \\
\text { Arms } \\
\text { S } \\
(\mathrm{mm})\end{array}$} & \multicolumn{2}{|c|}{ Total Number of Arms } & \multirow{2}{*}{$\begin{array}{c}\text { See } \\
\text { Figure(s) }\end{array}$} & \multicolumn{2}{|c|}{$\begin{array}{c}\text { Elevation of the Top of the } \\
\text { Highest Arm }(\mathrm{mm})\end{array}$} \\
\hline & & & installed & connected & & $\begin{array}{c}\text { down from } \\
\text { top } \\
\mathrm{T}\end{array}$ & up from bottom \\
\hline \multicolumn{8}{|c|}{ Arms in Contact Off Two Opposite Faces } \\
\hline & 87 & \multirow{6}{*}{$\begin{array}{l}\overrightarrow{0} \\
\mathbb{E} \\
\tilde{0} \\
. \\
. \\
0\end{array}$} & 10 & 10 & \multirow{6}{*}{$\begin{array}{c}14 \\
\text { and } \\
15\end{array}$} & \multirow{6}{*}{\multicolumn{2}{|c|}{ No Arm Elevations Recorded }} \\
\hline & 88,92 & & 11 & 11 & & & \\
\hline & 89 & & 11 & 10 & & & \\
\hline & 90 & & 11 & 8 & & & \\
\hline & 91 & & 11 & 6 & & & \\
\hline & 93 & & 12 & 12 & & & \\
\hline \multicolumn{8}{|c|}{ Two Arms Spaced in Vertical Planes Along All Four Faces } \\
\hline$\sim 1110$ & 94 & 25.4 & \multirow{6}{*}{8} & \multirow{6}{*}{8} & \multirow{6}{*}{16} & 1280 & 1155 \\
\hline$\sim 1170$ & 95 & 53.98 & & & & 1251 & 1184.4 \\
\hline 1238 & 96 & 88.9 & & & & 1215 & 1220.4 \\
\hline 1252.3 & 97 & 101.6 & & & & 1202.3 & 1233.1 \\
\hline 1345 & 98 & 114.3 & & & & 1189.6 & 1245.8 \\
\hline$\sim 2430^{\mathrm{a}}$ & 99 & 131.8 & & & & 1167.2 & 1268.2 \\
\hline \multicolumn{8}{|c|}{ Three Arms Spaced in Vertical Planers Along All Four Faces } \\
\hline & 100 & $228.6^{\mathrm{d}}$ & 12 & \multirow{4}{*}{12} & \multirow[b]{4}{*}{$19^{\mathrm{c}}$} & \multirow{4}{*}{$a=800$} & $1660.4^{\mathrm{d}}$ \\
\hline & 101 & 209.6 & 12 & & & & 1720.4 \\
\hline & 102 & 177.8 & 12 & & & & \\
\hline No & $103^{\mathrm{b}}$ & 168.28 & 12 & & & & 1800 \\
\hline
\end{tabular}

a. The Log Book identifies this case as "Just critical at [the] top [of the Central Column]." This top-of-the-column height was $2435.4 \mathrm{~mm}$; but experiments would not likely have approached closer than a few millimeters from the top. Therefore, this critical height may be taken as about $2430 \mathrm{~mm}$.

b. This is the experiment which suffered the collapse of one arm during the critical approach. This subject is discussed in detail in the section on Lessons Learned.

c. This one experiment in this table had adjacent arms offset. The offset equaled the arm diameter. That is, $\mathrm{S}=\mathrm{O}=$ $168.3 \mathrm{~mm}$. A small discrepancy exists in that $\left(\mathrm{f}^{\prime}-\mathrm{a}\right)=1000 \mathrm{~mm}$ but $6 \times 168.3 \mathrm{~mm}=1009.8 \mathrm{~mm}$.

d. Probably, the vertical spacing, $\mathrm{S}$, was incorrectly recorded. The distance ( $\mathrm{f}-\mathrm{a}$ ), $860.4 \mathrm{~mm}$, does not equal three times the arm diameter $(168.3 \mathrm{~mm})$ plus twice the recorded "9-inch" $(228.6 \mathrm{~mm})$ spacing; but the same formula appears better suited to a "7-inch" $(177.8 \mathrm{~mm})$ spacing: $[3(168.3 \mathrm{~mm})+2(177.8 \mathrm{~mm})]=860.5 \mathrm{~mm}$. Furthermore, increasing the apparent separation from $177.8 \mathrm{~mm}$ to $209.6 \mathrm{~mm}$ as in run \#101, the increase in " $\mathrm{f}$ " would be twice the increased spacing: $63.6 \mathrm{~mm}$. The observed increase in "f" is $60 \mathrm{~mm}$. Still, this observation about an error in recording $\mathrm{S}$ for run $\# 100$ is pure conjecture. 
Table VI. Experimental Configurations for 114.3-mm-Outside-Diameter Arms at $90^{\circ}$ to the Central Column and Extending Off All Four of Its Faces.

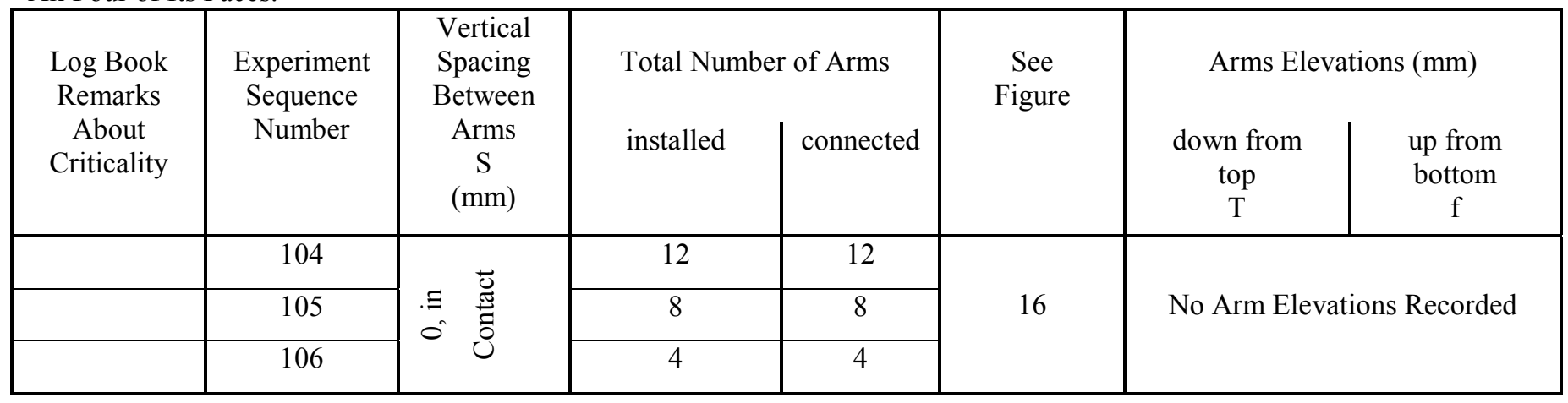




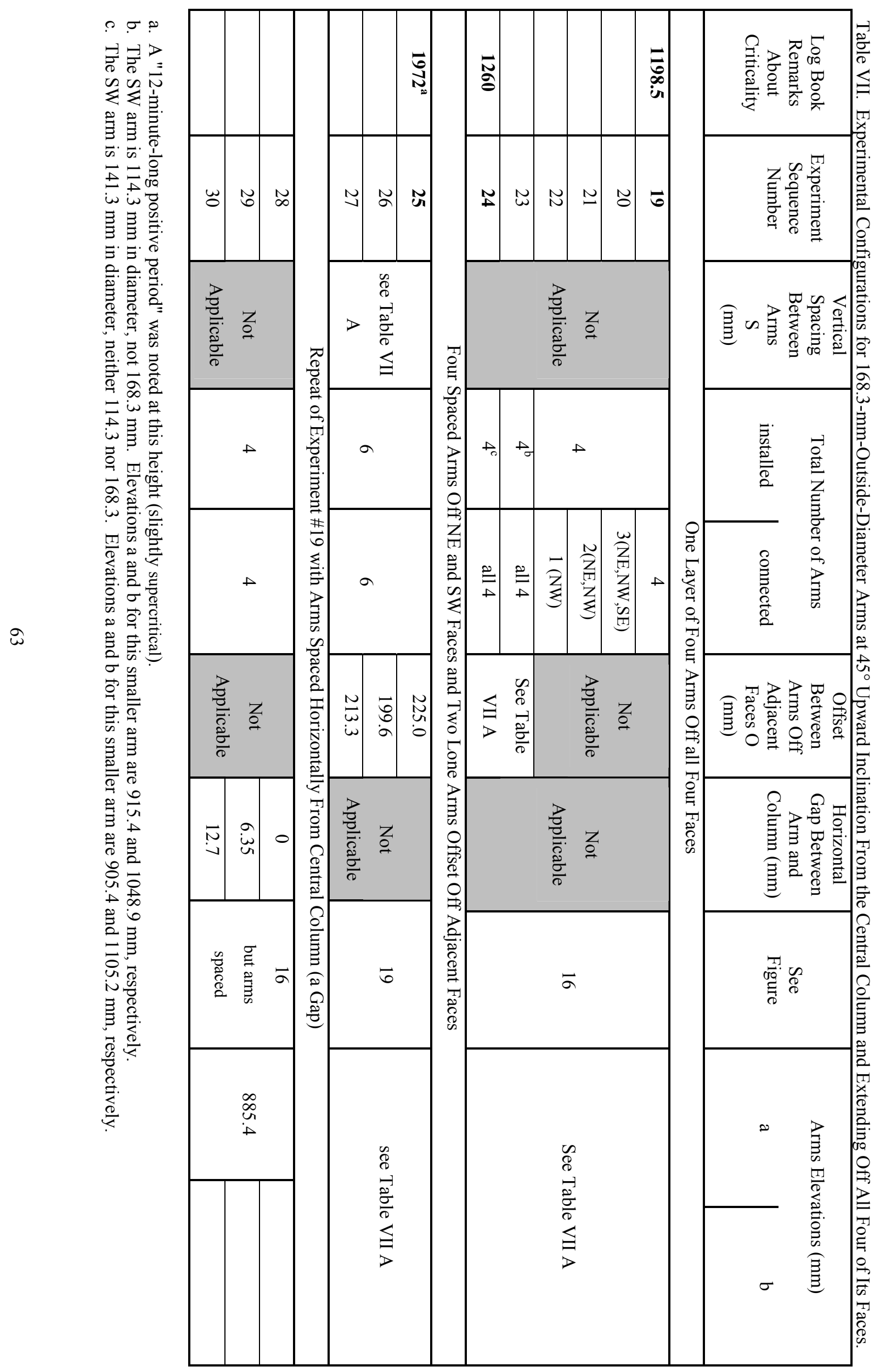




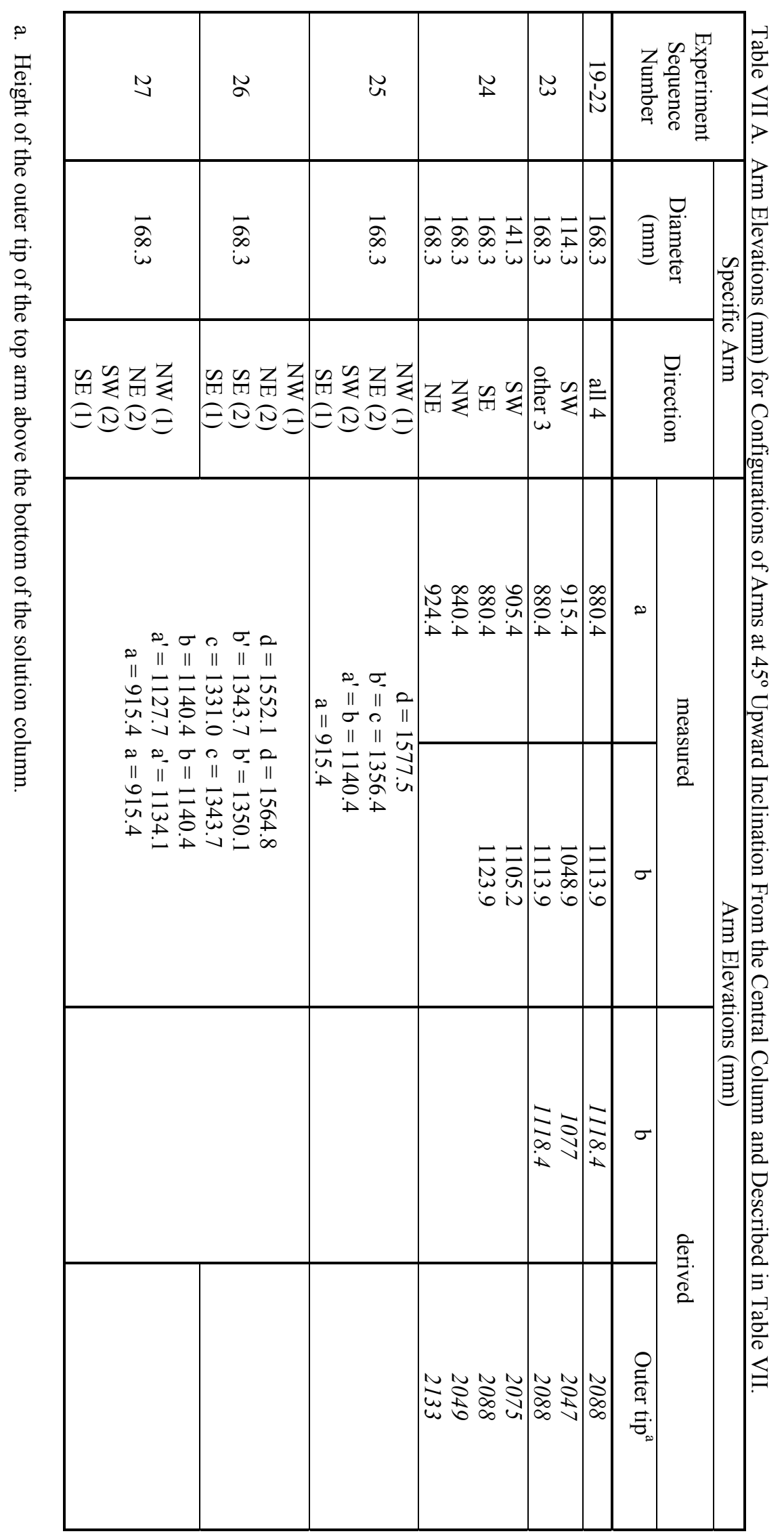


Table VIII. Experimental Configurations for 141.3-mm-Outside-Diameter Arms at $45^{\circ}$ Upward Inclination From the Central Column and Extending Off All Four of Its Faces.

\begin{tabular}{|c|c|c|c|c|c|c|c|}
\hline $\begin{array}{l}\text { Log Book } \\
\text { Remarks } \\
\text { About } \\
\text { Criticality }\end{array}$ & $\begin{array}{l}\text { Experiment } \\
\text { Sequence } \\
\text { Number }\end{array}$ & $\begin{array}{c}\text { Vertical } \\
\text { Spacing } \\
\text { Between } \\
\text { Arms } \\
\text { S } \\
(\mathrm{mm})\end{array}$ & $\begin{array}{l}\text { Total Nu } \\
\text { installed }\end{array}$ & $\begin{array}{l}\text { of Arms } \\
\text { connected }\end{array}$ & $\begin{array}{c}\text { See } \\
\text { Figure }\end{array}$ & Arms El & $\mathrm{ns}(\mathrm{mm})$ \\
\hline & 76 & $\mathrm{~N} / \mathrm{A}$ & 4 & 4 & 21 & 1444 & 991.4 \\
\hline $1320^{\mathrm{a}}$ & 77 & 86.52 & 12 & 12 & 22 & & \\
\hline $1371^{b}$ & 78 & 101.6 & \multirow{5}{*}{8} & \multirow{5}{*}{8} & \multirow{5}{*}{22} & & \\
\hline $1433^{\mathrm{c}}$ & 79 & 122.2 & & & & 1123.8 & 1311.6 \\
\hline No? & 80 & 187.3 & & & & 1057 & 1378.4 \\
\hline No & 81 & 166.1 & & & & & 1356 \\
\hline 1643 & 82 & 147.6 & & & & & \\
\hline
\end{tabular}

a. The words "Very close to critical" were noted at this height.

b. A "12-minute-long positive period" was noted at this height (slightly supercritical).

c. A "10.2-minute-long positive period" was noted at this high (slightly supercritical).

Table IX. Experimental Configurations for 177.8-mm-Square Arms at $45^{\circ}$ Upward Inclination From the Central Column and Extending Off One or Two Faces.

\begin{tabular}{|c|c|c|c|c|c|c|}
\hline \multirow{2}{*}{$\begin{array}{c}\text { Log Book } \\
\text { Remarks } \\
\begin{array}{c}\text { About } \\
\text { Criticality }\end{array}\end{array}$} & $\begin{array}{c}\text { Experiment } \\
\text { Sequence } \\
\text { Number }\end{array}$ & \multirow{2}{*}{$\begin{array}{c}\text { Number of } \\
\text { Faces With } \\
\text { Arms }\end{array}$} & \multicolumn{2}{|c|}{ Total Number of Arms } & \multicolumn{2}{|c|}{ Arms Elevations (mm) } \\
\cline { 4 - 5 } & 83 & 1 & 1 & 1 & & T \\
\hline & 84 & $?$ & 2 & 2 & & \\
\hline $\mathbf{1 1 9 6}$ & $\mathbf{8 5}$ & adjacent & 2 & 2 & & $\mathrm{~b}=1073.5$ \\
\hline & 86 & opposite & 2 & 2 & & \\
\hline
\end{tabular}

Table X. Experimental Configurations for "Donut" Along the Central Column in Place of Arms.

\begin{tabular}{|c|c|c|c|c|c|c|}
\hline $\begin{array}{c}\text { Log Book } \\
\text { Remarks About } \\
\text { Criticality }\end{array}$ & $\begin{array}{l}\text { Derived Critical } \\
\text { Height Relative to Top } \\
\text { of Donut (mm) }\end{array}$ & $\begin{array}{l}\text { Experiment } \\
\text { Sequence } \\
\text { Number }\end{array}$ & $\begin{array}{l}\text { Number } \\
\text { of Stacked } \\
\text { Donuts }\end{array}$ & $\begin{array}{c}\text { See } \\
\text { Figure }\end{array}$ & Donut $\mathrm{E}$ & $\begin{array}{r}\text { ns }(\mathrm{mm}) \\
\text { top of } \\
\text { donut }\end{array}$ \\
\hline & & 80 & 1 & N/A & 1420 & \\
\hline 1147 & -16.4 & 81 & 2 & 24 & 1265 & 1163.4 \\
\hline 1117 & +8.6 & 82 & 2 & 24 & 1320 & 1108.4 \\
\hline
\end{tabular}


Table XI. Various Reactor Periods Very Close to the Critical Uranium Solution Height for One Experiment ${ }^{\mathrm{a}}$

Configuration: 8 of 12 arms (141.3-mm-outside-diameter) connected to the solution distribution manifold off all four faces of the Central Column. The arm-to-arm spacing, $\mathrm{S}$, was $6.35 \mathrm{~mm}$.

\begin{tabular}{|c|c|c|}
\hline \multicolumn{2}{|r|}{ Uranium solution height ${ }^{\mathrm{b}}(\mathrm{mm})$} & $\begin{array}{c}\text { Log Book Comment pertaining to proximity to } \\
\text { Criticality }\end{array}$ \\
\hline \multirow{7}{*}{$\stackrel{\mathscr{\Xi}}{\Xi}$} & 2407 & "just critical" \\
\hline & 2350 & "critical with $\infty$ period" \\
\hline & 2310 & "now subcritical" \\
\hline & 2320 & "still subcritical" \\
\hline & 2350 & "not critical" \\
\hline & 2358 & "not quite critical" \\
\hline & 2407 & "just critical" \\
\hline
\end{tabular}

a. The second experiment numbered, accidentally, \# 61 .

b. All arms were full of solution and the solution rose well above the highest set of arms in the Central Column. 


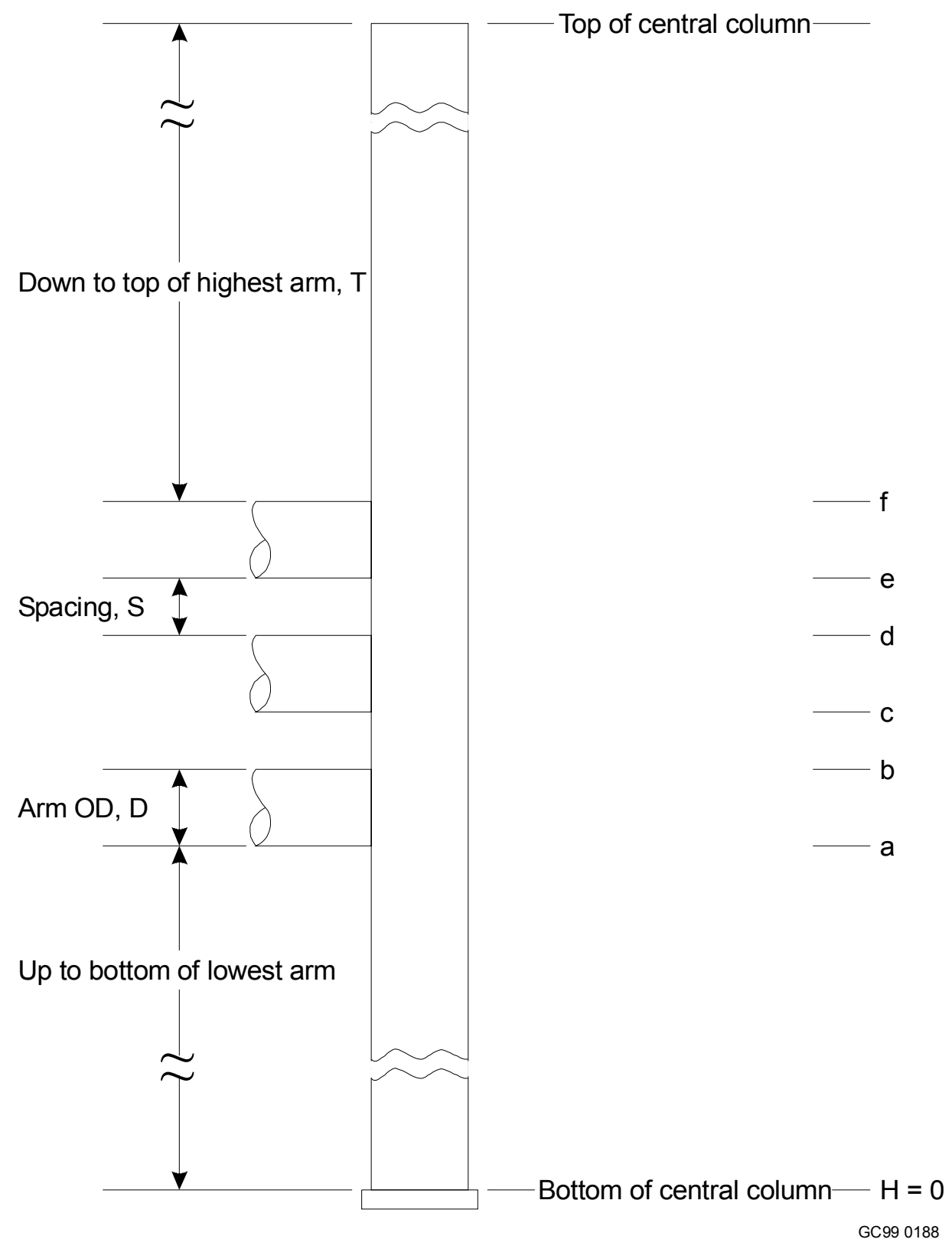

Figure 12. The elevation view of the experimental configurations for cases where horizontal arms projected off just one face of the Central Column identifies parameters discussed in the tables and text. Lower case letters to the far right pertain to arm elevations relative to the bottom $(\mathrm{H}=0)$ while other dimensions are identified by capital letters to the left. 


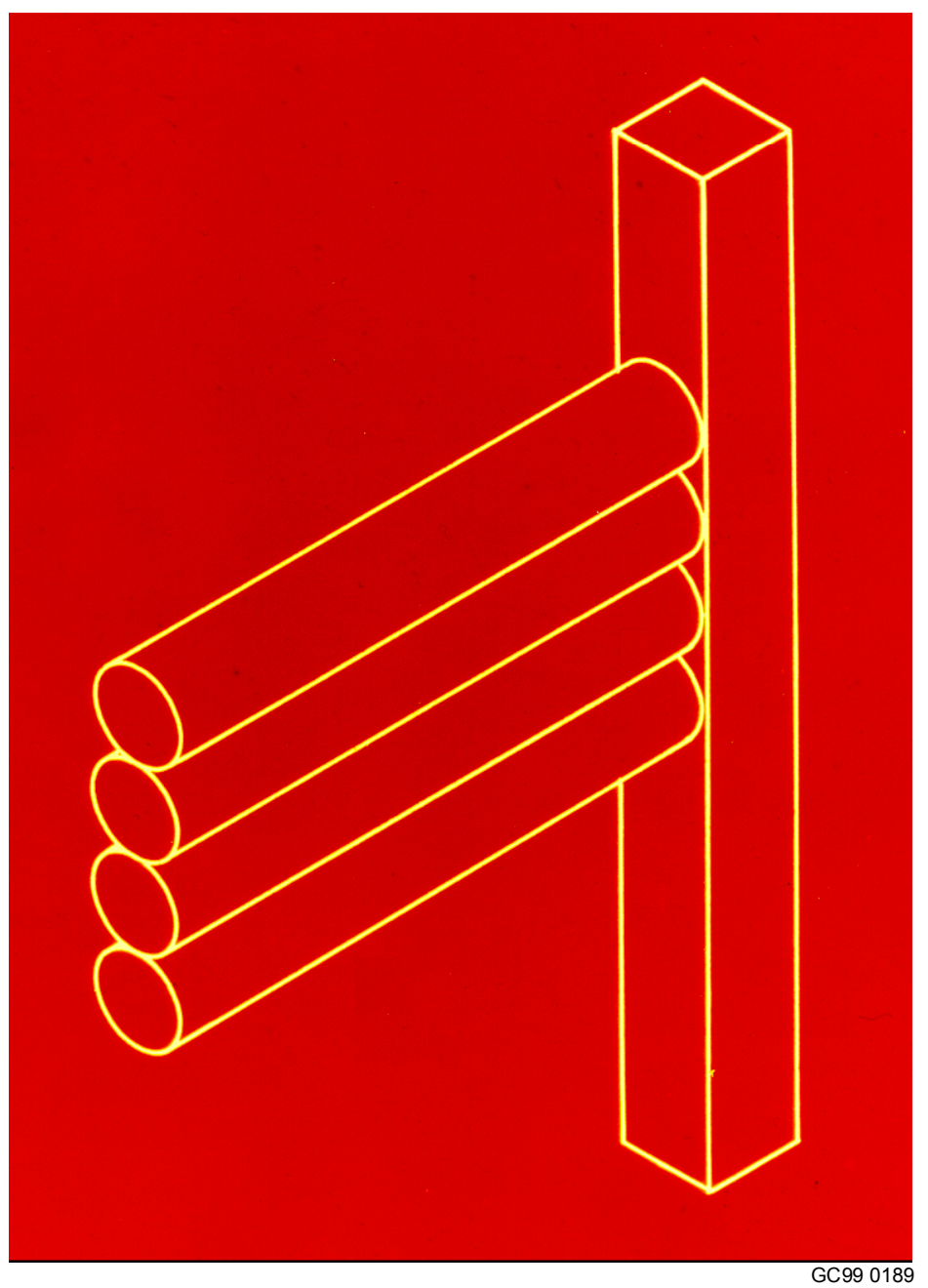

Figure 13. An isometric drawing of a special case of Fig. 12 for which $\mathrm{S}=0$. 


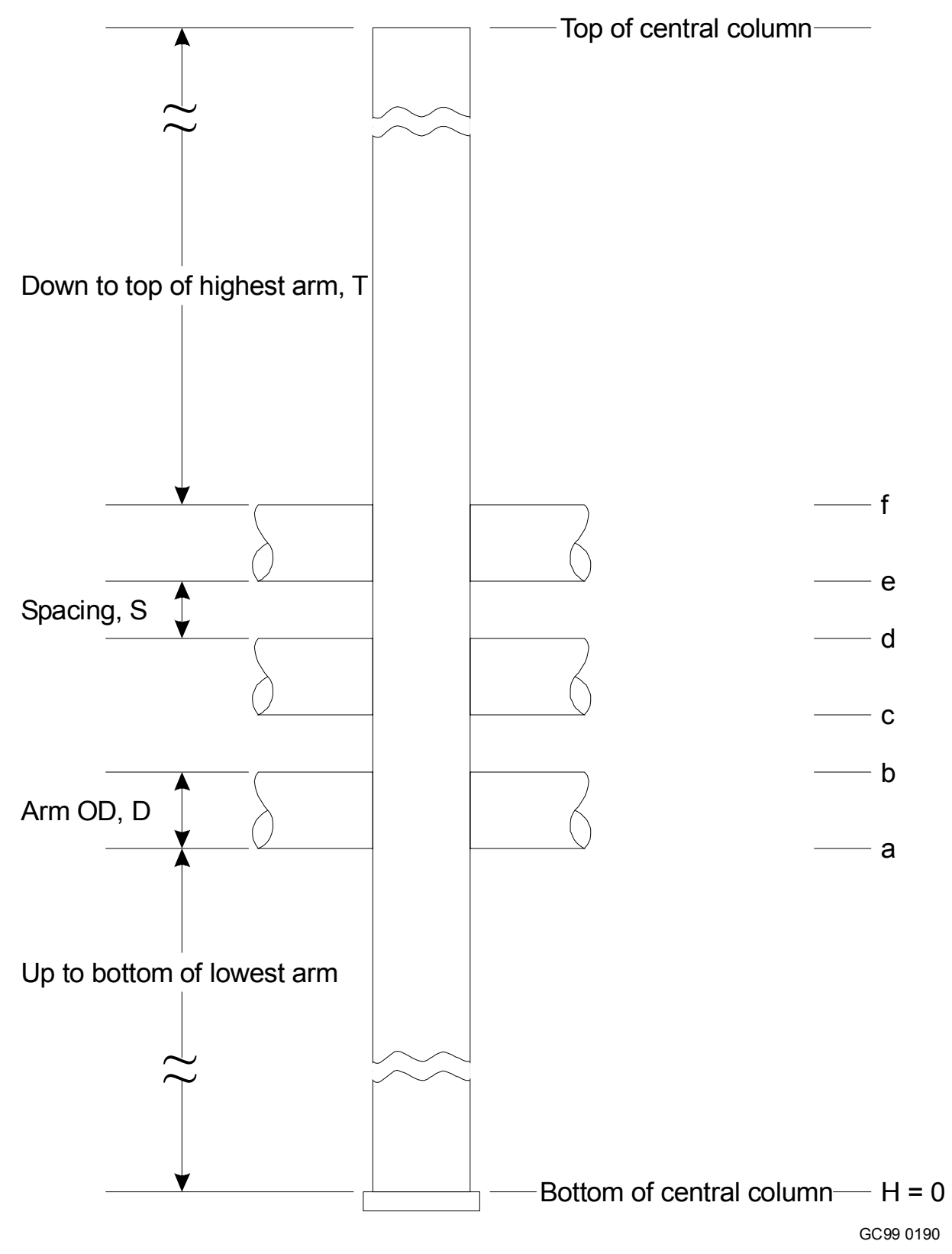

Figure 14. This elevation view of the experimental configurations for cases where horizontal arms projected off just two opposite faces of the Central Column identifies parameters discussed in the tables and text. Lower case letters to the right pertain to arm elevations relative to the bottom $(\mathrm{H}=0)$ while other dimensions are identified by capital letters to the left. 


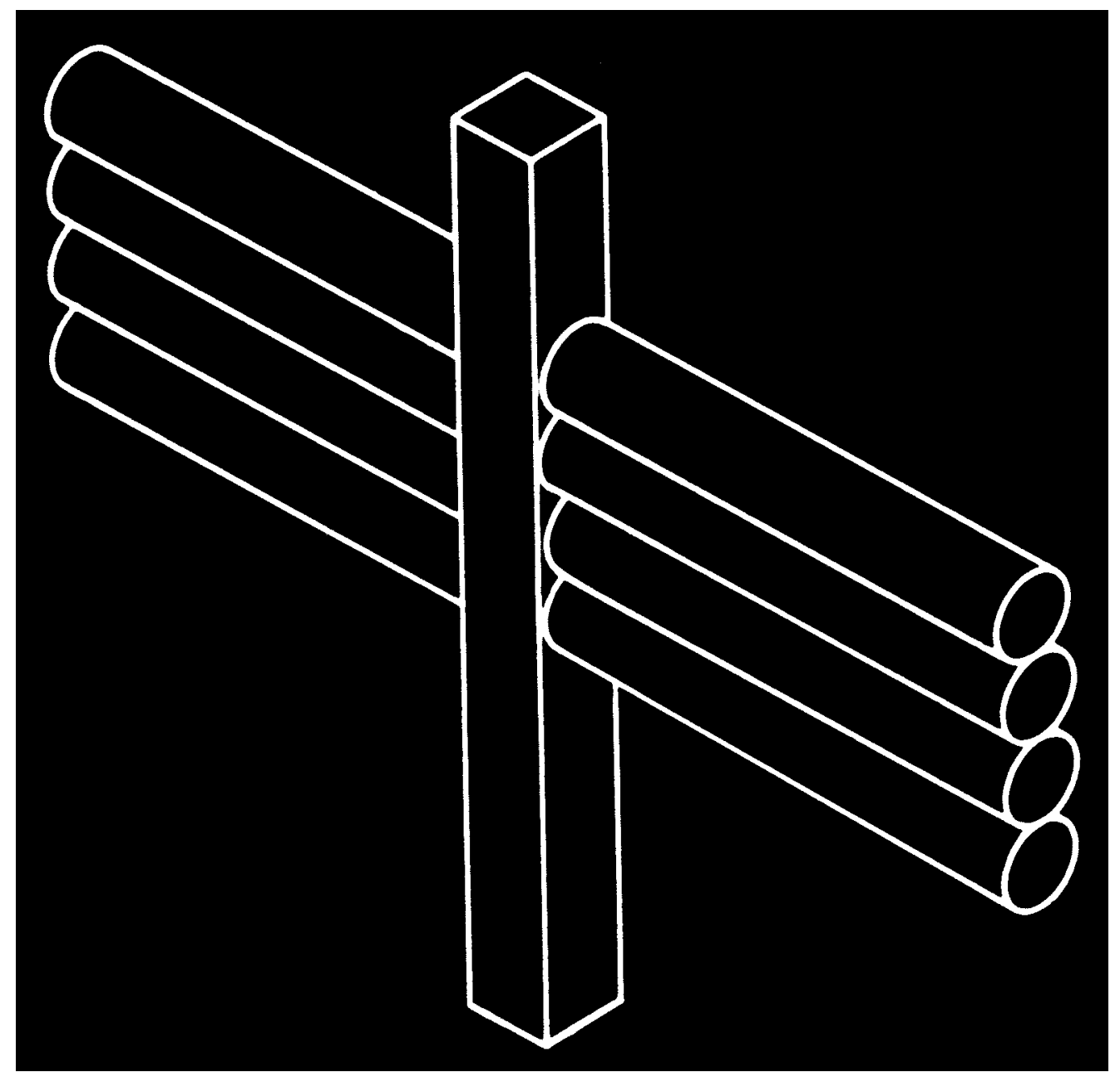

Figure 15. An isometric drawing of a special case of Fig. 14 for which $\mathrm{S}=0$. 


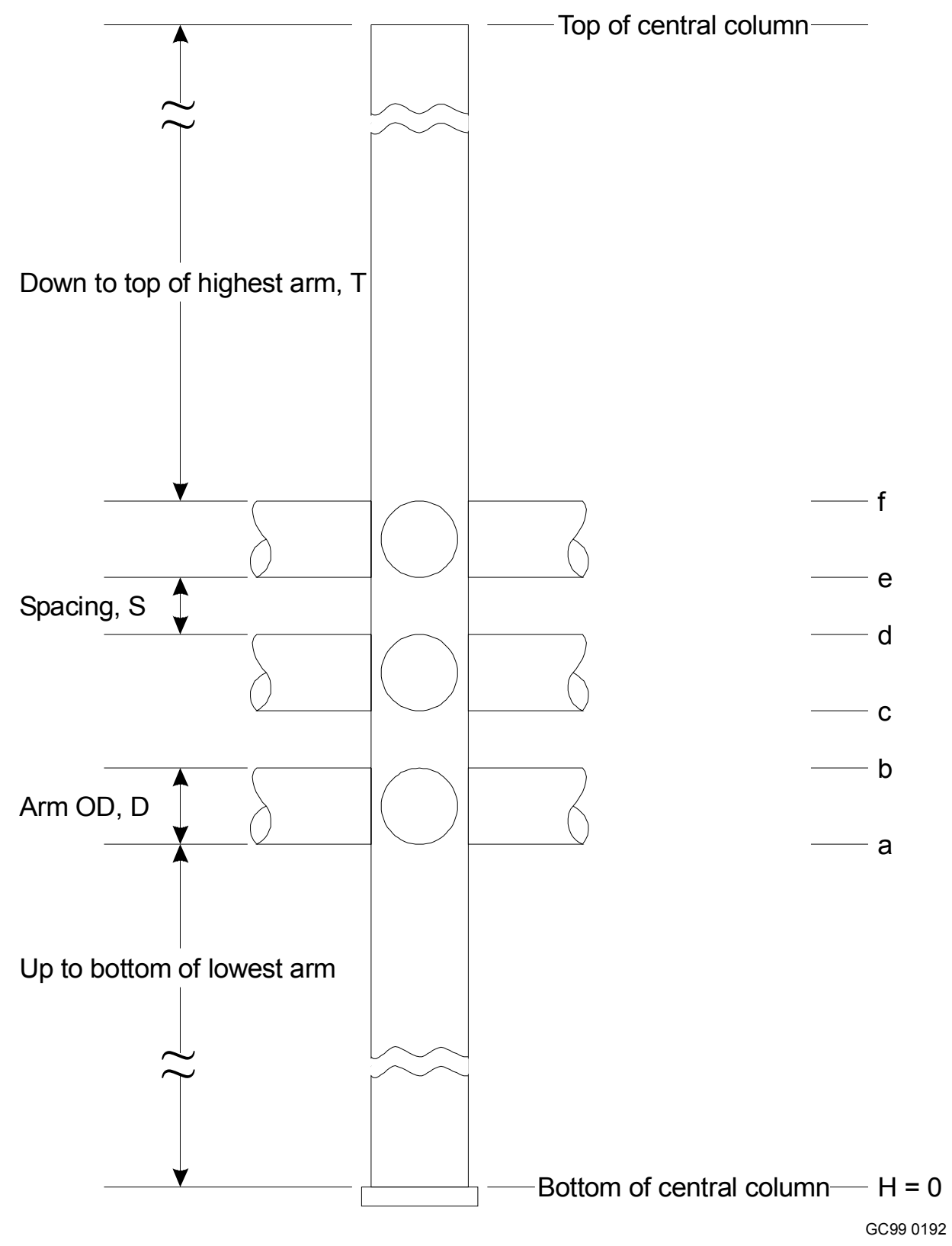

Figure 16. This elevation view of the experimental configurations for cases where horizontal arms projected off all four faces of the Central Column identifies parameters discussed in the tables and text. Lower case letters to the far right pertain to arm elevations relative to the bottom $(\mathrm{H}=0)$ while other dimensions are identified by capital letters to the left. 


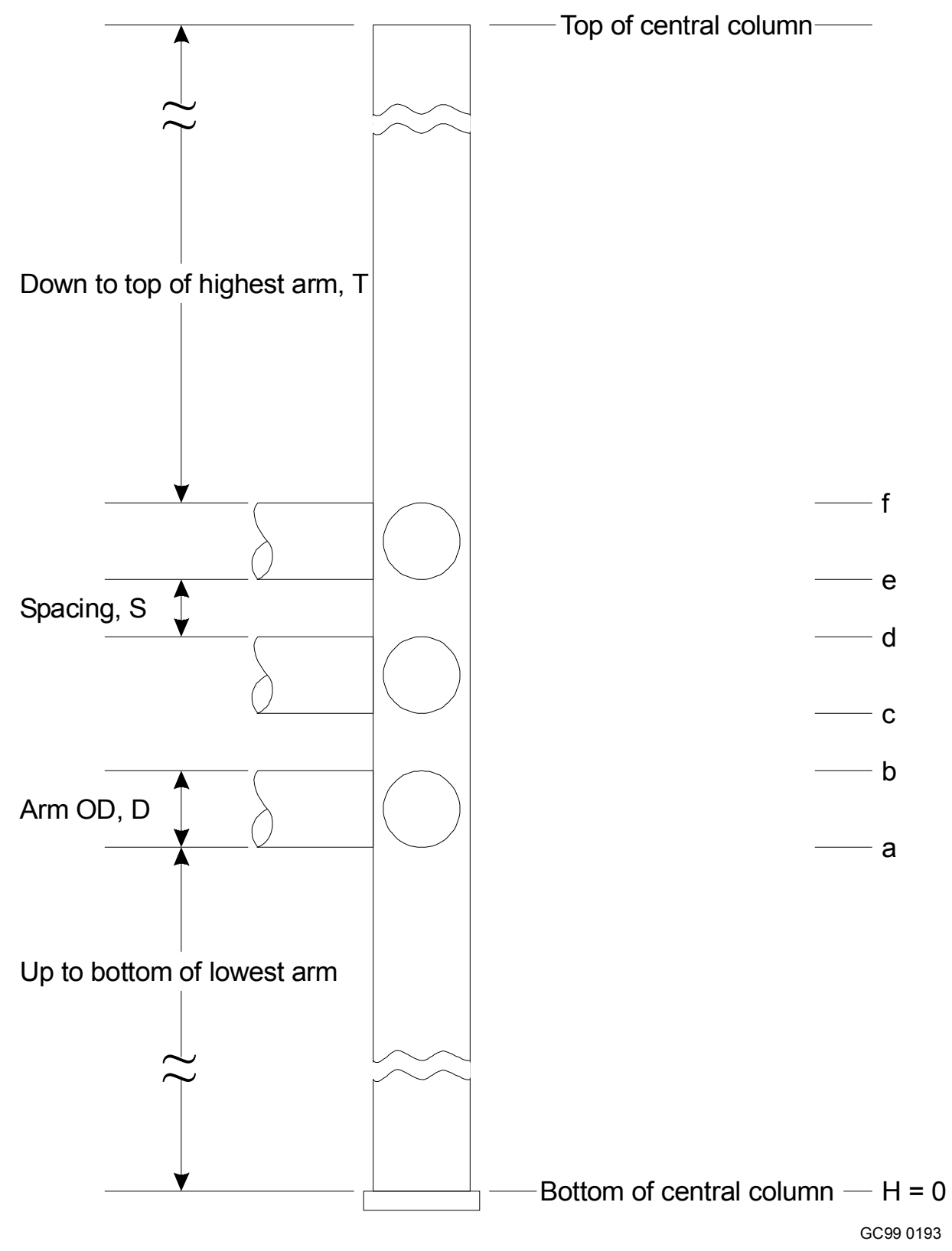

Figure 17. This elevation view of the experimental configurations for cases where horizontal arms projected off just two adjacent faces of the Central Column identifies parameters discussed in the tables and text. Lower case letters to the far right pertain to arm elevations relative to the bottom $(\mathrm{H}=0)$ while other dimensions are identified by capital letters to the left. 


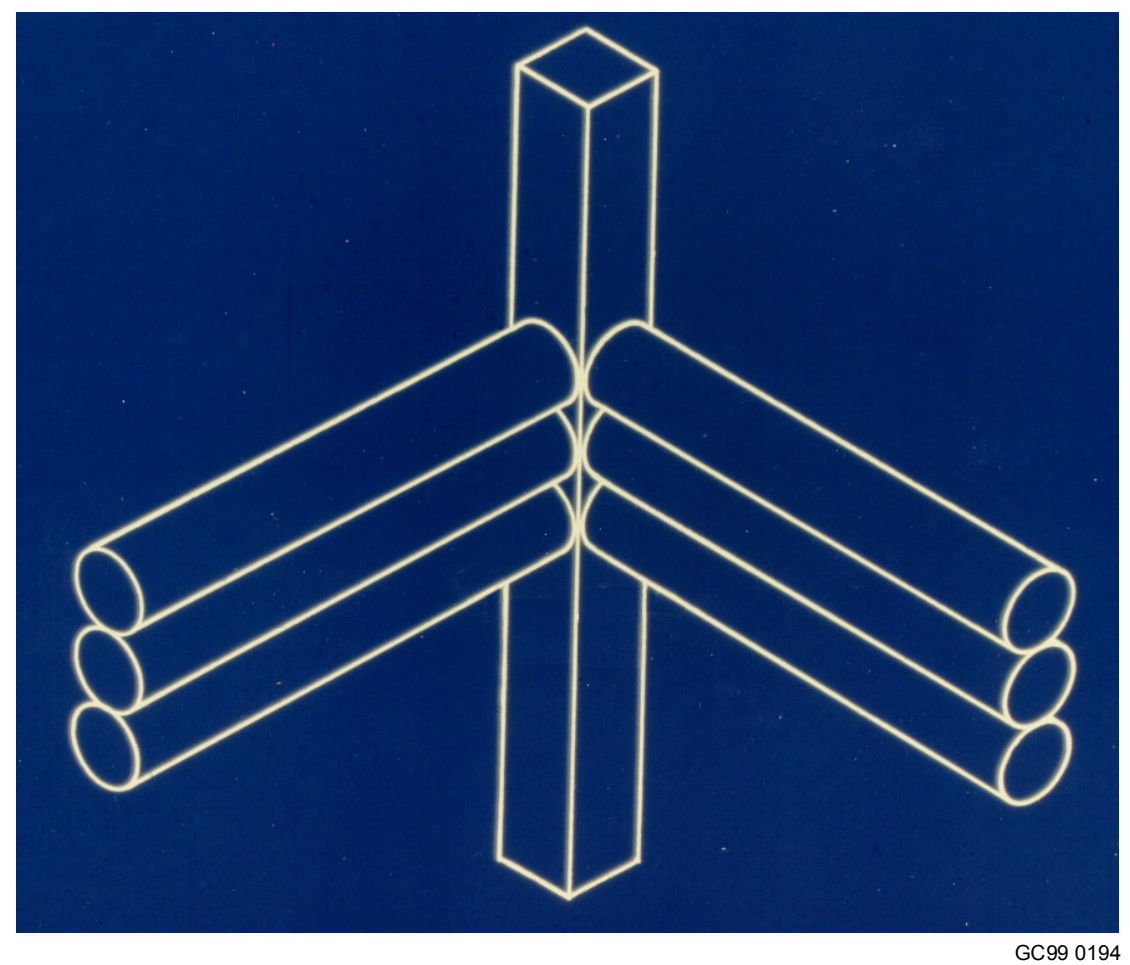

Figure 18. An isometric drawing of a special case of Fig. 17 for which $\mathrm{S}=0$. 


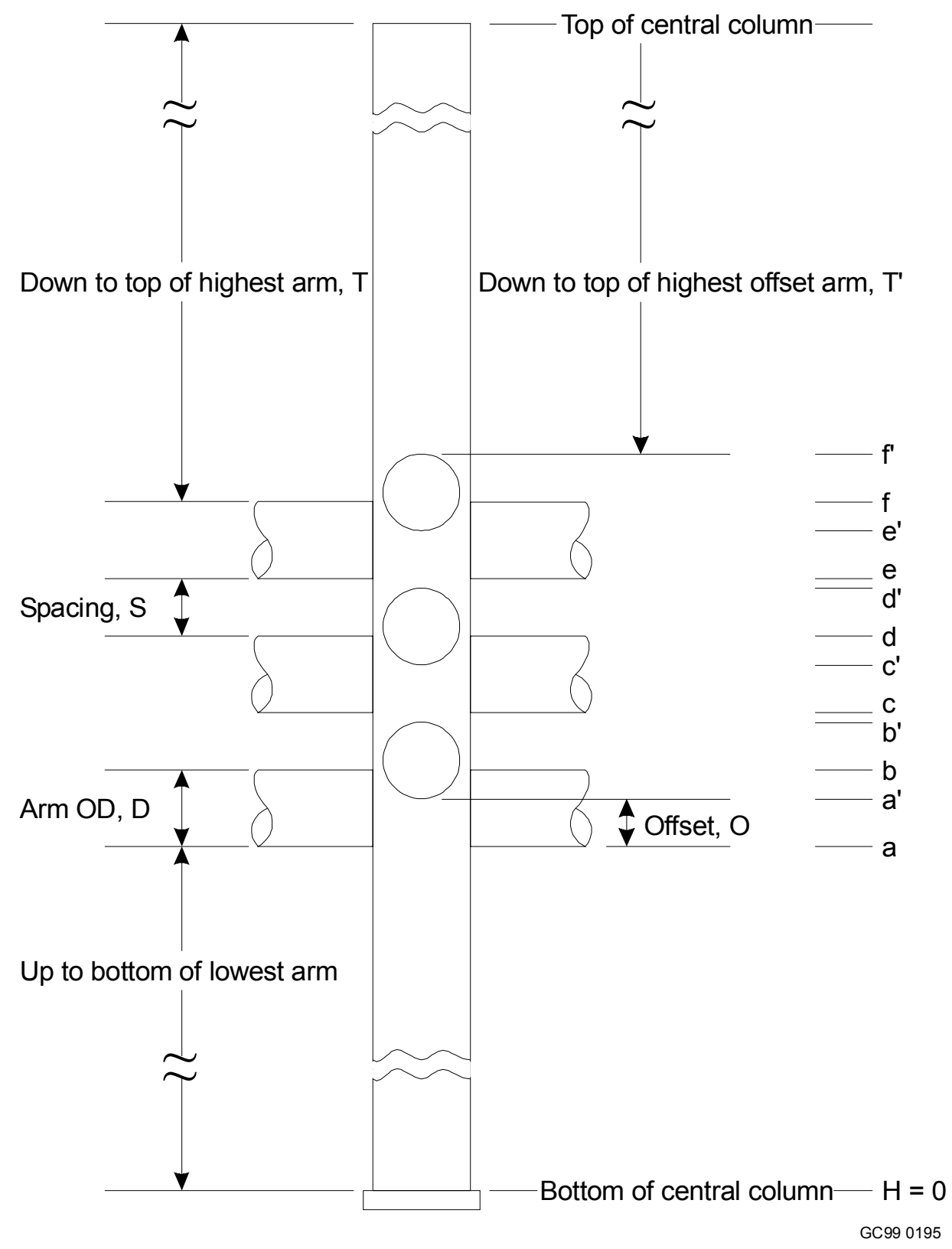

Figure 19. This elevation view of the experimental configurations for cases where horizontal arms projected off all four faces of the Central Column identifies parameters discussed in the tables and text. These cases differed from Fig. 16 in that arms extending toward and away from the viewer are offset by a distance $\mathrm{O}$. That is, adjacent arms do not lie in the same horizontal plane. Lower case letters to the far right pertain to arm elevations relative to the bottom $(\mathrm{H}=0)$. Primed letters pertain to the higher offset arms normal to the plane of the drawing. Other dimensions are identified by capital letters. 


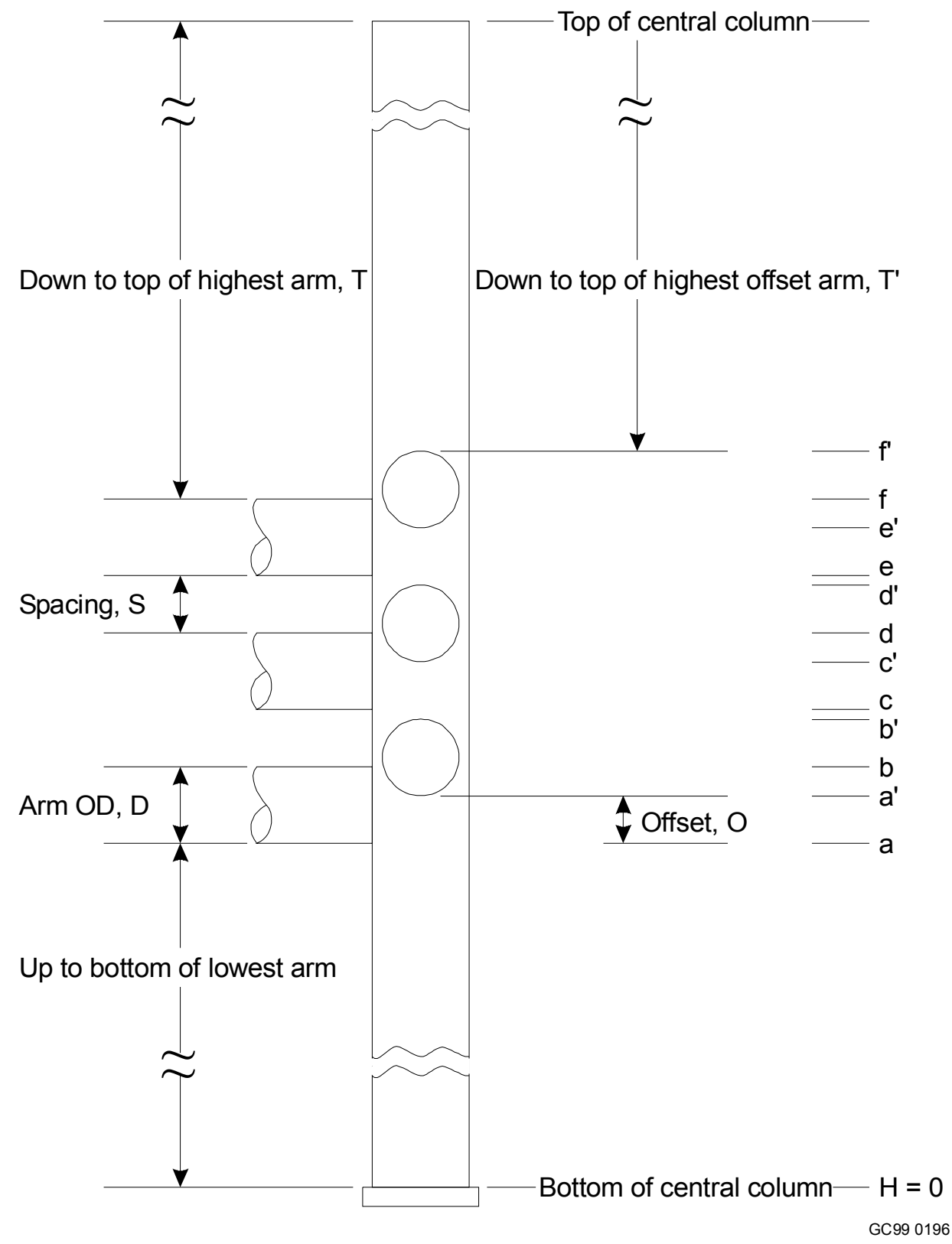

Figure 20. This elevation view of the experimental configurations for cases where horizontal arms projected off just two adjacent faces of the Central Column identifies parameters discussed in the tables and text. These cases differed from Fig. 17 in that arms extending toward the viewer are offset by a distance $\mathrm{O}$. That is, adjacent arms do not lie in the same horizontal plane. Lower case letters to the far right pertain to arm elevations relative to the bottom $(\mathrm{H}=0)$. Primed letters pertain to the higher offset arms normal to the plane of the drawing. Other dimensions are identified by capital letters. 


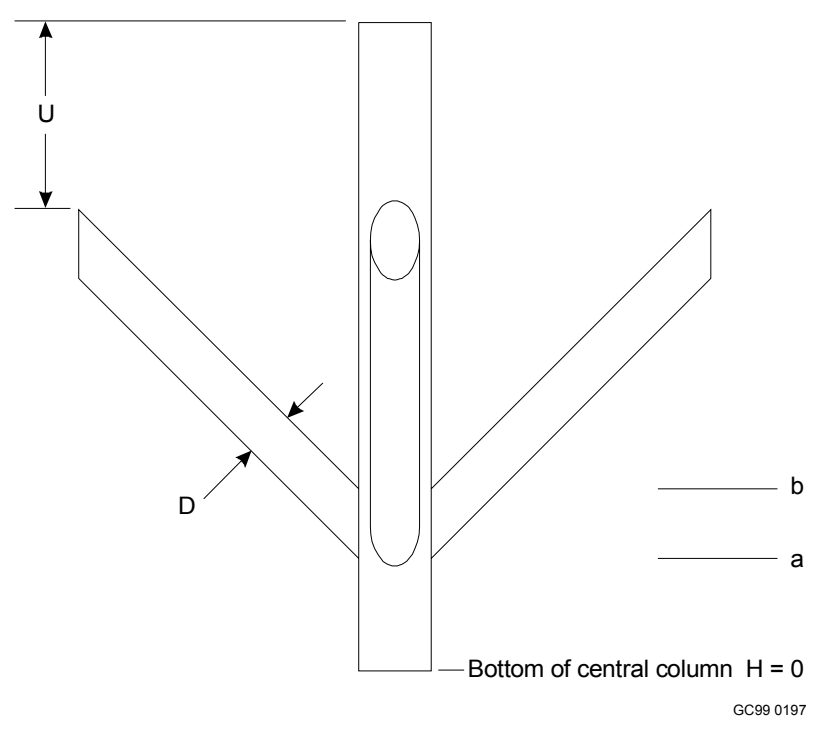

Figure 21. This elevation view of the experiment configurations for one case where one set of four arms inclined at $45^{\circ}$ from the Central Column projected off all four of its faces identifies parameters discussed in the tables and text. Lower case letters to the far right pertain to arm elevations relative to the bottom $(\mathrm{H}=0)$ while other dimensions are identified by capital letters.

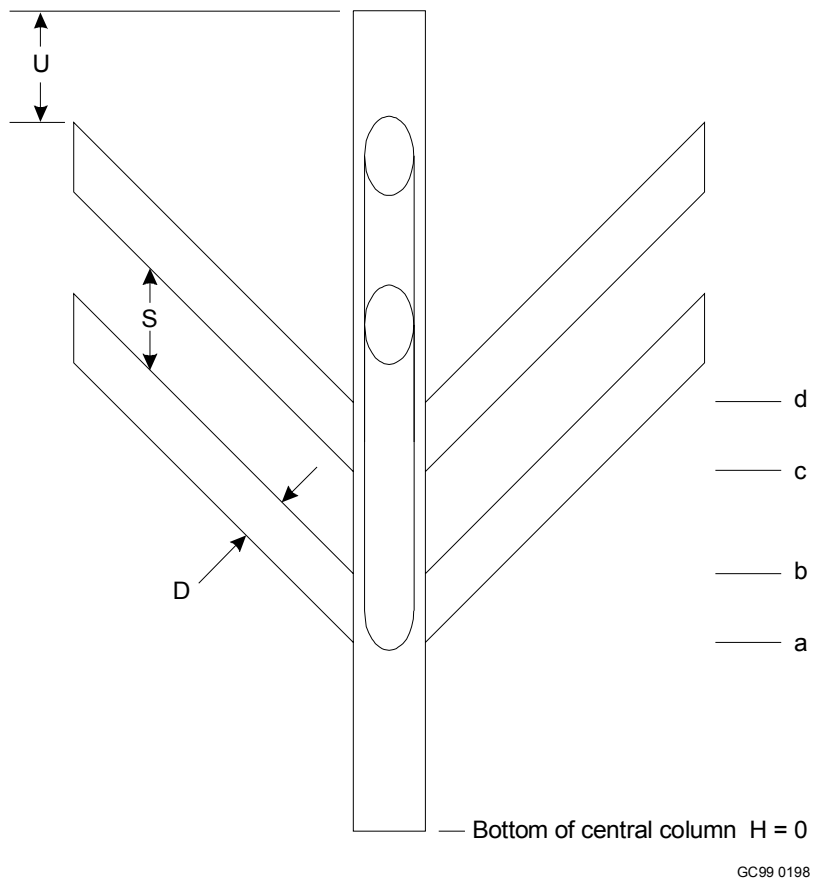

Figure 22. This elevation view of the experimental configurations for cases where arms inclined at $45^{\circ}$ to the Central Column projected off all four of its faces identifies parameters discussed in the tables and text. Lower case letters to the far right pertain to arm elevations relative to the bottom $(H=0)$ while other dimensions are identified by capital letters. 


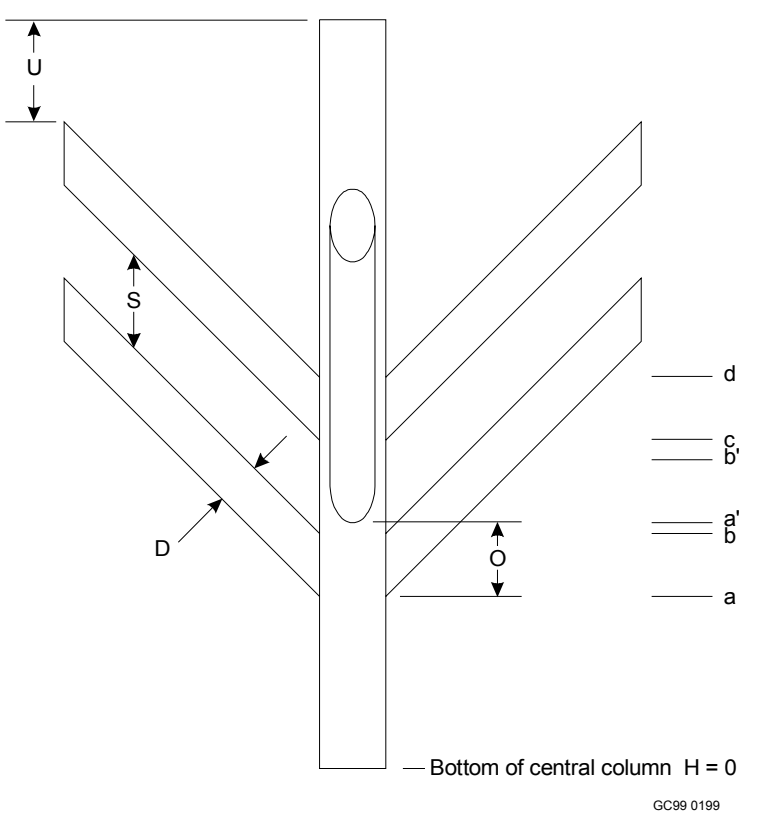

Figure 23. This elevation view of the experimental configurations for cases where arms inclined at $45^{\circ}$ to the Central Column projected off all four of its faces identifies parameters discussed in the tables and text. These cases differed from Fig. 22 in that arms do not lie in the same $45^{\circ}$ cone. Lower case letters to the far right pertain to arm elevations relative to the bottom $(\mathrm{H}=0)$. Primed letters pertain to the higher offset arms in the planes normal to that of the drawing. Other dimensions are identified by capital letters.

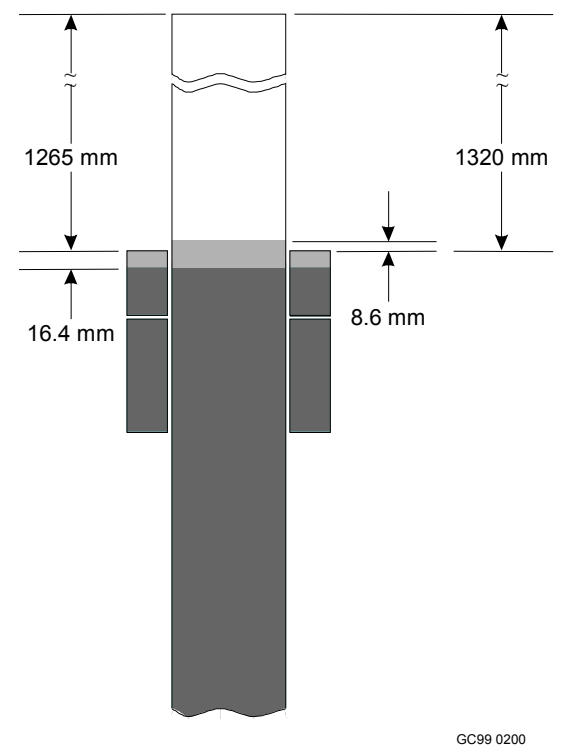

Figure 24. This elevation view of the last two of three experimental configurations where "donuts" replaced arms around the Central Column identifies critical parameters for these two experiments. These two experiments seemed to be identical except that the distance down from the top of the Central Column to the top of the upper donut appeared to differ by $55 \mathrm{~mm}$. In spite of that apparent similarity, criticality for the first occurred $16.4 \mathrm{~mm}$ before the donuts were full (heavy shading). Criticality for the second (light shading) occurred $8.6 \mathrm{~mm}$ above the top of the donut. 
The preceding lengthy discussion presents over thirty previously unpublished critical configurations, obtained from a direct reading of the two Log Books associated with this program. In addition to these, Ernst published other criticality data in RFP-1197 which had been derived by extrapolation techniques as discussed elsewhere. These results came from the same Log Books coupled with ancillary notes, including the now-lost reciprocal multiplication graphs generated during experiments. These additional critical cases were inferred from sequences of subcritical experiments. These sequences were otherwise identical to one another except for one parameter that varied toward increased reactivity such that an extrapolation produced an estimate of the critical situation. Interestingly, some critical parameters so derived become fractions of objects only manufactured in integral units under this approach - a non-physical concept. The critical number of arms in an array is one example. One application of this data is discussed later. In addition to this new information, some of Ernst's published critical configurations can be correlated one-for-one with configurations already presented in Tables I through X. These, then, are acknowledged repetitions of critical situations and not new data. Why not all critical cases from the Log Books were included in RFP-1197 is not understood.

Data from Ernst's earlier report are simply reproduced here with only small editorial modifications. These are presented in Table XII through Table XIV. Parameters have been converted to metric units to make comparisons easier. Experiments which appear to be directly correlated with a specific experiment in the first ten tables are identified by Experimental Sequence Number. This association was made by this author and could be in error in places. Another difference between that early report and Log Book documentation is the specific critical solution height parameter quoted. Log Books recorded the critical solution height relative to the bottom of the Central Column. Ernst chose to publish critical solution heights in terms of the height above the top surface of the highest arm. The two are obviously related. The elevation of the underside of the lowest arm plus the number of arms times their diameter plus the total amount of vertical spacing between arms should equal the elevation of the top of the highest arm.

The three new tables are also sufficiently complicated that a detailed explanation is provided for each portion. The table's title acknowledges that they present "derived" critical parameters as opposed to experimental measurements. These three tables, by themselves, are usually inadequate descriptions of the critical configuration without reference to the previous ten tables to permit a sufficiently complete description. The title also references that earlier report specifically. Finally, the title presents the diameter(s) of the arms, the number of faces of the Central Column, and the angle between arms and 
column as overall parameters. Allied sets of experiments having properties described in the table's title but otherwise differing in some other parameter are again broken into multiple regions.

The first three columns of two of the tables contain information on critical solution heights. Values from the first ten tables are simply copied in the third column for easy comparisons. The first two columns contain data from the early report. The first column is the critical solution height relative to the top of the highest arm. The second is this author's attempt to express that in terms of the elevation relative to the bottom of the Central Column so that a comparison between the two is possible. Critical heights extrapolated from sequences of subcritical cases pertain to a "full" Central Column; and that fact is so noted. Of course, no Log Book entry corresponds to those; so the third column is noted as "not applicable" (N/A). Two cases in the middle block of Table XII illustrate examples of critical experiments that were not recorded in the Log Book as being critical because of incomplete documentation. These are identified as "unspecified".

The fourth column associates each of the published critical cases with a suspected Experimental Sequence Number from one of the first ten tables. These associations are based on considerable detective work and may occasionally be in error. Whenever critical heights were extrapolated from sequences, these sets of experiments are enclosed in square brackets. The next column presents the vertical spacing between arms. These are identical to entries in the first ten tables; and this parameter was one principal means of correlating Log Book entries with published data. The second entry in the second block of Table XII is believed to be a mistake. It shows "0.00 spacing"; but no such case was studied. Furthermore, elsewhere in the table, the spacing, S, appears to increase moving down the table. An argument to the contrary is that the second and third critical height columns do not agree well with one another under this assumption. The sixth column lists the number of arms involved in a critical configuration. Cases where extrapolations were used usually resulted in non-integral numbers of arms, a difficult concept to visualize. The last column associates the geometry studied with one of the figures. Two cases in Table XII may be in error with respect to figure number. The last two entries in the second block were claimed to have been associated with configurations where arms contacted the Central Column at $45^{\circ}$; but a careful examination of actual experiments suggests that both may have involved cases where the arms were perpendicular to the column. This ambiguity is shown in the table. No figure exists truly corresponding to the last entry of Table XIV; but Fig. 17 is close substituting square arms for the circular ones shown. 
Table XIII is similar to the other two with a few exceptions. All critical conditions are extrapolated; so references to Log Book data are less relevant. The first line suggests that an infinitely tall array of arms extending off just one face would be just critical. The basis for that assessment is unclear; and which experiments might suggest that conclusion is equally unclear. The last entry leads to another confusion. The published document suggests that criticality would occur with six arms and the Central Column "full", that is, $\mathrm{H}_{\mathrm{c}}=2435.4 \mathrm{~mm}$; but the Log Book suggests a critical height of $1710 \mathrm{~mm}$. This discrepancy is not at all understood. Four essentially identical experiments relate to this particular geometry; and these sequence numbers are enclosed in curly braces. This result is not based on any extrapolation.

Fortunately, the difficult-to-interpret results predicting criticality for non-integral numbers of arms were derived for all three arm diameters. These three critical points were graphed against one another; and the result appears in Fig. 25. This curve can then be used to estimate critical diameters for whole numbers of arms which are more physically understandable. For example, twelve arms (four vertical stacks of three) would appear to be critical at a diameter of $122 \mathrm{~mm}$. A reasonable estimate for 20 arms is possible: about $112 \mathrm{~mm}$ diameter. Although a long and questionable extrapolation, a further argument could be made that the diameters of an infinite stack of arms off each of the four faces might be somewhere about $100 \mathrm{~mm}$.

A lengthy extrapolation to the right yields an interesting limiting value. The curve would seem to extrapolate to criticality for four arms at, perhaps, an arm diameter of about $230 \pm 30 \mathrm{~mm}$. This is the fewest number of arms possible for this configuration because the initial conditions specify one arm off each face; and there are four faces. This asymptotic configuration, then, would resemble three mutually perpendicular "pencils" of solution much like coordinate axes of three-dimensional Cartesian space. The Z-axis would be represented by the square Central Column and the other two by the 230 -mm-diameter very long arms extending in both positive and negative directions. 
Table XII. Derived Critical Parameters from RFP-1197 for Arms of All Three Diameters Extending at $90^{\circ}$ Off All Four Faces of the Central Column.

\begin{tabular}{|c|c|c|c|c|c|c|}
\hline \multicolumn{3}{|c|}{ Critical Solution Height Parameters (mm) } & \multirow{3}{*}{$\begin{array}{c}\text { Probable } \\
\text { Experiment } \\
\text { Sequence } \\
\text { Number }\end{array}$} & \multirow{3}{*}{$\begin{array}{c}\text { Vertical } \\
\text { Spacing } \\
\text { Between Arms, } \\
\text { S (mm) }\end{array}$} & \multirow{3}{*}{$\begin{array}{c}\text { Number } \\
\text { of } \\
\text { Arms }\end{array}$} & \multirow{3}{*}{$\begin{array}{c}\text { See } \\
\text { Figure }\end{array}$} \\
\hline \multicolumn{2}{|c|}{ RFP 1197} & Log Books & & & & \\
\hline $\begin{array}{l}\text { above top } \\
\text { arm }\end{array}$ & \multicolumn{2}{|c|}{ relative to bottom } & & & & \\
\hline \multicolumn{7}{|c|}{$168.3 \mathrm{~mm}$-Outside-Diameter Arms } \\
\hline "full" & "full" & $\mathrm{N} / \mathrm{A}$ & [extrapolated] & 0 & 5.8 & 16 \\
\hline 18.0 & 1238 & $\sim 1238$ & 96 & 88.9 & 8 & 16 \\
\hline 50.0 & 1283.1 & 1252.3 & 97 & 101.6 & 8 & 16 \\
\hline 108 & 1360 & 1345 & 98 & 114.3 & 8 & 16 \\
\hline 1167 & 2435.2 & $\sim 2435$ & 99 & 131.8 & 8 & 16 \\
\hline "full" & "full" & $\mathrm{N} / \mathrm{A}$ & $\begin{array}{c}73,74,75] \text { or } \\
{[100-103]}\end{array}$ & 168.3 & 12 & 16 \\
\hline "full" & "full" & "not critical" & {$[31,32,33,103]$} & 168.3 (offset) & $\infty$ & 19 \\
\hline \multicolumn{7}{|c|}{ 141.3-mm-Outside-Diameter Arms } \\
\hline "full" & "full" & N/A & [extrapolated] & 0 & 7.95 & 16 \\
\hline 1260 & 2552 & unspecified & 49 & 6.35 & 8 & 16 \\
\hline 111 & 1416 & 1260 & 50 & 12.7 & 8 & 16 \\
\hline 76.7 & 1457 & 1474 & 54 & 50.8 & 12 & 16 \\
\hline 623.6 & 2000 & 2000 & 59 & 53.975 & 12 & 16 \\
\hline 796 & 2435 & unspecified & 69 & 76.2 & 16 & 16 \\
\hline "full" & "full & 2350 & 74 & 69.85 & 16 & 16 or 19 \\
\hline "full" & "full" & 2403 & 67,68 & 44.45 & 12 & 16 or 19 \\
\hline 11.2 & 1335.6 & 1335 & 64 & 25.4 & 12 & 16 or 19 \\
\hline \multicolumn{7}{|c|}{ 114.3-mm-Outside-Diameter Arms } \\
\hline "full" & "full" & $\mathrm{N} / \mathrm{A}$ & [104-106] & 0 & 16.65 & 16 \\
\hline
\end{tabular}

[]$=$ Extrapolated from some set of subcritical experiments.

Table XIII. Derived Critical Number of 168.3-mm-Outside-Diameter Arms Extending in Vertical Contact and $90^{\circ}$ Off One or Two Faces of the Central Column and With That Column Full of solution (from RFP-1197).

\begin{tabular}{|c|c|c|c|c|c|}
\hline $\begin{array}{c}\text { Number of } \\
\text { Faces With } \\
\text { Arms }\end{array}$ & $\begin{array}{c}\text { Orientation } \\
\text { Between } \\
\text { Planes }\end{array}$ & $\begin{array}{c}\text { Probable } \\
\text { Experiment } \\
\text { Sequence Number } \\
\text { Relevant }\end{array}$ & $\begin{array}{c}\text { Log Book } \\
\text { Comments } \\
\text { Addressing } \\
\text { Criticality }\end{array}$ & $\begin{array}{c}\text { Critical Number } \\
\text { of Arms }\end{array}$ & $\begin{array}{c}\text { See } \\
\text { Figure }\end{array}$ \\
\hline 1 & N/A & $?$ & -none- & $\infty$ & 12,13 \\
\hline 2 & opposite & {$[87$ to 93$]$} & N/A & 18.25 & 14,15 \\
\hline 2 & adjacent & $\{15$ to 18$\}$ & $\mathrm{H}_{\mathrm{e}}=1710 \mathrm{~mm}$ & 6 & 17,18 \\
\hline
\end{tabular}

[] = Extrapolated from this set of subcritical experiments.

\{\}$=$ Obtained from a set of experiments but not an extrapolation. 
Table XIV. Derived Critical Parameter from RFP-1197 for Arms of Three Cross Sectional Sizes Inclined at $45^{\circ}$ From the Central Column.

\begin{tabular}{|c|c|c|c|c|c|c|}
\hline \multicolumn{3}{|c|}{ Critical Solution Height Parameters (mm) } & \multirow{3}{*}{$\begin{array}{c}\text { Probable } \\
\text { Experiment } \\
\text { Sequence } \\
\text { Number } \\
\end{array}$} & \multirow{3}{*}{$\begin{array}{c}\text { Vertical Spacing } \\
\text { Between Arms, S } \\
(\mathrm{mm})\end{array}$} & \multirow{3}{*}{$\begin{array}{c}\text { Number } \\
\text { of } \\
\text { Arms }\end{array}$} & \multirow{3}{*}{$\begin{array}{l}\text { See } \\
\text { Figure }\end{array}$} \\
\hline $\mathrm{RF}$ & & Log Books & & & & \\
\hline $\begin{array}{l}\text { above top } \\
\text { arm }\end{array}$ & \multicolumn{2}{|c|}{ relative to bottom } & & & & \\
\hline \multicolumn{7}{|c|}{ 168.3 mm Arms. All Four Faces Offset Arms } \\
\hline "full" & "full" & $\mathrm{N} / \mathrm{A}$ & [19 to 30$]$ & 240 & 6 & 23 \\
\hline 282 & 1859 & 1972 & 25 & 238 & 6 & 23 \\
\hline \multicolumn{7}{|c|}{ 141.3-mm-Arms. All Four Faces Not offset Arms } \\
\hline "full" & "full" & $\mathrm{N} / \mathrm{A}$ & {$[80,81]$} & 156 & 8 & 22 \\
\hline 304 & 1643 & 1643 & 82 & 147.6 & 8 & 22 \\
\hline 121 & 1432.6 & 1433 & 79 & 122.2 & 8 & 22 \\
\hline \multicolumn{7}{|c|}{ 177.8-mm Square Arms Off Adjacent Faces } \\
\hline 122.4 & 1196 & 1196 & 85 & N/A & 2 & $18^{\mathrm{a}}$ \\
\hline
\end{tabular}

a. Similar to Fig. 18 but only one square arm extending at $45^{\circ}$ (not $90^{\circ}$ ) off adjacent faces.

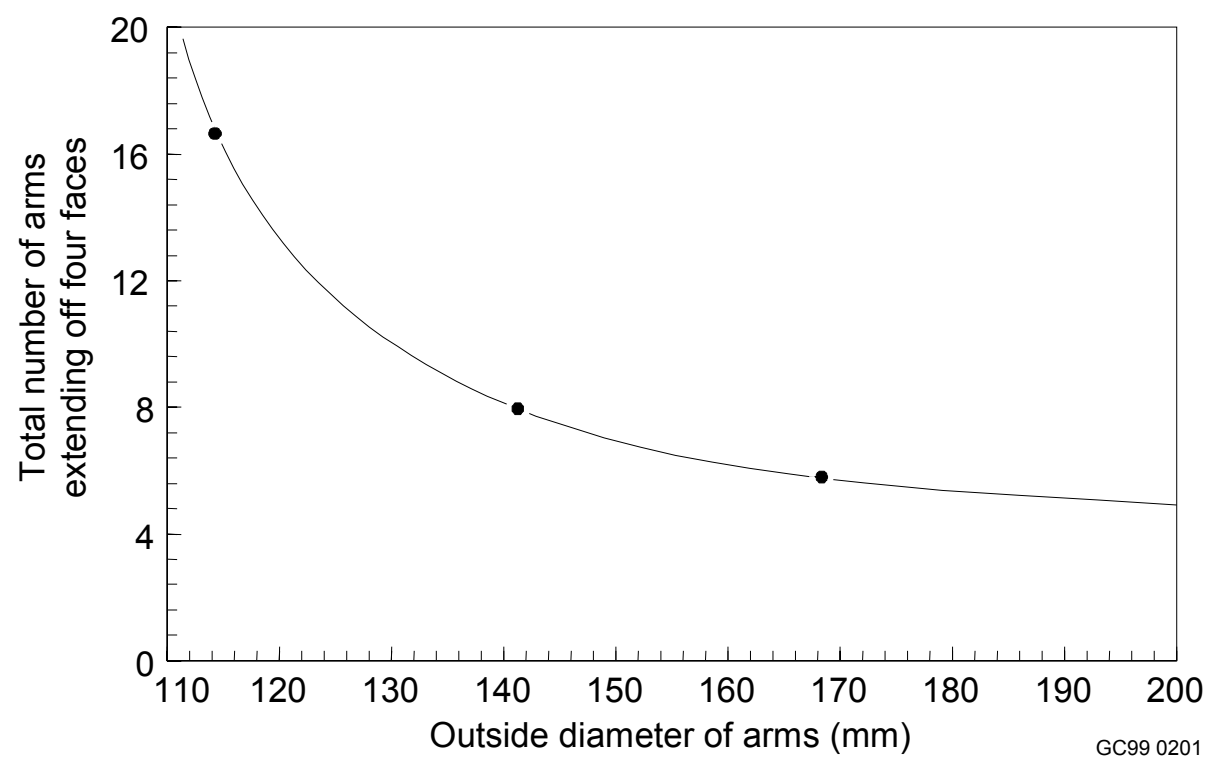

Figure 25. The derived critical number of arms of the three diameters used in this program when the Central Column was full (essentially infinite) were non-integral units; but graphing the two parameters against one another permits estimates for physically real situations involving integer numbers of four arms $(4,8,12,16,20$, etc. $)$. 


\section{UNCERTAINTIES}

This experimental program, more than any other at the Rocky Flats CML, exhibits a wide variability in accuracy of descriptions of individual experiments. The principal weakness probably involves geometrical parameters, especially arm elevations. As a result of this, some experiments may be accurately described while others are not. One experiment may describe arm elevations and other parameters quite well such that good agreement is attained when compared with computer code results. The next experiment may appear to be equally well described but yield much poorer agreement. Still other possibilities exist. Experiments which do not appear to be completely defined because some parameters may be left to inference (one arm elevation recorded along with arm spacings and diameter) may yield quite good agreement; or they may not. The reason for this range in validation comparisons lies mainly with the variability in accuracy and precision of specifications of arm elevations. Viewed differently, the failure of recorded arm elevations to be consistent with expected elevations calculated from arm diameters and spacings probably contributes to this variability in code validations.

The computer code validator is admonished not to dismiss the entire program on the basis of poor agreement found for any one case. Each comparison should be evaluated on its own individual merits because of this expected variability in description precision. Some are expected to agree well; others, not.

Uncertainties usually may have one of four meanings depending upon application. Which is used is made clear in the text, although the first one was probably not used at all.

(1) The first was where the uncertainty is the conventional standard deviation calculated for a statistically significant numbers of samples. No parameter in this program was measured a sufficient number of times to warrant that statistical approach. Failure to employ this recognized standard in scientific reporting is laid to lack of experience on the part of the young experimenters.

(2) The second kind of uncertainty concerns measured experimental parameters. Two examples are discussed. Uranium solution heights - especially critical heights - certainly were not the result of multiple measurements as that would have been both expensive and risky. These uncertainties are simply good guesses at the confidence placed in the quoted value. Those guesses were based, in part, on the readability of a curved meniscus in a fairly small diameter plastic tube viewed by television from some distance away and through a plastic window. At least, an effort was made to view this height in about the 
same region of the television monitor ${ }^{29}$ to restrict any uncertainty to a systematic error. The guesses also were based on how a particular critical height was determined from the assortment of methods discussed in other sections. In conclusion, the precision of critical uranium solution heights varied between a few tenths of a millimeter to a few millimeters. A second example of uncertainties being just good guesses involves the location of arms up and down the Central Column. Various parameters related to this were measured and they were not always consistent with one another. This has been mentioned previously. For example, a configuration consisting of three arms in a single plane off one face with each arm having a diameter, D, and spacing, S, between them did not perfectly agree with the measured elevation of the underside of the lowest arm, a, and the distance down from the top of the Central Column, T. If the top of this Central Column is designated "CC", then this discussion may be written:

$$
\mathrm{a}+3 \mathrm{D}+2 \mathrm{~S}=\text { "CC" }-\mathrm{T}
$$

but this equation was seldom satisfied to better than a few millimeters. This precision statement is assumed to apply to the geometrical modeling of any set of arms along the tall Central Column.

(3) Thirdly, only a very few measurements of some parameters were made. The number was too few for a good statistical analysis but more than one. In these cases, the uncertainty was estimated based on this author's personal observation that the range over a small set of measurements is often a good estimate of about three times the standard deviation a much larger set of measurement on the same parameter would have. This notion is not at all mathematically rigorous. Still, some uncertainties may have been unconsciously estimated in this fashion.

(4) Many times, the uncertainty expressed represents the consequence of missing or never recorded information. An example is the uranium concentration of the fissile solution. Therefore, following this fourth concept of an uncertainty, the concentration claimed for this program lies between the first and third and has a larger uncertainty proposed to cover missing information.

${ }^{29}$ One of the major contributors to difficulty in reading calibrated scales via television was not recognized during this program. Once recognized (in the early 1970s), the problem was easily fixed. Fiducial markings on the calibrated scale sometimes became confused with the retrace lines generated by the flyback transformer on the television monitor. This was eventually solved by rotating the television camera 901 so the markings on the scale were at right angles to the retrace lines. This improvement brought astounding clarity to these readings. 
Even when uncertainties are not specifically given, the number of significant figures expressed approximately signify confidence in the value. Some uncertainty is presumed to exist in the last significant figure. For example, the square dimensions of the solution base is stated as $1.50 \mathrm{~m}$. This suggests that its size would not have been measured to the nearest millimeter in which case the parameter would have been recorded as $1.500 \mathrm{~m}$. On the other hand, it was not so crudely measured as to be recorded as $1.5 \mathrm{~m}$, a truly coarse estimate. Any deviation from this policy tends toward giving too many significant figures. The Central Column, for example, was probably not actually $2435.4 \mathrm{~mm}$ tall. That precision is a concession to faithful reporting of dimensions recorded in Log Books and when making conversions from English to metric units.

Another application of this notion is the specification of nominal values for commercial stock items. Most such items are well-controlled in their manufacture such that catalog dimensions are quite accurate. The diameter of commercial stainless steel tubing, such as used for the arms, is probably accurate to a few parts in 10,000. The thickness of this stock is equally well known. Therefore, these diameters are expressed to four significant figures. Spacings between arms were usually measured with less precision; and this is reflected by fewer significant figures. Wood can shrink or expand a little with humidity; and variation in the thickness of nominal plastic stock has already been mentioned.

No material compositions were measured by analytical methods on samples from this program. Materials are simply reported by their common name; and elemental composition should be obtained from the literature ${ }^{30}$. The solution concentration uncertainty, discussed above, should not prove too troublesome because the concentration is so close to the broad range of concentrations corresponding to optimum moderation concentrations. One of the more important material specifications missing might be

${ }^{30}$ A argument is made that an analytical determination of elemental composition is not always better than assuming an industry-wide standard for that composition. Whenever many samples would be too expensive, difficult to obtain, or both, an elemental analysis is often deduced from a single sample. This single sample is subject to possible inhomogeneity such that it may not represent the whole in which case even a perfect analysis would yield wrong results. A single sample is also subject to unavoidable analytical uncertainties since most analytical techniques are not a great deal better than $\pm 1 \%$; and any error in laboratory technique would yield wrong results. Instead, a single sample of a common material readily available from a number of sources and manufactured under strict production controls is probably much better described by that industry-wide standard composition than by an analysis of a single sample. Alloys of aluminum, stainless steel, and steel and common plastics fall in this category. On the other hand, uncommon materials, ones with little manufacturing controls, or materials prepared in the field (such as concrete) should be sampled and analyzed. 
the precise composition of the stainless steel used in the Central Column and the arms. Whether this was Type 304 or Type 316 may make a difference. This might be important because the metal was so close to the fissile liquid. Precision in elemental composition is more important for components which are a major influence on reactivity. Close in and larger items also need better understanding. The stainless steel of the column and arms is more important than the walls of the Assembly Room Hood; and that is more important than the composition of the concrete walls of the Assembly Room.

The precision of the measurement of the uranium solution height varies in importance. Those on the level with the complex array of arms, fill hoses, and the Central Column ought to be specified much more precisely than those close to situations approaching the so-called "infinite critical cylinder height". Here, several millimeters uncertainty can easily be tolerated. How well this goal was actually met is open to debate.

The accuracy of this parameter is another issue. Solution heights were determined from three meter-long printed wooden sticks stacked one on top of another. The biggest possible source of a systematic error would be the setting of the bottom of the lowest meter stick at the correct height to represent the very bottom of the solution column. If that were a millimeter high or low, the error would enter into every critical height measurement. Considerable care was given to setting this scale such that zero corresponded to the very bottom of the solution column. A second source of systematic error would be any possible gap between any two of the three meter sticks. A third possible error, although quite small, would be a slight tipping of the linear scales such that they might not be truly vertical. This is small because the cosine function changes very slowly from unity for very small angles.

The transformation of all solution height data to a new height-related parameter is strongly suggested. This translation has not been accomplished in this document but is left to the computer code evaluator. That new parameter would be a height relative to arm elevations, not the bottom of the column. The reason for this is that arms were clustered near the center of the Central Column leaving long portions above and below to the top and bottom of the column, respectively. To the extent that both lengths approach anywhere close to "effectively infinite", an error in locating the bottom of the height measuring scale does not affect criticality readings any more than the discussion earlier about cases for which criticality occurred well above the arms. That new parameter might be, for example, the uranium solution height above the underside of the lowest arm of the whole array. 
In modeling any configuration, the important parameter to make the model as accurate as possible is the critical height of the solution relative to the elevations of the arms. This, then, accounts for effectively infinite columns of solution above and below the arms. This may be the goal; but it will be difficult to achieve. This is so because vertical distances were measured relative to different points; and these points were only assumed to have been in the same horizontal plane. The sight gauge which was used to measure all solution heights was a distance away from the Central Column and only attempted to be located in the same plane as the bottom of the Central Column. Arm elevations, on the other hand, were, indeed, measured relative to the actual bottom of the column. Distances down from the top of the column to the top of the highest arm can, likewise, be considered measured relative to the bottom of the Central Column, although indirectly so.

Considering these differences, the possibility exists that a systematic error could exist between solution height measurements and arm elevations. Happily, this error would be systematic throughout all experiments within this program. If computer validations of supposedly critical measurements were found to consistently predict the same degree of subcriticality or super criticality, code evaluators might choose to use a few experiments to determine a potential bias correction that would force critical predictions for critical experiments. Then, the same bias correction could be applied to all other cases. 


\section{LESSONS LEARNED}

Two events with possibly unnerving consequences happened during this program. Nothing bad actually happened; but the potential for a nuclear criticality accident was increased somewhat on both occasions. Both situations were the result of an incomplete understanding of the physics involved and a blind assumption that all systems would always function normally. Reasonably credible upset conditions were not taken into account. Both events are discussed here in an attempt to warn future people engaged in handling fissile solutions to consider all possible modes of failure. This author accepts some responsibility for this naive approach to experimental design concerning the second of the events. The first would probably never have been anticipated given any amount of pre-engineering review.

\section{$\underline{\text { Vent Line Overflow }}$}

A significant discharge of uranyl nitrate solution into an unanticipated location occurred during this program. This misdirected solution, which had occurred in increments on a number of occasions, had continued undetected for several days prior to its discovery. Over that time, an unknown volume of fissile solution in unknown increments had been removed from of the once-presumed "closed-loop" solution handling system. These discharges occurred toward the end of each of an unknown number of experiments. The misdirected solution passed into a critically unsafe geometry, described below; and this alone constitutes a potentially dangerous situation. Fortunately, the problem was detected well before a sufficient quantity of solution had accumulated to cause a criticality accident; but that was just a stroke of good luck. It is disquieting when nuclear criticality safety is the consequence of good luck.

This analysis of the physical phenomenon at the root of this problem may prove useful in preventing future undesirable releases of fissile solution into critically unsafe geometries. Perhaps this lesson learned may prevent a criticality accident somewhere at some time in the future. If so, it is worth describing in some detail.

Well over twenty liters of high-concentration uranyl nitrate solution had passed into a 250 -mmdiameter horizontal pipe buried just below grade level. The long length of the pipe limited the collected solution to a well-subcritical depth - thus preventing a criticality accident. The uranium solution had been stored in a set of nine critically safe tanks in one room and was connected by a single stainless steel line to a small system of valves, meters, and other plumbing components in another room normally. The fissile solution moved from one room to the other at the beginning of an experiment and flowed the 
opposite direction at its conclusion. The system in the latter room was often referred to as the "Solution Base" because it was the starting point for all critical approach experiments involving enriched uranium solution at the Rocky Flats CML. This storage and handling system contained in two rooms remained essentially unchanged from experiment to experiment and throughout the history of the facility. It was completely self-contained such that fissile solution ought never be misdirected from it. All systems were carefully engineered to prevent such inadvertent transfers.

Each experiment was performed in apparatus attached to this unchanging Solution Base. Experimental equipment, unlike the Solution Base, varied markedly from program to program. Furthermore, individual parameters even within a program varied from individual experiment to experiment. In the case of this study, those parameters were the number of arms branching off the Central Column, the diameter of these arms, the vertical spacing between them, the number of faces of the Central Column having arms, and a few others. Still, this program-specific apparatus was also carefully engineered to preclude inadvertent transfer of the solution away from the supposed closed-loop system.

That careful design failed to provide the needed integrity in this one program. Design engineers should not necessarily be faulted for this failure; the underlying physical phenomenon was very difficult to anticipate. Even after the accident had been discovered, many rejected the physical mechanism suggested which explained the obvious consequences. It was said to be "contrary to physical laws". They were proven wrong and the proposed physical mechanism confirmed by two means, both discussed later.

The situation was first discovered on November 30, 1967, following an experiment within this program. During routine end-of-experiment shutdown procedures, a small pile of dried, yellow, uranium salt crystals was discovered on the floor of the stainless steel enclosure surrounding the Solution Base. These crystals were in the form of dried droplets of solution; and they spanned an area about one to two meters in diameter. From the splatter pattern, the source of the contamination was easy to determine. It was a clear plastic vertical tube which had been installed as part of another solution study to be performed at another time. It was to have been a sight tube ${ }^{31}$ in that other study. The installation had never been used or exposed to uranyl nitrate solution; so it was difficult to understand how the inside of that tube had become contaminated. In fact, bottom connections to that sight tube had been temporarily removed a few

${ }^{31}$ A "sight tube" is a transparent vertical line used to measure the fissile solution height within the apparatus via closed circuit television. 
weeks earlier to make room for some other valves and solution lines associated with still another program. The plastic tubing had been left in place connected to the laboratory's ventilation line. This line ran high above the floor and served all uranium solution systems as a vent. It was connected at the top to the clear tubing even though the tubing hung free. An elevation drawing of the situation during discovery is shown in Fig. 26.

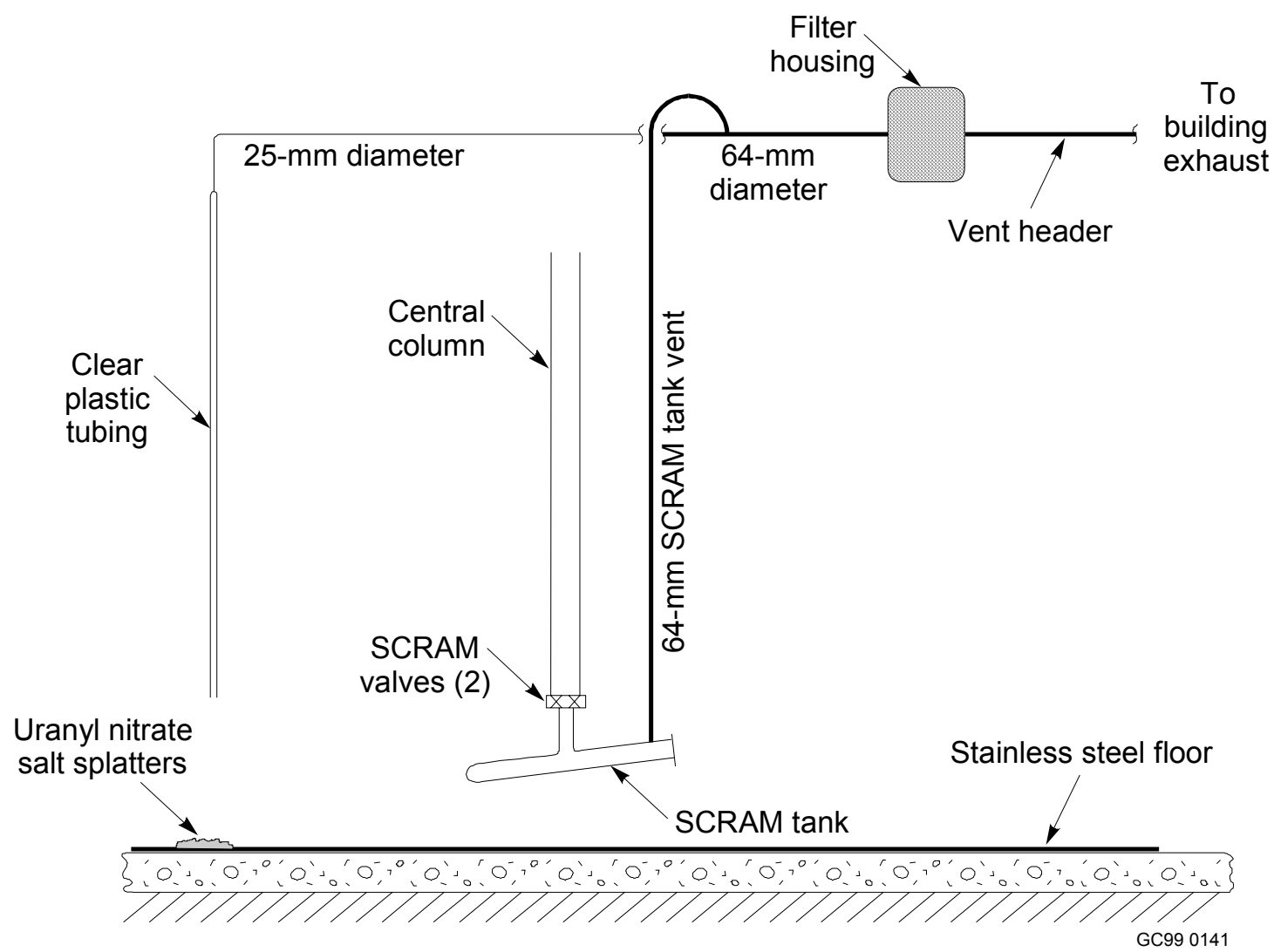

Figure 26. Splatters of dried droplets of uranyl nitrate solution were found on the stainless steel floor as indicated at the lower left of this elevation drawing of a portion of the experimental apparatus. The discovery was made November 30, 1967. The liquid had obviously fallen from an unused length of clear plastic tubing attached to a very high horizontal line which served as a ventilation header leading, in turn, to the building's exhaust system for potentially contaminated air. This header stood well above the highest point to which solution could possibly rise in the experimental apparatus it vented; and diameter of the horizontal line connected to the filter housing are shown.

This ventilation line was still connected to the vent from the SCRAM tank (safety shutdown tank) associated with the present program. This provided a path for escaping air from the SCRAM tank if uranium solution were ever admitted to it at any time. The unused line leading in the opposite direction 
and having the open-ended plastic tube dangling from it was ignored. It was believed that it would never see fissile solution; so why consider it? That horizontal ventilation line was near the top of the Assembly Room Hood and well above (nearly a meter) the maximum height ever attained by fissile solution during any experiment.

That line had a paper air filter in a housing between the SCRAM tank and the building's contaminated air exhaust system. That paper filter was contained in a metal box about $180 \mathrm{~mm}$ square and about $250 \mathrm{~mm}$ high with a removable cover plate on one face. The day after the initial discovery, that filter box was opened with the intention of just confirming that the solution, which had obviously gone the opposite direction, had not also traveled so far as to contact this filter housing. Upon opening the box another surprising discovery was made. The entire housing was almost completely packed with damp uranyl nitrate salt! The salt was not so fluid as to run out the opened face of the box; but the yellow iridescence of the contents produced surprise and alarm to the eyes of this author!

The immediate concern was the potential for a prompt criticality accident which could have occurred had parameters been just a little different. The volume of the nearly cubical box may have been close to critical dimensions. It was a large enough volume to be not immediately obvious that it was critically safe. While the damp salt was clearly seen to be significantly under moderated, it still contained a significant amount of water and, therefore, moderation. A second and immediate realization and related to the first safety concern was that the close proximity of body and arms of the person opening the box most certainly would have constituted a significant neutron reflector on at least some surfaces. Workers expressed significant relief that a nuclear criticality accident had not, indeed, happened. Perhaps the absence of a nuclear accident during this event was simply another stroke of good luck.

In contrast, filter housings installed in similar applications elsewhere within the CML were much larger. The author recalls that those atop storage tanks may have been as large as $250 \mathrm{~mm}$ square by 400 $\mathrm{mm}$ long, although these estimates are not certain.

At this point, several projects were begun simultaneously; and each is elaborated in the following paragraphs: (1) The damp salt in the filter housing was removed and as much recovered as possible. (2) The horizontal ventilation line near the top of the hood was removed and cut into short lengths to recover those salts also. (3) A large rectangular hole was cut into the building's 250-mm-diameter ventilation line to view inside for possible contamination. These projects led to other tasks. 
The cover plate to the filter housing had been returned, again enclosing the housing, only moments after discovering uranium within it. A few days later, the again-sealed housing was disconnected from the horizontal ventilation line along the top of the hood, bagged, and moved to another room where it was placed inside an open-faced hood with a controlled air flow into it. Loose salts above and below the filter medium were carefully collected for recovery. About $2 \mathrm{~kg}$ of "yellow cake" was collected and dissolved easily in about 3 of $1 \mathrm{~N}$ nitric acid. This uranium, once filtered, was returned immediately to the storage tanks.

The heavily uranium-laden paper filter medium was carefully removed from inside the housing and gently kneaded and shaken to loosen uranium salts. These salts were also collected for later recovery, dissolution, and eventual return to the storage tanks. The heavily contaminated filter paper medium was even washed in nitric acid (up to $10 \mathrm{~N}$ ) to dissolve and recover as much uranium as possible. These wads of paper were squeezed in the gloved hand for a more-complete recovery. The still-yellow paper, by now reduced almost to pulp, was returned to a container of fresh water for further dissolution. This water had to be filtered to separate the uranium solution from the paper fibers. When the paper was judged to contain no more recoverable uranium, both the metal housing and paper pulp were discarded. Even the final filter papers used in the filtering of the filter media pulp were rinsed and, in turn, filtered to recover as much uranium as possible. Over nine kilograms of uranium were recovered in this operation and eventually returned to the solution tank storage farm.

The short lengths of horizontal ventilation line consisted of two sizes. The supposedly uninvolved stainless steel line leading to the clear plastic tubing was nominally $25 \mathrm{~mm}$ pipe; and the stainless steel line between the SCRAM tank vent and the building's exhaust system for contaminated air was nominally $64 \mathrm{~mm}$ in diameter. Both were found to contain a small amount of dried salts; but most of the uranium had collected in the filter housing and in the underground buried exhaust duct. These were removed from the pipes as described below and collected. The last amount had to be scraped from the 25-mm and 64 $\mathrm{mm}$ pipes which were then rinsed with water before being discarded. Not much uranium was recovered from these smaller diameter pipes.

Fissile solution had obviously passed through the now-plugged paper filter because dried salts had been recovered from beyond the housing. To explore just how far uranium solution had traveled, a rectangular hole was cut into a vertical segment of that 250-mm-diameter exhaust duct. The hole was large enough to permit easy viewing inside the pipe. The hole was about $4 \mathrm{~m}$ past the plugged filter 
housing and a little over a meter above the floor. That vertical line was designed only to carry contaminated air from the experimental area to a below-grade horizontal run of this $250-\mathrm{mm}$ pipe. It was never intended to contain solution. This buried line, in turn, led to a large, multi-stage filter plenum. Following this plenum, the once-contaminated air was considered pure enough to release up the stack to the atmosphere. A simplified schematic drawing of the building's exhaust system for potentially contaminated air is shown in Fig. 27.

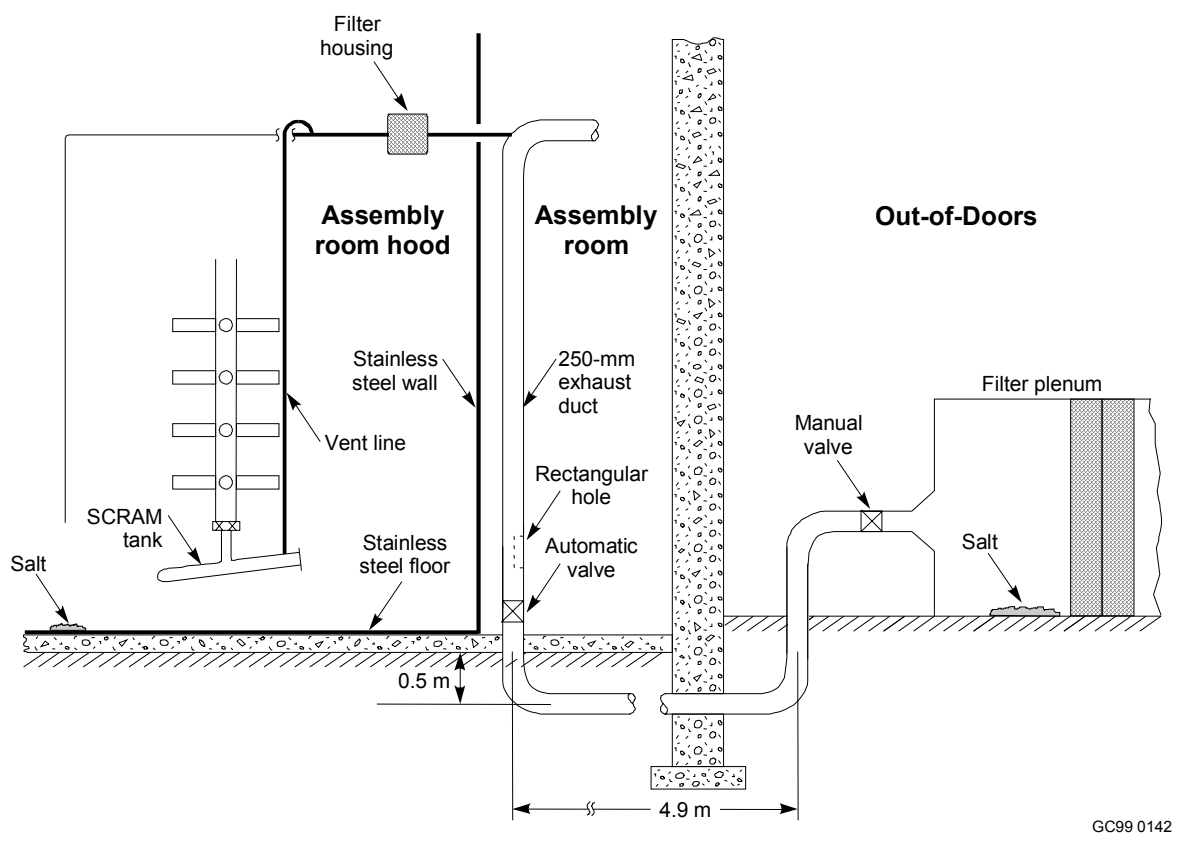

Figure 27. Regions of the ventilation header and the building's exhaust system heavily contaminated with uranium salts are labeled in this elevation drawing. One hypothetical tree-like experiment is shown to the left. The Assembly Room Hood is separated from the Assembly Room by a thin stainless steel wall. The dotted rectangle just above the automatic valve marks the opening cut into the exhaust duct when the incident was first discovered. Exhaust air passed through the east wall of the Assembly Room (shown in concrete cross section) before rising above grade only to pass into the filter plenum. There, the air passed through filter banks (crosshatched) shown to the far right before being released to the atmosphere through a chimney off the drawing to the right. The drawing is not to scale. Bends into other planes have been ignored in this 2-dimensional schematic drawing. 
Once the rectangular hole had been cut, a depressing scene was revealed. Dried and brightly colored yellow salts of uranyl nitrate spotted and streaked down $10 \%$ to $40 \%$ of the visible interior of this line. Although streaks were thin, they extended as far as could be seen inside this line. Thicker layers of dried salt were found all over internal surfaces of the Butterfly Valve - a distance below the opening and just above the floor of the Assembly Room. Obviously, a lot of uranyl nitrate solution had passed through the filter housing before it plugged up. The butterfly valve operator can be seen near the bottom of the photograph of Fig. 28. The location of the rectangular hole is revealed by the patch seen bolted to the exhaust duct in the middle of the photograph.

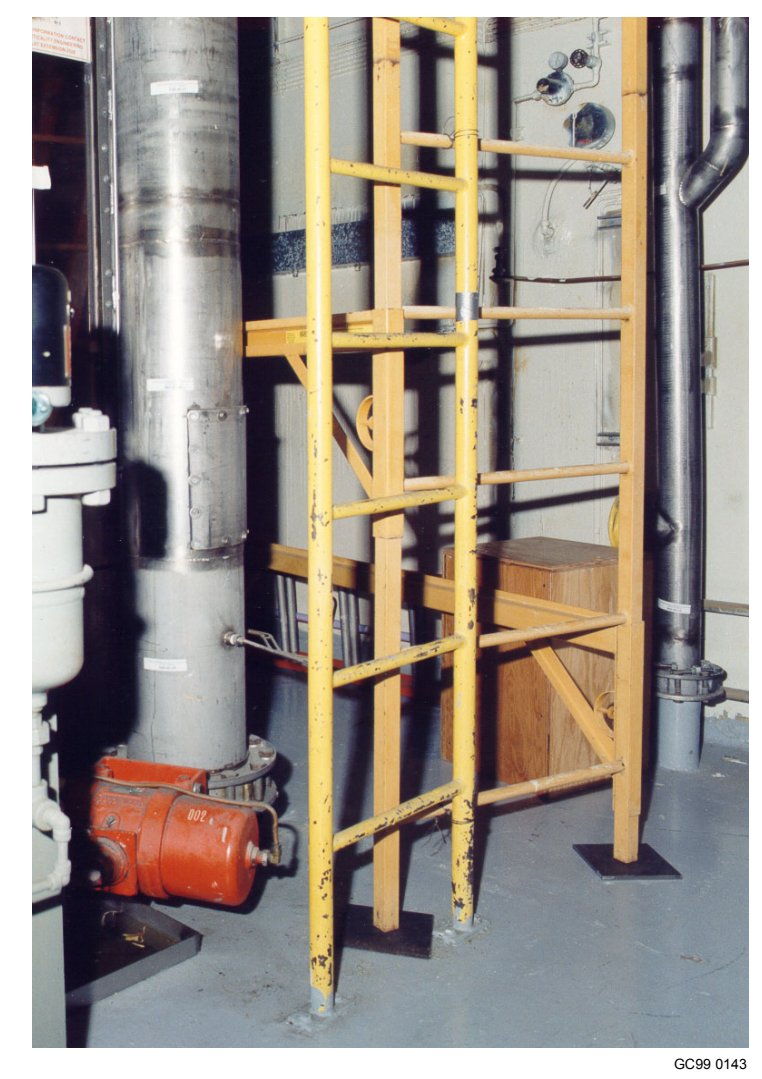

Figure 28. The vertical leg of the 250-mm-diameter building exhaust duct is shown to the left as it enters the floor of the Assembly Room. Just below grade, the line curves and leads horizontally under the wall seen to the right background. The cover plate (seen on the right side of the duct in the middle of the photograph) was later installed over the hole cut into this line to view for the first time the extent of this contamination incident. Close inspection above that patch shows the weld seam when the length of exhaust line was reinstalled after completing cleanout. The horizontal object at the bottom where the duct enters the floor is the butterfly valve discussed to in the text. 
To facilitate cleanup and recovery of these dried salts from this large-diameter exhaust line, a 1.5 $m$ length was removed just above the Butterfly Valve. The weldment upon returning the length after cleanup can be seen to the left in Fig. 28 between the $4^{\text {th }}$ and $5^{\text {th }}$ rungs of the ladders. This removal permitted unobstructed views back up the vertical exhaust line as well as down into the buried portion of the line. Both views revealed a lot of dried uranyl nitrate salts. A mirror was lowered into the buried pipe to permit viewing the buried line several meters underground. The bottom of this line was covered by a thick layer of uranyl nitrate salts as far as the hand-held light source could illuminate the interior of this 6.3-m-long underground duct. The river of dried salt was about $150 \mathrm{~mm}$ wide. The sight was most depressing; and the presence of such a large amount of fissile material in critically unsafe containers was disconcerting.

The Butterfly Valve was scraped clean of easily collected salts and washed. The partially cleaned valve was then bagged in plastic and stored until it could be returned to routine service. The long, underground, buried, exhaust duct proved a bigger challenge. A hoe was built to facilitate recovery of the salts as far as the arm could reach extended by the hoe's handle. The profile of the hoe matched the circular cross section of the duct; and this worked well to recover salts within a meter or so of the opening.

Reaching deeper into the abyss proved much more challenging. A child's roller skate was employed for this purpose! This formed a unique solution to the problem. Another scraper blade with the same profile as the bottom of the duct was fixed to the middle of the skate. A long string was attached to the front end; and a cloth parachute was fixed to the opposite end. The assembly was lowered into the duct and set on its wheels. Then, the exhaust ventilation was turned ON just slightly. The draft inflated the parachute and pulled the skate deep into the blind duct work. The ventilation was turned OFF; and the skate was slowly drawn back toward the opening by the long string. The blade scraped the salt from the bottom of the duct and plowed it back toward the opening. From there, it could be retrieved using the long-handled hoe. This procedure was repeated many times until not a great deal of salt was collected per operation.

A considerable amount of salt still remained. It could be seen stuck to the bottom of the duct such that the roller skate would have just ridden over the hard-to-remove yellow cake. After discussion with safety personnel, a quantity of warm water was poured down into the horizontal duct. This water 
was intended to dissolve the stuck salt and put it into the form of a damp paste. The roller skate withdrawal procedure was repeated several times collecting additional uranium.

With a significant number of kilograms of uranium retrieved from this underground duct and an unknown remnant still contained there, the question naturally surfaced: "How much further did the dried salt propagate toward the exhaust stack?" The buried duct again rose above grade just outside the building and led into an open chamber in front of the first of two closely spaced banks of HEPA filters. The front face of the first filter bank was found to be somewhat contaminated; but this was expected. Thankfully, the back face of the second set of filters was found to be completely free of contamination. The furthest point of the salt propagation had been determined; and, fortunately, no contaminated air had ever been released to the atmosphere via the tall stack.

The chamber in front of the first bank of HEPA filters did present one surprise during this investigation. When the door to this chamber was opened from the out-of-doors, a layer of well-dried uranyl nitrate salts were observed lying on the stainless steel floor in front of the first bank. The size of this layer is difficult to estimate except from pure recollection because the floor area was not recorded. It was an approximate circle probably between 200 and $400 \mathrm{~mm}$ in diameter.

At this point, the author made another error in judgement and learned a second lesson. Not wanting to disrupt the building's flow, he made the decision to collect these salts off the floor without shutting down the exhaust fan. The task seemed simple enough. The salt crystals were very dry and appeared to be quite stable on the floor; and the air flow appeared to be well above the salt. The plan was to slide a thin sheet of metal under the salt such that they might be transferred into a wide-mouth bottle to be carried back inside the building. The problem was that the air flow really did sweep low across the top of the salt collection. Even though not much air flow could be felt just above the layer, sufficient turbulence existed only millimeters above it such that the very first minimal disturbance of this collection caused a puff of yellow salt to become caught up in the air stream. This puff struck this author in the face causing considerable surface contamination of the skin. Fortunately, contamination was limited to the skin; none was found in the eyes, nose, or mouth. Two facts contributed to a very red face that evening: embarrassment and the chlorine-based bleach needed to decontaminate the author's skin.

The amount of enriched uranium recovered from each of the several areas discussed on the preceding pages is presented in Table XV. These are very coarse estimates of the uranium and are almost 
Table XV. Estimated Weights of Enriched Uranium Eventually Recovered from Various Locations Following the Vent Line Overflow Problem Discovered November 30, 1967.

\begin{tabular}{|c|c|}
\hline Area Described in Text & Uranium (g) \\
\hline In-line filter housing close to experimental apparatus & 3100 \\
\hline Horizontal lines just before and after filter housing & 230 \\
\hline 250 -mm-diameter buried exhaust duct & 4100 \\
\hline On floor in front of first bank & 740 \\
\hline Front bank of HEPA filters & 900 \\
\hline Total & $\mathbf{9 0 7 0}$ \\
\hline
\end{tabular}

certainly underestimates of the amounts actually involved in the incident in some cases. A roller skate on the end of a long string run out into the dark abyss of an impossible-to-view hole is not likely to enable acomplete recovery of yellow cake. Whether $10 \%$ or $90 \%$ of the solution inadvertently misdirected into this exhaust duct was ever recovered is not at all known. Over $9 \mathrm{~kg}$ was recovered; how much remains is still unknown. That duct could, to this day, contain anywhere from a few grams to many kilograms of dried salts.

This author has discussed the potential for residual uranyl nitrate salts in that buried line with many people at Rocky Flats and elsewhere. All persons responsible for the disassembly of that Rocky Flats facility during the coming years are warned to be cautious of this particular area.

The cause of this unusual event was not at all easily explained. When viewed as a simple Ushaped tube composed of the Central Column and the vent line as vertical legs connected only by the SCRAM tank, laws of physics argue that the height attained in the vent line ought never exceed the highest height of solution in the Central Column. This is so regardless of the elevation of the bottom of the Central Column (that is, the length of the solution leg in that column) and also regardless of the differences in diameters. Therefore, even following a SCRAM of an experiment with the Central Column brim full, physical arguments suggest that the same solution could never rise above the initial height of the Central Column. Frictional losses, in time, would eventually end up with solution filling the SCRAM tank and both legs of the "U" to the same heights. 
Evidence, however, clearly shows that the fissile solution did rise much higher than that and did so on a number of occasions. Something was flawed in these physical arguments. After considerable discussion, an hypothesis was proposed which attempted to explain the obvious facts. Initially rejected as being physically implausible, two different demonstrations verified the truth of the conjecture; and these are described below.

The column of solution contained in the vertical Central Column just prior to opening the pair of SCRAM valves rested about $0.75 \mathrm{~m}$ above the entrance to the SCRAM tank which was full of air. Upon initiating the SCRAM action (opening these valves) solution plunged into the air-filled SCRAM tank. There, the uranyl nitrate solution mixed with the air because of the turbulence of the rapidly falling solution. Huge "gulps" of air would be trapped by solution as the splashing liquid sloshed about within the SCRAM system. Rather than expelling air up the vent line as anticipated, well ahead of the smoothly flowing solution, the liquid being pushed up the ventilation line was a random and varied mixture of uranyl nitrate solution and air.

This air/solution mixture may be viewed in two ways; but both produce the same explanation of the observed phenomenon. First, the contents within the vent line may be considered full density solution merely displaced upward by sometimes large cushions of air. Under this interpretation, the laws of physics discussed earlier are correct except that this solution would be displaced upward by the sum of the height of all air bubbles trapped within the solution. Second, the air/solution mixture may be considered a reduced density solution, $\rho$, with that density being the weight of full-density solution in a volume occupied by solution and air. Under this interpretation, the physical laws of hydrostatics would apply:

$$
\rho g H=\rho^{\prime} g H^{\prime},
$$

where $\mathrm{H}$ is the initial height of the full density $(\rho)$ solution and $\mathrm{H}^{\prime}=$ is the (greater) height of the lower density $(\rho ')$ air/solution mixture; of course, $g$ is the acceleration of gravity.

The first demonstration that validated this unexpected conjecture involved a glass model of the complex geometry involved. This was constructed with glass tubing of different sizes representing the Central Column, the SCRAM tank, and the ventilation line. A single glass valve was fused into the model to represent the two SCRAM valves. The "SCRAM" valve was closed and the "Central Column" 
filled with dark colored water. When the glass valve was opened, the situation shown in the photograph of Fig. 29 clearly demonstrated precisely the phenomenon postulated.

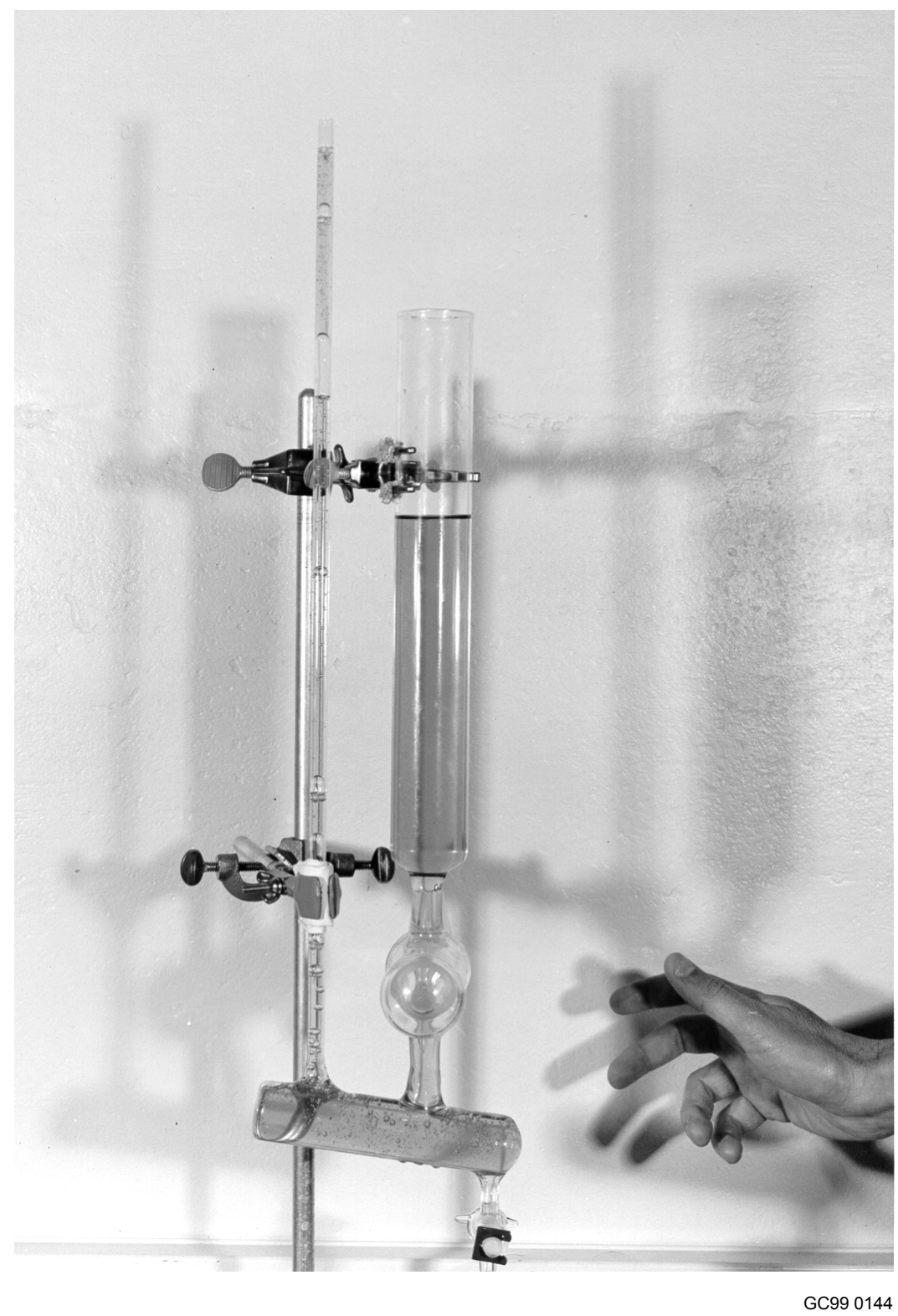

Figure 29. A glass model of the experimental apparatus clearly demonstrates the accident phenomenon. The large diameter tube represents the Central Column sitting on top of a single simulated SCRAM valve. The vent to the SCRAM Tank, at the bottom of the photograph, is represented by the smaller diameter vertical tube. Colored water in this demonstration clearly shows the liquid being broken up by large air bubbles. 
The second demonstration was even more dramatic. The vertical ventilation line leading from the SCRAM tank was disconnected from that system and temporarily rerouted back into the top of the tall Central Column via a length of 64-mm-diameter clear plastic tubing. This would indeed make a closedloop system out of the experimental apparatus because the entire system would exhaust into itself; and this configuration is shown in Fig. 30 approximately to scale except for the vertical legs of the Central Column and the vent line. The Central Column was then filled with uranyl nitrate solution as had been done many times before. When the SCRAM valves were opened, the uranium solution quickly dropped from view as it plummeted into the SCRAM tank. All remained quiet for a second or two. Then, suddenly, dozens of liters of yellow, foamy, frothy, liquid spewed through the clear tubing and gushed back into the Central Column. The photograph of Fig. 31 shows this curved length of large-diameter tubing. The tube does not appear clear because it was, indeed, full of high concentration uranyl nitrate solution. The fluid looked like yellow water gushing out of a firehose; but the realization that the fluid was concentrated uranyl nitrate solution added more gravity to the scene.

A movie camera was set up to view the Central Column from above and to record this unique occurrence for posterity. For the movie, the uranium solution was brought to within a few millimeters of the top of the Central Column. Suddenly, the solution droped out of sight. A very short time later, copious quantities of this liquid were disgorged into the Central Column in a most awe-inspiring scene. That very short motion picture reel has been donated to the National Archives at the Los Alamos National Laboratory. The movie has been converted to video; and both are stored there under Collection A-96051, Series \#17, Box \#43. The photograph of Fig. 31 is a copy of one frame from that 2-minute-long silent 8-mm movie film made January 26, 1968. 


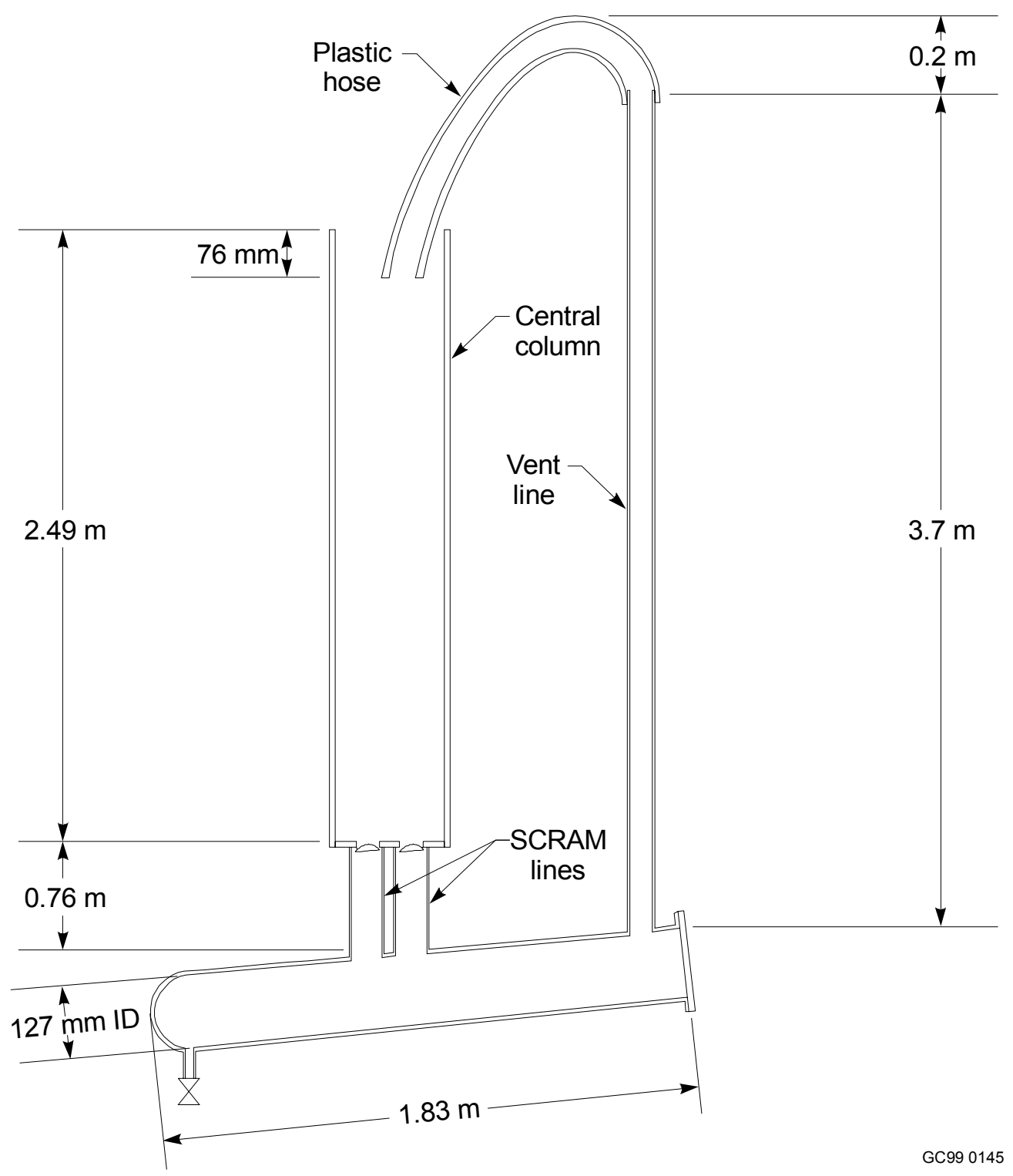

Figure 30. This closed loop ventilation system constructed after the contamination incident had been discovered was composed of the Central Column (left), the SCRAM valves and tank (bottom), the vertical ventilation riser (right), and the clear plastic hose (top) which passed solution back into the Central Column. The two SCRAM lines actually had two $90^{\circ}$ bends each and a total length of $1 \mathrm{~m}$. 


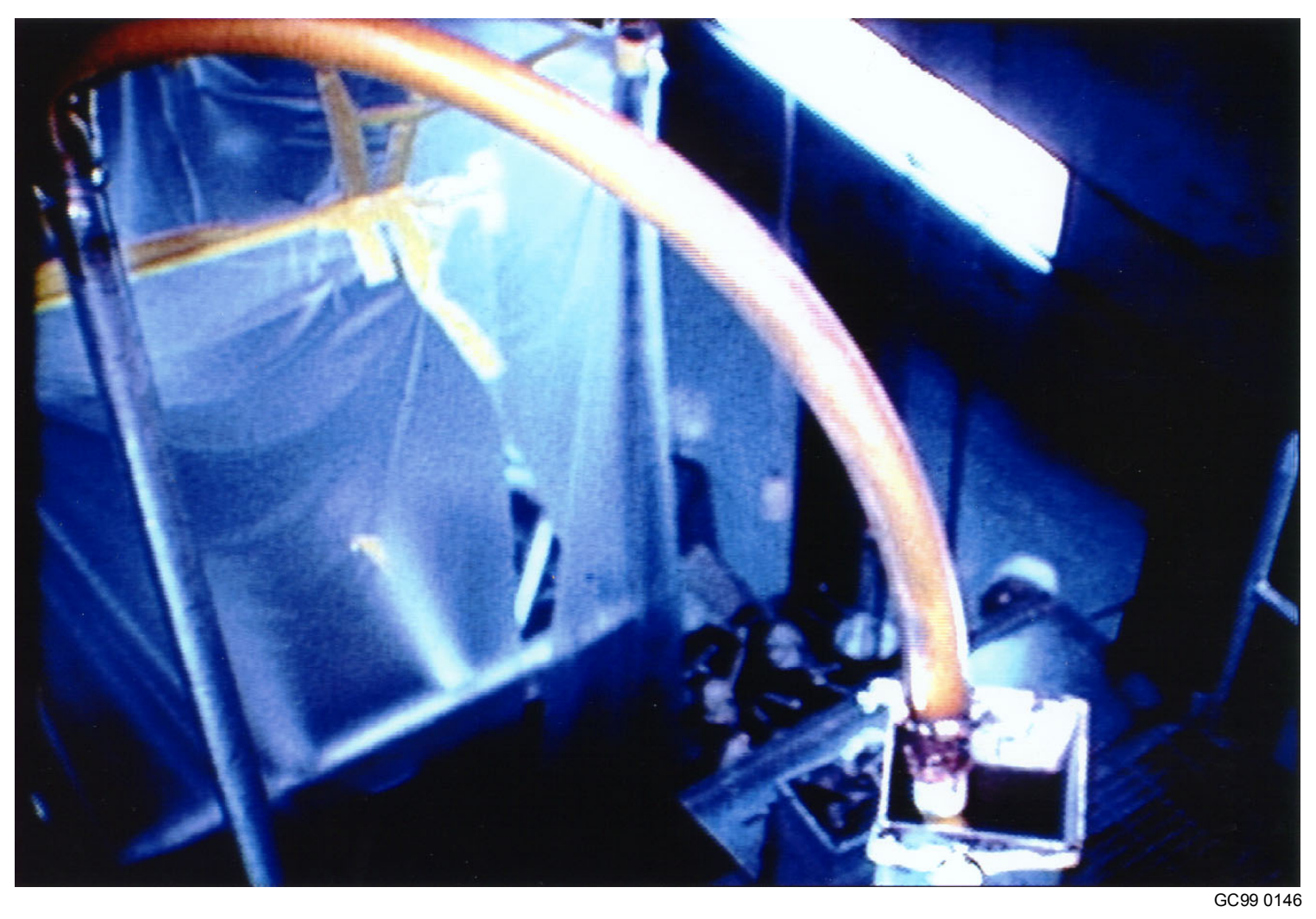

Figure 31. This photograph is excerpted from a 2-minute-long motion picture made of the ventilation line overflow problem. The accident phenomenon was demonstrated most graphically by reenacting the scene with actual equipment and uranyl nitrate solution. The curved plastic tube connects the vertical ventilation line (left) to the opened top of the square Central Column (lower right). The tube does not appear clear because it was gushing full of frothy, foamy uranyl nitrate solution during this frame of the movie.

\section{Inadequate Support for Arms}

One arm branching off the Central Column slipped on one occasion and collapsed toward the arm below it. This event occurred during the $103^{\text {rd }}$ experiment in this series. The date was January 22, 1968, less than two months after the discovery of the vent line overflow problem. In particular, the slippage occurred during the filling of that arm with fissile solution but before the arm was anywhere near full. The event was caused by inadequate support under the arm which failed. 
The experiment in question consisted of 12 arms with vertical stacks of three arms branching off each of the four faces. The spacing between arms equaled the outer diameter of each arm: $168.3 \mathrm{~mm}$. Arms extending in opposite directions were colinear with one another; and arms orthogonal to that vertical plane were similarly spaced but offset by $\mathrm{O}=\mathrm{D}$.

Each arm was supported above the arm below it by either wood or metal supports. The details of this support mechanism are not recalled; but simple logic dictates that some spacing support must have existed. When metal supports were used, they were probably short sections of slotted angle bolted between the vertical framework. When wood supports were used, they were rectangular blocks of 38.1mm-thick wood precisely cut and sanded to yield the desired separation between arms. When wood was used, it is recalled to have simply raised the arm above an otherwise stable arm. The wood blocks were held in place simply by the weight of the arm it supported and any fissile solution it might contain.

Logically, there were two potential supports per arm or 24 in all. One would be nearer the Central Column, the other, somewhere close to the far end of each. The text of the experimental Log Book presents the following possibly confusing statement as part of the post-incident discussion:

"Thus, of the 24 possible support points, half the supports were in place. This was a common practice for all runs up to today. Clearly, this is a bad practice. It will be stopped."

How half the supports could be missing and the tree retain any semblance of structural integrity is not clear three decades later. Unfortunately, details of the arm support mechanism are not recalled; and no additional explanation is given in the Log Book. Possibly, these metal or wood supports were in addition to a fundamental arm-support system; but that notion is mere conjecture.

The text further identifies which end(s) of which arms were supported with metal supports. It does not specify whether or not other support points were supported by wood.

Regardless of the details of arm support in general for this one experiment, at least one arm had at least one end supported above the supposedly stable arm below it by a wooden block. That block was not fastened in place but relied on the weight of the arm it supported to hold it in place. During routine filling of the apparatus, that wooden block slipped out of place and fell to the floor. This, in turn, allowed the arm to fall onto the arm below it. This metal-to-metal contact made a loud sound which was heard in the Control Room through the audio communications in use at the time. An immediate glance at the neutron 
flux measuring instruments showed that there had not been an increase in neutrons; so no criticality accident had occurred. Still, something bad had happened. The experiment was shut down; and the Assembly Room was entered for investigation.

Upon investigation, one arm was found resting against its lower neighbor at the outer end of the arm. It was one of the arms extending from the SW face of the Central Column; but which arm fell is not stated. Furthermore, that detail does not seem relevant to this safety discussion. The wooden $38.1 \mathrm{~mm}$ spacer block had vanished. The failed arm was still properly supported at the end nearer the Central Column. All other arms appeared to be as stable as at the beginning of the experiment.

The failed arm fell at some point during its filling. It is recalled to have been between one-third and two-thirds full at the moment the wooden block slipped. Evidently, the block was sufficiently stable when the arm was empty but obviously not under the added weight. The cause of the failure is probably due to the changing weight of the fissile solution entering the arm during filling. The failure may have had a dynamic factor, too. Electrical forces holding SCRAM valves closed during an experiment cause small vibrations throughout the apparatus. In addition, the dynamic act of pumping solution into the arm may have caused a sloshing about of the solution. This movement may have caused the weight on the wooden block to shift accordingly.

Nevertheless, the arm fell with a loud sound. Because the wooden block happened to have been under the outer end of the arm, the solution flowed to the outer end of the collapsed arm. That meant that the solution flowed away from the Central Column. This direction would tend to decrease reactivity of the system. Had the wooden block been under the end nearer the column, fissile solution would have flowed uncontrollably closer to the column; and this could have caused a criticality. Positioning the blocks had been purely a matter of choice; so simple good luck may have prevented a criticality accident. As stated earlier, the absence of a nuclear criticality accident because of good luck is an unsettling notion.

Whether or not a criticality accident would have occurred had the arm fallen in the other direction is not known. The neutron reproduction factor for this accident condition could be calculated, although assumptions would have to be made as to which arm fell and how much solution was in it at the time. Nonetheless, a valuable lesson was learned that all experiments must be adequately supported to withstand any and all static and dynamic forces coming into play throughout. 
The failure occurred about 3:30 in the afternoon; and the text of the Log Book goes on to observe:

6:15 PM Restarted experiment and finished it at 7:15 PM. It was subcritical with a multiplication of about 20.

This remark is included to illustrate differences in philosophy between the 1960s and the 1990s in the conduct of operations involving fissile materials. In retrospect, this entire experimental study should have been summarily terminated until a better way of stabilizing the apparatus had been designed and implemented. Instead, a simple modification was made on the spot and the experiment continued. A decision was made to improve the support system; but that was purely an informed decision on the part of the experimenters. It was not mandated in any procedural sense. 


\section{ACKNOWLEDGMENTS}

This paper is written under the auspices of the International Criticality Safety Benchmark Evaluation Project, funded by the United States Department of Energy. The project is administered by J. Blair Briggs of the Idaho National Engineering and Environmental Laboratory. This author is grateful to Mr. Briggs for the opportunity to publish these data in the peer-reviewed literature before the author's full retirement. This is the last of seven papers presenting previously unpublished or inadequately documented results from criticality experiments performed at the Rocky Flats Critical Mass Laboratory. These seven documents will mark a satisfying closure to this author's long career in the arena of critical experiments.

Special recognition is due Mr. Bruce B. Ernst, the designer and Lead Experimenter of this experimental program. Mr. Ernst, referred to frequently throughout this paper, was a Certified Experimenter at the Rocky Flats CML at the time of these studies. Following these experiments, he authored two reports both of which are referenced in the Introduction Section of this paper. One of these was an internal Rocky Flats report. The other was written in draft form only and was never published because it was thought to contain much the same information as the published one. Fortunately, one copy of that unpublished document has been found because, only recently, a careful study of the unpublished document revealed that it did contain useful additional information. This new data has been incorporated into this treatise.

Mr. Ernst left Rocky Flats but remained active in the Nuclear Criticality Safety industry. $\mathrm{He}$ contributed to the writing of some of the American National Standards now in effect throughout this industry. Thus, he continues to serve the nuclear industry. He currently resides in the eastern part of the United States; and he willingly consented to this author's attempt to document his work into this document. This author accepts all responsibility for any errors that may have crept into this writing; and he gratefully acknowledges the gracious permission to publish the work rightfully belonging to another person.

Several colleagues participated in at least one experiment in one way or another in addition to Bruce B. Ernst and this author. These persons were all associated with the nuclear safety program at Rocky Flats in those years. Participants included: Harold E. Clark, Ellis E. Hicks, Douglas C. Hunt, 
Warren R. Sheets, Grover Tuck, and Clarence Lee Schuske, the laboratory's director. Many of these gentlemen are now deceased.

The patient and capable efforts of Christine White and Peggy Shiffer, who work at the Idaho National Engineering and Environmental Laboratory are, as in past papers under this program, gratefully recognized. They prepared figures and tables, respectively. This task was rendered more difficult because of great distances separating involved persons. They work in Idaho, the author, Colorado. 


\section{APPENDICES}

Two internal reports were prepared concurrently in the late 1960s dealing with these measurements. The plan was to present the experimental data and a description of the apparatus in the first document and a safety analysis of the data in the later one. The principal author of both was to have been Bruce B. Ernst. The first, RFP-1196, was never published because sufficient data was deemed present in the second, RFP-1197, when it was completed. For that reason, RFP-1197 was the only one published as a Rocky Flats document. In reality, however, the assumption that RFP-1197 contained all pertinent information needed for code validations in the year 2000 is not quite true; the earlier report does contain some useful information not contained in the later one.

Only one copy of the never-published RFP-1196 remained in existence. It was discovered at Rocky Flats in February of 1999. To avoid the possibility that any of this data might be forever lost, this text is copied here - without editing - as Appendix A. Even pencilled notes and the author's first attempt at editing the late-1960s document are left intact. Recently, the document was reviewed for classification and released for this use (November, 1998). The Rocky Flats Technical Information Department requires that this information be clearly recognized to be "Unpublished Data".

Copies of the other, once-published report, RFP-1197, are rare because it received limited distribution at the time. The library of the once-active Rocky flats Plant is no longer able to provide copies. By including RFP-1197 here as Appendix B, essentially all available information concerning this experimental program --beyond the raw data sheets and the two Long Books, themselves, are collected in one document. Additionally, RFP-1197 can be obtained with some effort from any of the following sources: (1) The National Archives of Critical Mass Laboratories maintained at the Los Alamos National Laboratory, (2) Mr. Calvin Hopper of the Oak Ridge National Laboratory, X-10 Plant, who maintains the extensive library of criticality data and reports collected over decades by Mr. Howard R. Dyer, now retired, and (3) this author, also retired, living in Boulder, Colorado.

The last appendix, Appendix C, is a very brief paper with unknown distribution. Many decades ago, empirical methods were developed to aid nuclear criticality safety engineers ensure safety in fissile material handling plants. One of these methods, closely related to the experiments reported here, was developed by Mr. Clarence Lee Schuske (deceased), founder of the Nuclear Criticality Safety Group at Rocky Flats. The title of his report was "An Empirical Method for Calculating Sub-Critical Pipe 
Intersections". It was written at Rocky Flats and is dated July 17, 1956. This method may or may not be of interest today in light of the industry's present powerful computer capability; but the proposed method is copied in Appendix $\mathrm{C}$ to preclude its loss to history. 


\title{
APPENDIX A
}

\section{"Critical Parameters of Bare Intersection Pipes}

\author{
Containing Fissile Solution."
}

By

Bruce B. Ernst

RFP-1196

Rocky Flats Division, The Dow Chemical Company, Golden, CO.

Unpublished Data 


\section{APPENDIX B}

\section{"Empirical Method for Calculating Pipe Intersections Containing Fissile Solutions"}

By

Bruce B. Ernst and C. L. Schuske

RFP-1197

Rocky Flats Division, The Dow Chemical Company, Golden, CO.

September 9, 1968 


\section{APPENDIX C}

“An Empirical Method

for Calculating

Sub-Critical

\section{Pipe Intersections"}

By

Clarence Lee Schuske

Rocky Flats Division, The Dow Chemical Company, Golden, CO.

July 17,1956 
FUPIRICAT METHOD FOR PIPE INTERSECTIONS

The purpose of this report is to present an emplrical method for calculating simple pipe intersections.

Th1s method was used to obtain intersections given in

Part (IV) of the Nuclear Safety Gulde.. The method provides

conservat1ve results for cases for whech data ex1sts."

III Method:

$90^{\circ}$ Intersections

$\operatorname{step} 1$

$a>b$

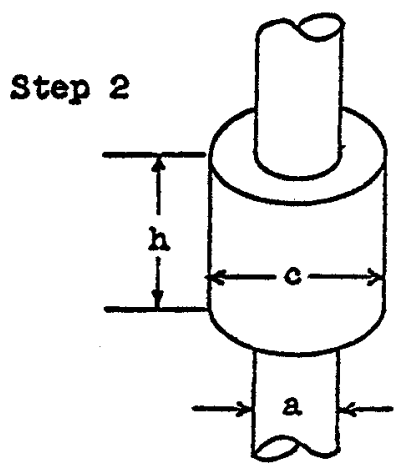

C - diameter of tho expanded section h

$c=\sqrt{a^{2}+b^{2}}$

$h=5 a$

If a cyinder of height $h$

is not critical for diameter

$C$, then the intersection 13

considered safe.

Examples: Given in Nuclear Safety Guide.

Private commun1cat1on w1th A. D. Ca111han, Oct 6, 1955, ORAL. 


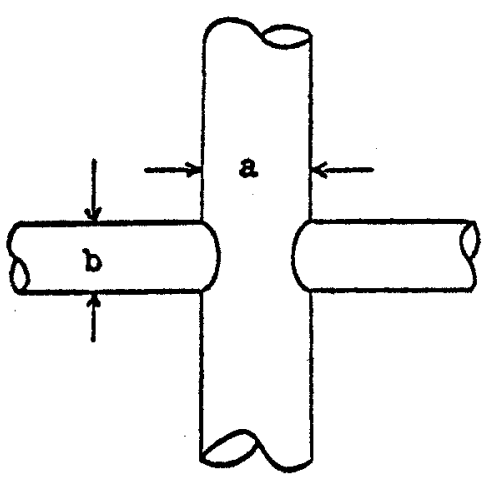

$90^{\circ}$ Cross
$a>b$
$h=5 a$
$c=\sqrt{a^{2}+2 b^{2}}$

If $h$ is not critical for diame ter $c$ then the intersection is safe.

(A) Example: This method ylelds a 3.65 inch cross as safe for aluminum walled plpes heavily tamped with water. Experiment Indicates that a 4 inch cross w1Il not become critical.

(B) Example: The method is even more conservative for untamoed intersections. For example, the method yields a 5 inch cross as safe whereas experimont indicates an intersection of greater than 7 1nches as suberitical.

* Private communication w1tis A. D. Cal11han, 0ot 6, 1955, ORNL. 


\title{
$45^{\circ}$ Intersection
}

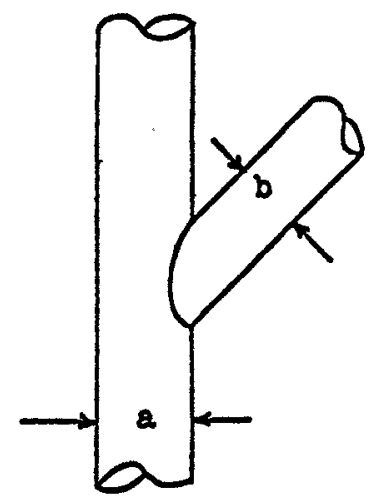

\author{
a) b \\ Same principle as Step 2. \\ $h=\frac{5 \mathrm{a}}{0.707}$ \\ $c=\sqrt{a^{2}+b^{2}}$
}

If $h$ is not critical for diameter $C$, then intersection is consldered safe.

Examples: Given in Nuclear Safety Gu1de.

$30^{\circ}$ on Less

$b=\infty$

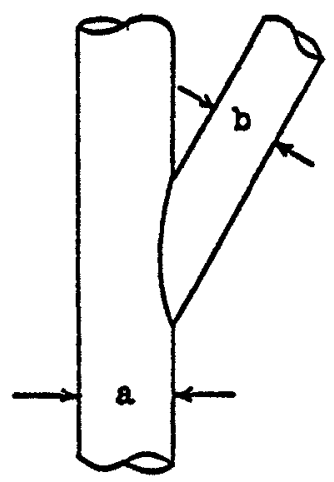

$c=\sqrt{a^{2}+b^{2}}$

If $c$ is not critical for a pipe of $h=\infty$, then the intersection is safe.

Examples: Given in Nuclear Safety Guide.

GC99 01543 